\title{
Novel IncRNA-HZO4 Promotes BPDE-Induced Human Trophoblast Cell Apoptosis and Miscarriage by Up-Regulating IP3R1/CaMKII/SGCB Pathway by Competitively Binding with miR-hz04
}

\author{
Wenxin Huang \\ Fujian Medical University \\ Mengyuan Dai \\ Fujian Medical University \\ Chenyang Mi \\ Sichuan university \\ Tingting Liang \\ Sichuan university \\ Taotao Qiu
}

South China Agricultural University

Zhongyan Xu

Sichuan University

Jiayu Xie

Sichuan University

Weina Chen

sichuan university

\section{Peng Tian}

Sichuan University

Shuming Zhang

Sichuan University

Huidong Zhang ( $\nabla$ huidong.zhang@scu.edu.cn )

Sichuan University https://orcid.org/0000-0001-7845-3331

\section{Research}

Keywords: Non-coding IncRNA-HZO4 and miR-hz04, Competing endogenous RNAs (ceRNAs), Environmental BaP or BPDE, Female trophoblast cell apoptosis, IP3R1/Ca2+/CaMKII/SGCB; Miscarriage or spontaneous abortion

Posted Date: November 5th, 2020 
DOl: https://doi.org/10.21203/rs.3.rs-101844/v1

License: (c) (1) This work is licensed under a Creative Commons Attribution 4.0 International License. Read Full License 


\section{Abstract}

\section{Background}

Miscarriage seriously hinders human reproduction. BaP (benzo(a)pyrene) and its metabolite BPDE (benzo(a)pyrene-7,8-dihydrodiol-9,10-epoxide) could cause trophoblast cell dysfunctions and might further induce human miscarriage. However, the underlying mechanisms remain largely unknown.

Results

Herein, we identified a novel Inc-HZO4 up-regulated and a novel miR-hz04 down-regulated in the unexplained recurrent miscarriage (RM) villous tissues relative to the healthy control tissues and also in the BPDE-exposed trophoblast cells. Lnc-HZO4 served as competing endogenous RNA (ceRNA), directly and specifically bound with miR-hzO4 on its target site, and diminished the inhibition effects of miR-hzO4 on $\mathrm{IP}_{3} \mathrm{R}_{1}$ mRNA expression level and its mRNA stability, thus activated $\mathrm{Ca}^{2+}$-mediated $\mathrm{IP}_{3} \mathrm{R}_{1} / \mathrm{p}$ CaMKII/SGCB apoptosis pathway, which further promoted trophoblast cell apoptosis. The miR-hz04 target site, but not its mutant, on Inc-HZO4 played important roles in these regulations. In normal trophoblast, relatively less Inc-HZO4 and more miR-hzO4 inhibited this apoptosis pathway and gave normal pregnancy. After exposure to BPDE or in the RM tissues, relatively more Inc-HZO4 and less miRhz04 activated this apoptosis pathway and induced miscarriage. BaP could also induce mice miscarriage by up-regulating this corresponding murine apoptosis pathway.

\section{Conclusions}

This work discovered that Inc-HZO4 served as a ceRNA for miR-hzO4 and up-regulated $I_{3} R_{1} /$ CaMKII/SGCB pathway, which promoted the BPDE-induced human trophoblast cell apoptosis and the occurrence of miscarriage, providing novel scientific and clinical understanding in the occurrence of unexplained miscarriage.

\section{Background}

Polycyclic aromatic hydrocarbons (PAHs) are widely distributed in our daily environment. It was reported that the total PAHs on atmospheric fine particular matter (PM) samples were 5.60-16.3, 3.02-7.75 and 0.658-3.44 $\mathrm{ng} \mathrm{m}^{-3}$ in Oporto, Florence, and Athens in Southern European, respectively [Science of the Total Environment 595 (2017) 494-504], and up to $174 \mathrm{ng} \mathrm{m}^{-3}$ in a suburban area of Zhengzhou, China [Atmospheric Environment 104 (2015) 228e236]. High levels of benzo(a)pyrene (BaP), a representative of $\mathrm{PAHs}$, have been detected out on environmental PM and also in fried or smoked food. The total $\mathrm{BaP}$ intake was estimated to be $125 \mathrm{ng} /$ person/day based on the daily food consumption and BaP level [1]. Moreover, the lipophilicity and long half-life of $\mathrm{BaP}$ further increase its accumulation in body.

Approximately $15 \%-25 \%$ of total pregnant women experience miscarriage [2], and roughly $3 \%$ suffer from recurrent miscarriage (RM, two or more consecutive miscarriages) [3]. In general, chromosomal 
abnormalities, hormonal abnormalities, uterine deformation, psychological trauma, infection, stressful life events, and immune disorders are considered as the known causes for RM [4,5]. However, there are still approximately $50 \%$ RM unexplained [6]. Thus, it is urgent to identify the causes for the unexplained RM and explore their pathogenesis and regulation mechanisms.

Increasing epidemiological studies have indicated that exposure of PAHs is associated with miscarriage $[7,8,9]$. Female smokers have significantly higher levels of $\operatorname{BaP}(1.32 \pm 0.68 \mathrm{ng} / \mathrm{ml})$ in their follicular fluid compared with their non-smoking $(0.03 \pm 0.01 \mathrm{ng} / \mathrm{ml})$ counterparts [10]. Higher levels of BaP were found in the follicular fluid of women who were not pregnant $(1.79 \pm 0.03 \mathrm{ng} / \mathrm{ml})$ compared with those that achieved a pregnancy $(0.08 \pm 0.03 \mathrm{ng} / \mathrm{ml})$ [11]. BaP can be metabolized to BPDE (benzo(a)pyren-7,8dihydrodiol-9,10-epoxide), which further form BPDE-DNA adducts [12]. A case-control study of miscarriage has shown that high levels of BPDE-DNA adducts in human maternal blood is correlated with the high risk of miscarriage during early pregnancy [13]. In animal studies, after treatment with BaP, the uterus morphology becomes abnormal, the number of germ cells and the fertility rates decrease, and the miscarriage rates increase [14] [15]. All these evidences show that BaP could induce miscarriage. However, the underlying mechanisms remain largely unknown.

Extravillous trophoblast cells take important roles in embryo implantation and the formation of functional placenta [16]. Trophoblast cell apoptosis results in abnormal placental development and miscarriage [17] [18] A higher degree of trophoblast cell apoptosis has been found in the tissues of the miscarriage patients [19]. On the other hand, human trophoblast cells are very sensitive to environmental carcinogens. Recently, we have found that BPDE could result in human trophoblast Swan 71 cell apoptosis due to the disorders of mitochondrial fission/fusion [20]. However, the detailed regulation mechanisms are still poorly understood.

Intracellular $\mathrm{Ca}^{2+}$ plays important roles in the regulation of a variety of cellular processes, such as cell cycle, apoptosis, and migration [21] [22]. Recent studies have shown that inositol trisphosphate receptor type $1\left(\mathrm{IP}_{3} \mathrm{R}_{1}\right)$-mediated $\mathrm{Ca}^{2+}$ release increases the cytosolic free $\mathrm{Ca}^{2+}$ level, which induces miscarriage in rat [23]. $\mathrm{Ca}^{2+}$ binds to calmodulin, which activates the calmodulin-dependent protein kinase (CaMK), increases the CaMKII phosphorylation [24], and then activates guanylyl cyclases (SGC), which triggers a wide range of signaling pathways, including mitochondrial damage and cell apoptosis [25]. Thus, $\mathrm{IP}_{3} \mathrm{R} / \mathrm{Ca}^{2+} / \mathrm{CaMKII} / \mathrm{SGCB}$ pathway could regulate cell apoptosis. However, whether this pathway is also involved in the regulation of human trophoblast cell apoptosis is completely unknown.

Long non-coding RNAs (IncRNAs) and microRNAs (miRNAs) are emerging to play significant roles in the epigenetic regulation of trophoblasts cell functions and miscarriage [26, 27, 28, 29, 30, 31]. These IncRNAs or miRNAs are differentially expressed in the RM villous tissues relative to those in the health control tissues, and they regulate the signaling pathways that are related with the occurrence of miscarriage [32, 33]. LncRNAs generally regulate miRNAs by taking the roles of competing endogenous RNAs (ceRNAs) [34]. In this mechanism, IncRNA and mRNA, which harbor the same miRNA binding site, could mutually and negatively regulate each other's expression levels by competitively binding with this 
miRNA [35]. Reversely, miRNAs could also bind to their target IncRNAs to promote their degradation [34]. However, there are still a large number of unidentified non-coding RNAs. The combined roles of IncRNA and miRNA in the regulation of miscarriage were poorly reported. Moreover, the non-coding RNAs that could simultaneously regulate the occurrence of miscarriage and the BPDE-induced human trophoblast cell apoptosis have never been reported.

In this work, we expected to correlate the occurrence of miscarriage and the BPDE-induced human trophoblast cell apoptosis, to find out novel non-coding RNAs and signaling pathway that are simultaneously differentially regulated in both the RM tissues and the BPDE-treated trophoblast cells, to explore the roles of these non-coding RNAs in the regulation of this pathway in both the RM tissues and the BPDE-treated trophoblast cells, to discover new mechanisms underlying BPDE-induced miscarriage due to human trophoblast cell apoptosis, and to provide novel scientific and clinical understanding in the occurrence of miscarriage.

\section{Materials And Methods}

\section{Chemicals}

Benzo[a]pyren-7, 8-dihydrodiol-9, 10-epoxide (BPDE) was from MRIGlobal (purity 99.9\%, MRIGlobal, Kansa s City, Missouri, USA). Anhydrous DMSO, benzo[a]pyrene (BaP, purity 99.9\%), corn oil, and actinomycin D were from Sigma-Aldrich (St. Louis, MO, USA). BPDE was dissolved in DMSO and stored at $-80^{\circ} \mathrm{C}$. All the vehicle control and the treated cultures contained the identical amount of DMSO $(0.03 \%, \mathrm{v} / \mathrm{v})$.

\section{Cell culture}

Human trophoblast Swan 71 cells are immortalized by human telomerase, which were constructed by Gil Mor group at Yale University [36]. Human trophoblast Swan 71 and HTR-8/SVneo cells were cultured in DMEM/F12 medium (GIBCO, Invitrogen, Carlsbad, CA, USA) containing 10\% fetal bovine serum (FBS, GIBCO), MEM Non-Essential Amino Acids Solution (GIBCO), and $100 \mathrm{mM}$ Sodium Pyruvate Solution (GIBCO) at $37{ }^{\circ} \mathrm{C}$ in a saturated humidity atmosphere containing $95 \%$ air and $5 \% \mathrm{CO}_{2}$.

\section{Tissues collection and statement}

Fifteen patients with RM (the RM group) in the age between 25 and 30 were recruited, who were treated at the West China Fourth Hospital (Sichuan Province, China) between March and December in 2019. All patients had two or more consecutive unexplained miscarriage. Any patient with one of the following features was excluded [37]: (1) autoimmune abnormality, luteal phase defects, hyperprolactinemia, antiphospholipid antibody syndrome, or hyperandrogenemia; (2) uterine abnormalities or cervical incompetence; (3) abnormal karyotype of the parents or abortus; (4) polycystic ovarian syndrome; (5) the symptoms of endocrine or metabolic diseases (e.g., diabetes, hyperthyroidism, and hypothyroidism); (6) viral infectious disease (e.g., syphilis, gonorrhea, AIDS, tuberculosis); (7) tuberculosis, HBV, HCV, HIV, or with positive results from $\mathrm{y}$-interferon release tests; and (8) eclampsia or pre-eclampsia. Additionally, 
fifteen women in the matched age between 25 and 30 were recruited as the healthy control (the $\mathrm{HC}$ group), who had undergone artificial miscarriages to terminate unwanted pregnancies at 6-10 weeks of gestation. All of the $\mathrm{HC}$ group have previous pregnancies and lacked any of the eight features as described above. The villous tissue samples were dissected from other abortus materials from these two groups at 6-10 weeks of gestation, serially washed, and immediately frozen in liquid nitrogen. RNA and proteins were extracted from these tissue samples and used for RT-qPCR (15 pairs) and western blot (10 random pairs) analysis, respectively. The relative levels of two biomolecules in each RM or HC sample were linearly correlated using SPSS 24.0 software (SPSS Inc, Chicago, IL, USA). The research protocols were approved by the Medical Ethics Committee of the West China Fourth Hospital, Sichuan University. Written informed consents were obtained from all the participants.

\section{High-throughput RNA sequencing}

Total RNA was extracted from the Swan 71 cells treated with $0,0.5$, or $1.5 \mu \mathrm{M}$ BPDE for $24 \mathrm{~h}$. Highthroughput RNA sequencing was conducted on the HiSeq 2000 sequencing platform (BGI-Shenzhen, Shenzhen, China) according to BGI commercial standard process (https://www.bgi.com/). The raw sequencing data are analyzed by bioinformatics developed by BGI. Differentially expressed miRNAs, IncRNAs, and mRNAs were searched in the NCBI database (http://www.ncbi.nlm.nih.gov/) to determine their genome loci. The target genes of miR-hz04 were predicted by RNA22 (https://cm.jefferson.edu/rna22/Interactive/) [38].

\section{$5^{\prime}$ and $3^{\prime}$ rapid amplification of CDNA ends (RACE) assays}

The 5'- and 3'-RACE assays were performed using the SMARTer RACE 5'/3' Kit (Takara Bio, Tokyo, Japan). Total RNAs were extracted using the RNeasy Micro Kit (Bio-Rad, Hercules, CA, USA) and treated with DNase. RNA integrity was assessed using the Agilent 4200 TapeStation system. After reverse transcription of total RNA to CDNA, 5'- and 3'-RACE PCRs were performed using the universal and genespecific primers listed in Table S3. The resulting PCR products were cloned into linearized pRACE vector and were sequenced. The full-length nucleotide sequence of Inc-HZO4 was shown in Fig. S1C.

\section{Cell transfection}

SiRNAs of IncRNA-HZO4 (si-HZ04), siRNAs of $\mathrm{IP}_{3} \mathrm{R}_{1}\left(\mathrm{si}^{-\mathrm{IP}_{3}} \mathrm{R}_{1}\right)$ [39], miRNA-hz04 mimics (miR-hz04 mimics), miRNA-hz04 inhibitor (miR-hz04 inhibitor), and their negative control (NC) were synthesized by Thermo Fisher Scientific Company (Waltham, MA,USA) and their sequences were shown in Tables S5. The siRNA sequences are specific to the target sequence and the NC sequences do not recognize any other sequences by searching against the human genome using BLAST. Plasmid with overexpression of Inc-HZO4 (pcDNA3.1-HZO4-wt/mut) or $\mathrm{IP}_{3} \mathrm{R}_{1}$ mRNA (pcDNA3.1- $\mathrm{IP}_{3} \mathrm{R}_{1}$-wt/mut) containing wild-type (wt) or mutant (mut) target site for miR-hz04 was synthesized (Addgene, Watertown, MA, USA). Empty pcDNA3.1 was used as negative control (Vector). Before transfection, trophoblast cells were seeded in 6-well plates and incubated in starvation medium ( $0.1 \%$ or $1 \%$ FBS/DMEM) for $24 \mathrm{~h}$. Then, cells were transiently transfected with $50 \mathrm{nM}$ miRNA (siRNA, mimics, inhibitor, or its NC) or $2.0 \mu \mathrm{g}$ plasmid (pcDNA3.1-HZ04, 
pcDNA3.1-IP $\mathrm{P}_{3} \mathrm{R}_{1}$, or Vector) per well and incubated for $24 \mathrm{~h}$ in Lipofectamine 3000 (Invitrogen), according to the manufacturer's instructions. After $24 \mathrm{~h}$, cells were harvested and the knockdown or overexpression efficiencies were validated by RT-qPCR analysis.

\section{Cell apoptosis analysis}

Swan 71 cells, which have been exposed to $\operatorname{BPDE}(0,0.25,0.5,1.0$, or $1.5 \mu \mathrm{M})$ for $24 \mathrm{~h}$, or transfected with various miRNA or plasmid for $24 \mathrm{~h}$, were harvested and treated with a commercial AnnexinV-

FITC/Propidium lodide (PI) Kit (Sigma-Aldrich, St. Louis, MO, USA) according to the manufacturer's instructions. The cells were immediately detected by flow cytometry (BD Accuri C6, Becton-Dickinson, Franklin Lakes, NJ, USA) and the data was analyzed by FlowJo software (TreeStar, San Carlos, CA, USA).

\section{Measurement of the intracellular $\mathrm{Ca}^{2+}$ concentrations}

After exposure to $\operatorname{BPDE}(0,0.25,0.5,1.0$, or $1.5 \mu \mathrm{M})$ or transfection with various miRNA or plasmid for 24 h, Swan 71 cells were harvested and their intracellular $\mathrm{Ca}^{2+}$ concentrations were detected using $\mathrm{Cell} \mathrm{Ca}^{2+}$ Kit (Invitrogen) according to the manufacturer's instructions. The fluorescence intensity corresponding to $\mathrm{Ca}^{2+}$ concentration in Swan 71 cells was detected on ECLIPSE Ti fluorescence microscope (Nikon), and the data was analyzed by Image $\mathrm{J}$ software. $\mathrm{Ca}^{2+}$ concentrations were expressed as the change folds of the fluorescence intensity of the treated cells relative to that of the control cells.

\section{Quantitative real-time polymerase chain reaction (RT-qPCR)}

Total RNA was extracted from cells or tissues using TRIzol reagent (Invitrogen). RNA quality and concentration were measured with a NanoDrop1000 spectrophotometer (NanoDrop Technologies, Wilmington, DE, USA). Subsequently, mRNA and IncRNA were reversely transcribed into cDNA using the Prime Script RT Reagent Kit with gDNA Eraser (Takara). MiRNA was transcribed into cDNA using microRNA First Strand cDNA Synthesis Kit (Thermo Fisher Scientific). Quantitative detection was performed using an iQ5 real-time detection system (Bio-Rad Laboratories) and SYBRVR Premix Ex TaqTM II (Bio-Rad Laboratories). The reaction conditions were $3 \mathrm{~min}$ at $95^{\circ} \mathrm{C}$, followed by 40 cycles of $15 \mathrm{~s}$ at 95 ${ }^{\circ} \mathrm{C}$ and $30 \mathrm{~s}$ at $65^{\circ} \mathrm{C}$. The expression levels of RNA were calculated using the $2^{-\Delta \Delta \mathrm{Ct}}$ method. GAPDH mRNA was used as the normalization internal standard for IncRNA and mRNA; and U6 was used for miRNA. The primers used in these RT-qPCR assays were listed in Table S6.

\section{Western blot analysis}

Total proteins were extracted from cells or tissues using RIPA lysis buffer (Thermo Fisher Scientific) according to the manufacturer's instructions. The protein concentrations in lysates were detected by BCA Kit (Thermo Fisher Scientific). The equal weight of proteins were separated by $6 \%-12 \%$ SDS-PAGE and transferred to PVDF membranes (Bio-Rad Laboratories). After blocking with 5\% BSA in TBST buffer containing $20 \mathrm{mM}$ Tris $-\mathrm{HCl}\left(\mathrm{pH}=7.5\right.$ at $\left.25^{\circ} \mathrm{C}\right), 150 \mathrm{mM} \mathrm{NaCl}$, and $0.1 \%$ Tween-20 for $1 \mathrm{~h}$ at $25^{\circ} \mathrm{C}$, the membranes were incubated in the primary antibody in blocking solution overnight at $4{ }^{\circ} \mathrm{C}$. After wash 
thrice in TBST for $15 \mathrm{~min}$, the membranes were incubated with the secondary antibody for $1 \mathrm{~h}$ at $25^{\circ} \mathrm{C}$. Immunoblots were visualized using enhanced chemiluminescence (Thermo Fisher Scientific) by Molecular Imager ChemiDoc XRS+ imaging system (Bio-Rad Laboratories) and the integrated density values were analyzed with Image $\mathrm{J}$ software with GAPDH or $\beta$-Tublin as the internal standard. The primary antibodis contained anti-IP $\mathrm{P}_{3} \mathrm{R}_{1}$ (dilution 1:1000, ab264281, Abcam, Cambridge, UK), anti-CaMKII (dilution 1:1000, 4436S, Cell Signaling Technology, Boston, USA), anti-p-CaMKII (dilution 1:1000, 3356S, Cell Signaling Technology), anti-SGCB (dilution 1:100, sc-5306, SANTA Cruz, Texas, USA ), anti-GAPDH (dilution 1:10000, ab8245, Abcam). The secondary antibodies included goat anti-rabbit IgG (dilution 1:5000, ab205718, Abcam) and goat anti-mouse IgG (dilution 1:5000, ab205719, Abcam). Blotting for GAPDH was used throughout as a loading control. The intensity of the western blot bands was quantified by Image $\mathrm{J}$.

\section{Fluorescence in situ hybridization (FISH)}

FISH assays were performed using Invitrogen ${ }^{\text {TM }}$ FISH Tag ${ }^{\text {TM }}$ Detection Kits (Thermo Fisher Scientific) according to the manufacturer's instructions. Briefly, Swan 71 cells were rinsed with PBS and then fixed in $4 \%$ formaldehyde for $10 \mathrm{~min}$ at $25^{\circ} \mathrm{C}$. The cells were permeabilized in PBS containing $0.5 \%$ Triton X-100 on ice for $10 \mathrm{~min}$, and then washed with PBS. Subsequently, Inc-HZO4 was hybridized with Cy5-labelled ssDNA probe (5'-Cy5-GGCTXTTGCCTGTGGTXTCTTTCTTCG-3', X means locked nucleotide acid modification) (Empire Genomics, Williamsville, NK, USA) at $37^{\circ} \mathrm{C}$ for $12 \mathrm{~h}$. After staining nucleus with DAPI, images were digitally captured by confocal microscopy (N-STORM+A1R, Nikon, Japan) at $600 \times$ magnification. Nuclei with $\geq 5$ foci was considered positive [40] and the relative levels of Inc-hZO4 in the nucleus and cytoplasm were calculated from 20 random cells.

\section{mRNA stability assays}

The de novo RNA synthesis was blocked by addition of $5 \mu \mathrm{g} / \mathrm{mL}$ ActD (Apexbio, Madison, WI, USA) to Swan 71 or HTR-8/SVneo cells with overexpression or knockdown of Inc-HZ04 and/or miR-hz04. The total RNA was extracted after $0,1,2$, or $3 \mathrm{~h}$, and the mRNA levels of Inc-HZO4 or $\mathrm{IP}_{3} \mathrm{R}_{1}$ were detected by RT-qPCR. GAPDH was used as the normalization internal standard. Expression levels were calculated using the $\Delta \mathrm{Ct}$ method by normalizing to the $0 \mathrm{~h}$ time point.

\section{Dual-Luciferase reporter assays}

Lnc-HZO4 and $I_{3} R_{1}$ mRNA containing wild-type (wt) or mutant (mut) binding site for miR-hzO4 were generated and fused into the luciferase pGL3-basic reporter vector (Promega, Madison, USA). Swan 71 cells were seeded into 6-well plates and then co-transfected with $100 \mathrm{ng}$ pmirGLO-HZ04-wt/-mut, or pmirGLO-IP $\mathrm{R}_{3} \mathrm{R}_{1}$-wt/-mut and $200 \mathrm{nM}$ miR-hz04 mimics or control in Lipofectamine 3000 Transfection Reagent (Invitrogen) according to the manufacturer's instructions. After transfection, the firefly luciferase activity in each well was measured using Dual Luciferase Reporter Assay System (Promega) according to the manufacturer's protocol. 


\section{Ago2 RNA immunoprecipitation (RIP) assays}

Ago2 RIP assays were performed using a Magna RIP RNA-Binding Protein Immunoprecipitation Kit (Millipore, Bedford, MA, USA) according to the manufacturer's instructions. Briefly, cell lysates of Swan 71 cells or Swan 71 cells transfected with pcDNA3.1-HZO4, si-HZO4, pcDNA3.1-IP $\mathrm{R}_{1}$, or si-IP $\mathrm{P}_{3} \mathrm{R}_{1}$ were incubated with magnetic beads conjugated with antibody of human Ago2 (dilution 1:50, ab186733, Abcam) or mouse IgG (dilution 1:5000, ab190475, Abcam) as negative control at $4{ }^{\circ} \mathrm{C}$. The immunoprecipitated RNAs were extracted and their enrichments on Ago2 or IgG were detected by RTqPCR.

\section{MS2-RIP assays}

We co-transfected pcDNA3.1-MS2, pcDNA3.1-MS2-HZ04-wt/-mut, or pcDNA3.1-MS2-IP $\mathrm{P}_{3} \mathrm{R}_{1}$-wt/-mut along with pMS2-GFP (Addgene) into Swan 71 cells or Swan 71 cells with overexpression or knockdown of wt $\mathrm{IP}_{3} \mathrm{R}_{1}$ mRNA using Viafect reagent. After $48 \mathrm{~h}$, cell lysate was obtained and used for RNA immunoprecipitation (RIP) experiments using GFP antibody (dilution 1:100, ab290, Abcam) and the Magna RIP ${ }^{\text {TM }}$ RNA-Binding Protein Immunoprecipitation Kit (Millipore) at $4{ }^{\circ} \mathrm{C}$ according to the manufacturer's instructions. The immunoprecipitated RNAs were extracted and the enrichments of miRhz04 and miR-502-3p, which was used as negative control, by Inc-HZO4 or $\mathrm{IP}_{3} \mathrm{R}_{1}$ mRNA were detected by RT-qPCR. The primers used for detection of miR-hz04 or miR-502-3p were listed in Table S6.

\section{RNA immunoprecipitation (RIP) assays}

RNA immunoprecipitation (RIP) experiments were carried out using the Magna RIP RNA-Binding Protein Immunoprecipitation Kit (Millipore) according to the manufacturer's instructions. Briefly, cells lysates were incubated with protein $A+G$ magnetic beads at $4{ }^{\circ} \mathrm{C}$ overnight. The beads conjugated antibody of $I_{3} R_{1}$ (dilution 1:100, ab264281, Abcam), CaMKII (dilution 1:100, sc-5306, SANTA Cruz), p-CaMKII (dilution 1:100, sc-32289, SANTA Cruz), SGCB (dilution 1:100, sc-393679, SANTA Cruz), or non-immune species matched IgG (Abcam). The lysate was also used as pre-immunoprecipitation input. After extensive wash, the immunoprecipitated RNA was extracted. Lnc-HZO4 and negative control GAPDH mRNA were quantified by RT-qPCR, with the pre-immunoprecipitation as input and the lgG as control. The primers used in these assays were listed in Table S6.

\section{In vitro RNA pull-down assays}

Lnc-HZO4 or $\mathrm{IP}_{3} \mathrm{R}_{1}$ mRNA containing wild-type (wt) or mutant (mut) target site for miR-hz04 was transcribed in vitro from pGEM-T-HZO4-wt/-mut or pGEM-T-IP $\mathrm{P}_{3} \mathrm{R}_{1}$-wt/-mut, respectively. The vector $\mathrm{pGEM}$ - $\mathrm{T}$ was used as the negative control. All the transcripts were biotin-labeled by T7 RNA polymerase with the Biotin RNA Labeling Mix (Roche), treated with RNase-free DNase I (Roche), and then purified with an RNeasy Mini Kit (Qiagen, Valencia, CA, USA). These transcripts were then incubated with the lysates of Swan 71 cells or Swan 71 cells with overexpression or knockdown of wild-type Inc-HZO4 or $\mathrm{IP}_{3} \mathrm{R}_{1} \mathrm{mRNA}$ 
overnight at $4{ }^{\circ} \mathrm{C}$. The complexes were isolated by streptavidin agarose beads (Invitrogen) and RNA in the pull-down material was detected by RT-qPCR. The relative retention was calculated against the input RNA level.

\section{Mice and experimental design}

C57BL/ 6 mice with age between 6 and 8 weeks (Charles River, Beijing, China) were raised in a filter-top cages with a $12 \mathrm{~h}$ light/dark cycle, autoclaved bedding, food, and water. Female mice were mated with male mice overnight. The appearance of vaginal plug was defined as day 1 (D1). Pregnant mice were randomly divided into three groups. Each group $(n=9)$ were dosed daily with corn oil (control) or 0.05 or $0.2 \mathrm{mg} / \mathrm{kg} \mathrm{BaP}$ in corn oil by oral gavage from D1 to D13 [41] [42]. The pregnant mice were euthanized on D14. The embryo resorption was identified by smaller or darker appearance than the viable and pink healthy embryos [43]. The embryo resorption rate for each mouse was calculated as the number of the embryo resorption divided by the total number of embryos (the resorption and healthy embryos). The average resorption rate in each group was calculated. A random placenta was collected from each of nine mice in each group. RNA and proteins were extracted from each placenta tissue for RT-qPCR (each $n$ $=9$ mice) and western blot (each $n=6$ random mice) analysis, respectively. The relative levels of two biomolecules in each mouse placenta tissue were linearly correlated using SPSS 20.0 software. The research protocols were approved by the Medical Ethics Committee of the West China Fourth Hospital, Sichuan University.

\section{Statistical analysis}

Each experiment was repeated independently thrice with similar results and the data were presented as mean \pm SD (standard deviation). Statistical analysis was performed using SPSS 24.0 software (SPSS Inc, Chicago, IL, USA). Data are analyzed using independent-samples Student's test between two groups and one-way analysis of variance for more groups with Dunnett's or LSD post hoc test. The correlation was analyzed by pearson analysis. All graphs were prepared using GraphPad Prism version 8.0. Differences were considered significant when ${ }^{*} p<0.05,{ }^{\star *} p<0.01$, or ${ }^{\star \star \star} p<0.001$.

\section{Results}

\section{A novel Inc-HZO4 and $\mathrm{IP}_{3} \mathrm{R}_{1} / \mathrm{p}$-CaMKII/SGCB pathway were up-regulated and a novel miR-hz04 was down-regulated in both trophoblast cells treated with BPDE and human RM tissues}

In our recent work, we have found that BPDE exposure could induce human trophoblast Swan 71 cell apoptosis [20]. Then, we further explored the roles of novel non-coding RNAs in the regulation of trophoblast cell apoptosis. Based on the occupational exposure, diffusion of BaP from environment into cells, and high accumulation of BaP metabolite in follicular fluid and serum, we still used 0-1.5 $\mu \mathrm{M} \mathrm{BPDE}$ to treat human trophoblast Swan 71 or HTR-8/SVneo cells [20] [44]. Swan 71 cells treated with $0,0.5$, or $1.5 \mu \mathrm{M}$ BPDE were used for transcriptome sequencing to identify the differentially expressed mRNAs, novel IncRNAs, and novel miRNAs. In the IncRNA sequencing data, total 223 novel differentially 
expressed IncRNAs were identified, all of which were not annotated in NCBI database. After selecting IncRNAs with expression level differences $>2$-fold and $p$ values $<0.05$ in both 0 vs 0.5 and 0.5 vs 1.5 groups, 22 were monotonously increased and 6 were monotonously decreased with BPDE concentrations. Then, these 28 novel IncRNAs were validated by RT-qPCR in the untreated or $0.5 \mu \mathrm{M}$ BPDE-treated Swan 71 cells (Fig. S1A). In this work, we selected the novel Inc-14628 and investigated its roles in the regulation of trophoblast cell functions in details.

This IncRNA was further identified to be up-regulated in the BPDE-treated Swan 71 or HTR-8/SVneo cells by RT-qPCR analysis (Fig. 1A, B). It was verified as a sense transcript with a full length of 318 nucleotides (nt) by rapid amplification of cDNA ends (RACE) assays (Fig. S1B, Table S1) and resided at chromosome 16 (chr 16: 3,170,699 - 3,171,016, NC_000016.10). Thus, this IncRNA was also termed as Inc-HZO4 and submitted to NCBI with No. MT821846. The protein-coding potential of Inc-HZO4 was very weak, as predicted by Coding Potential Assessment Tool (https://lilab.research.bcm.edu/cpat/index.php) and NCBI ORF finder (https://www.ncbi.nIm.nih.gov/orffinder/) [45]. Additionally, Inc-HZ04 was predicted to have no conserved domains using Conserved Domain Database (https://www.ncbi.nlm.nih.gov/cdd/) and Pfam (http://pfam.xfam.org/) [46, 47]. The data supported that Inc-HZO4 could not encode a protein. Lnc-HZO4 was distributed to both the cytoplasm and nucleus in Swan 71 cells, as determined by fluorescent in situ hybridization (FISH) (Fig. S1C, D).

BPDE could induce trophoblast cell apoptosis [20]. The apoptosis of Swan 71 cells was significantly increased after BPDE treatment (Fig. S1E), similar to our previous results [20]. It has been reported that $\mathrm{IP}_{3} \mathrm{R}_{1}$ is an important protein that regulates apoptosis of ovarian carcinoma cells [48] and also regulates calcium homeostasis in Purkinje cells [49]. In our mRNA sequencing data, we also found that the mRNA level of $I P_{3} R_{1}$ was significantly monotonously increased with BPDE concentrations, with expression level differences $>2$-fold and $p$ values $<0.05$ in both 0 vs 0.5 and 0.5 vs 1.5 groups (Fig. S1F). This upregulation was further confirmed by RT-qPCR in the BPDE-treated Swan 71 and HTR-8/SVneo cells (Fig. $1 C, D)$. In signaling pathway, the mRNA and protein levels of CaMKII, p-CaMKII, and SGCB, which were located downstream of $\mathrm{IP}_{3} \mathrm{R}_{1}$, were all up-regulated in the BPDE-treated Swan 71 and HTR-8/SVneo cells (Fig. S1G, H; 1E). Since $\mathrm{Ca}^{2+}$ is required to activate this pathway [24, 25], the cellular $\mathrm{Ca}^{2+}$ level in Swan 71 cells was determined. It was found that the $\mathrm{Ca}^{2+}$ level was increased with BPDE concentrations (Fig. S1I). Therefore, BPDE may induce trophoblast cell apoptosis by activating the cellular $\mathrm{Ca}^{2+}$-mediated $I \mathrm{P}_{3} \mathrm{R}_{1} / \mathrm{p}$ CaMKII/SGCB signaling pathway.

Sequence alignment using NCBI Blast showed that no regions in Inc-HZO4 sequence could be complementary with the sense or antisense strand mRNA of $\mathrm{IP}_{3} \mathrm{R}_{1}, \mathrm{CaMKII}$, or SGCB. Additionally, IncHZO4 is located on chr16, distinct from that of $\mathrm{IP}_{3} \mathrm{R}_{1}$ in chr3, CaMKII in chr10, and SGCB in chr4, ruling out the possible cis regulation of $\mathrm{IP}_{3} \mathrm{R}_{1}$, CaMKII, or SGCB expression by Inc-HZ04. Moreover, the interactions of Inc-HZO4 with the mRNA or protein of $\mathrm{IP}_{3} \mathrm{R}_{1}$, CaMKII, or SGCB were very weak, as indicated by NCBI Blast and catRAPID (http://service.tartaglialab.com/page/catrapid_group) [50, 51]. Furthermore, RIP assays also confirmed that none of $\mathrm{IP}_{3} \mathrm{R}_{1}$, CaMKII, $\mathrm{p}$-CaMKII, or SGCB protein could interact with Inc- 
HZO4 (Fig. S1J). Therefore, these results suggested that Inc-HZO4 seemed not to directly interact with the mRNA or protein of $I P_{3} R_{1} / p$-CaMKII/SGCB signaling pathway. Since $\mathrm{IP}_{3} \mathrm{R}_{1}$ was located upstream of this signaling pathway, we tried to seek for some novel miRNAs that might interact with both Inc-HZO4 and $\mathrm{IP}_{3} \mathrm{R}_{1}$ mRNA.

In the miRNA sequencing data, total 44 novel differentially expressed miRNAs were identified, all of which were not annotated in NCBI database. After selecting the miRNAs with expression level differences $>2$ fold and $p$ values $<0.05$ in both 0 vs 0.5 and 0.5 vs 1.5 groups, four were monotonously increased and nine were monotonously decreased with BPDE concentrations. Then, these 13 miRNAs were validated by RT-qPCR in the untreated or $0.5 \mu \mathrm{M}$ BPDE-treated Swan 71 cells (Fig. S1K). Among these candidates, a novel miR-hz04, which has been submitted to NCBI with No. MW192196, might interact with both Inc$\mathrm{HZO4}$ and $\mathrm{IP}_{3} \mathrm{R}_{1}$ mRNA because both of which harbored the binding site for miR-hz04 (Fig. 1F), as predicted by RNA22 (https://cm.jefferson.edu/rna22/Interactive/) [38]. MiR-hz04 was further confirmed to be down-regulated in the BPDE-treated Swan 71 and HTR-8/SVneo cells (Fig. 1G, H). Thus, Inc-HZO4 and miR-hz04 might be involved in the up-regulation of $\mathrm{IP}_{3} \mathrm{R}_{1} / \mathrm{p}$-CaMKII/SGCB apoptosis pathway in the BPDE-treated trophoblast cells.

It has been reported that the apoptosis of human trophoblast cells could lead to miscarriage [18]. In order to correlate the occurrence of unexplained miscarriage with the BPDE-induced human trophoblast cell apoptosis, and also to verify whether the regulation mechanisms identified in trophoblast cells were also consistent with those in the villous tissues, we collected the villous tissue samples from the unexplained $\mathrm{RM}$ and healthy control $(\mathrm{HC})$ groups (each $n=15$ ). The RM group had experienced two or more consecutive unexplained miscarriage, and the known causes, such as chromosomal abnormalities, hormonal abnormalities, uterine deformation, have been excluded. Additionally, the parameters of the RM and $\mathrm{HC}$ groups, such as age, body mass index, menopause days, had no significant differences (Table S2). Then, the expression levels of Inc-HZO4 and this $I_{3} R_{1} / p-C a M K I I / S G C B$ signaling pathway were detected in the HC and RM tissues. RT-qPCR and western blot analysis showed that Inc-HZO4, $\mathrm{IP}_{3} \mathrm{R}_{1}$, CaMKII, p-CaMKII, and SGCB were all significantly up-regulated but miR-hz04 was down-regulated in the RM tissues relative to the healthy control tissues (Fig. 1I-N). These changes were completely agreed with those found in the BPDE-treated trophoblast cells, suggesting that both the RM tissues and the BPDEtreated trophoblast cells may share the similar regulation mechanism, in which Inc-HZO4 and miR-hzO4 might be involved in the regulation of $\mathrm{IP}_{3} \mathrm{R}_{1} / \mathrm{p}$-CaMKII/SGCB apoptosis pathway in both the RM tissues and BPDE-treated trophoblast cells.

\section{Up-regulated Inc-HZO4 activated $\mathrm{Ca}^{2+}$-mediated $\mathrm{IP}_{3} \mathrm{R}_{1} / \mathrm{p}$-CaMKII/SGCB pathway to induce cell apoptosis in the BPDE-treated trophoblast cells and the human RM tissues}

It has been identified that Inc-HZO4 was up-regulated in both the RM tissues and the BPDE-treated trophoblast cells (Fig. 1A, B, I). Then, the roles of Inc-HZO4 in the regulation of trophoblast cell apoptosis were explored. Lnc-HZO4 was overexpressed by transfecting pcDNA3.1-HZO4 and silenced by 
transfecting siRNA-HZO4 (si-HZ04) in the untreated or $0.5 \mu \mathrm{M}$ BPDE-treated Swan 71 or HTR-8/SVneo cells, and the efficiencies were validated by RT-qPCR analysis (Fig. S2A, B). Overexpression of Inc-HZO4 increased, whereas knockdown of Inc-HZO4 inhibited, the apoptosis of the untreated or BPDE-treated Swan 71 cells (Fig. 2A, B; Fig. S2C, D), showing that Inc-HZ04 promoted trophoblast cell apoptosis. In pathway, overexpression of Inc-HZO4 up-regulated, whereas knockdown of Inc-HZO4 down-regulated, the mRNA and protein levels of $\mathrm{IP}_{3} \mathrm{R}_{1}$, CaMKII, p-CaMKII, and SGCB in the untreated or BPDE-treated Swan 71 or HTR-8/SVneo cells (Fig. 2C-J; S2E, F). Moreover, overexpression of Inc-HZO4 also increased, whereas knockdown of Inc-HZO4 decreased, the cellular $\mathrm{Ca}^{2+}$ level in both the untreated and BPDE-treated Swan 71 cells (Fig. 2K, L; Fig. S2G, H). Thus, the up-regulated Inc-HZO4 activated $\mathrm{Ca}^{2+}{ }^{2}$-mediated $\mathrm{IP}_{3} \mathrm{R}_{1} / \mathrm{p}$ CaMKII/SGCB signaling pathway and promoted cell apoptosis of the untreated or BPDE-treated trophoblast cells.

The apoptosis of human trophoblast cells could lead to miscarriage [18]. Then, Inc-HZO4 and this $I_{3} R_{1} / p$-CaMKII/SGCB pathway were detected in the villous tissues. It was found that the RNA and protein levels of Inc-HZO4, IP $\mathrm{R}_{1}, \mathrm{CaMKII}, \mathrm{p}$-CaMKII, and SGCB were all up-regulated in the RM tissues relative to those in the $\mathrm{HC}$ tissues (Fig. $1 \mathrm{I}-\mathrm{N}$ ). After normalization of their relative levels, $\mathrm{IP}_{3} \mathrm{R}_{1}, \mathrm{CaMKII}, \mathrm{p}$ CaMKII, and SGCB were all positively and linearly correlated with Inc-HZO4 in the RM tissues (Fig. 2M, N; S2I-M). The data points were highly dispersed in the RM group but were relatively compressed in the HC group. The locations of data points in both groups were obviously separated, manifesting that these molecules were differentially regulated. The correlations among Inc-HZO4, IP ${ }_{3} \mathrm{R}_{1}, \mathrm{p}-\mathrm{CaMKII}$, and SGCB in the RM tissues were similar to those found in the BPDE-treated trophoblast cells, suggesting that both cases may share the similar regulation mechanism in which the up-regulated Inc-HZO4 activated the $\mathrm{IP}_{3} \mathrm{R}_{1} / \mathrm{p}$-CaMKII/SGCB pathway.

\section{Down-regulated miR-hz04 activated $\mathrm{Ca}^{2+}{ }^{-}$-mediated $\mathrm{IP}_{3} \mathrm{R}_{1} / \mathrm{p}$-CaMKII/SGCB pathway to induce trophoblast cell apoptosis in the BPDE-treated trophoblast cells and the human RM tissues}

Since miR-hz04 was down-regulated in both the RM tissues and the BPDE-treated trophoblast cells (Fig. $1 G, H, M)$, the roles of miR-hz04 in the regulation of trophoblast cell apoptosis were explored. MiR-hzO4 was overexpressed by transfecting its mimics and silenced by transfecting its inhibitor in both the untreated and $0.5 \mu \mathrm{M}$ BPDE-treated Swan 71 or HTR-8/SVneo cells, and their efficiencies were validated by RT-qPCR analysis (Fig. S3A, B). Overexpression of miR-hz04 inhibited, whereas knockdown of miRhz04 increased, cell apoptosis in either the untreated or BPDE-treated Swan 71 cells (Fig. 3A, B; S3C, D). For the signaling pathway, overexpression of miR-hz04 reduced, whereas knockdown of miR-hz04 increased, the mRNA and protein levels of $\mathrm{IP}_{3} \mathrm{R}_{1}$, CaMKII, p-CaMKII, and SGCB in the untreated or BPDEtreated Swan 71 or HTR-8/SVneo cells (Fig. 3C-F; S3E-H). Overexpression of miR-hz04 also decreased the cellular $\mathrm{Ca}^{2+}$ level; and vice versa (Fig. 3G, H; S3I, J). Taken together, the down-regulated miR-hz04 activated $\mathrm{Ca}^{2+}$-mediated $\mathrm{IP}_{3} \mathrm{R}_{1} / \mathrm{p}$-CaMKII/SGCB pathway and induced cell apoptosis in the untreated and BPDE-treated trophoblast cells. 
The similar regulations were also observed in the RM tissues. MiR-hz04 was down-regulated but the $I_{3} R_{1} / p$-CaMKII/SGCB pathway was up-regulated in the RM tissues relative to those in the HC tissues (Fig. 1J-N). After normalization of their relative levels, $\mathrm{IP}_{3} \mathrm{R}_{1}$, CaMKII, p-CaMKII, and SGCB were all negatively and linearly correlated with miR-hzO4 in the RM tissues but were almost constant and independent of miR-hzO4 levels in the HC tissues (Fig. 3I, J; S3K-O). The locations of data points in both groups were relatively separated. These results were similar to those found in the BPDE-treated trophoblast cells. Therefore, the RM tissues and the BPDE-treated trophoblast cells may share the similar mechanism in which the down-regulated miR-hz04 activated $\mathrm{Ca}^{2+}{ }^{2}$-mediated $\mathrm{IP}_{3} \mathrm{R}_{1} / \mathrm{p}$-CaMKII/SGCB pathway and induced trophoblast cell apoptosis.

\section{Lnc-HZO4 acted as a ceRNA for miR-hzO4 and up-regulated $\mathrm{IP}_{3} \mathrm{R}_{1}$ expression level to inhibit trophoblast cell apoptosis}

Since miR-hz04 might base pair with Inc-HZO4 or $\mathrm{IP}_{3} \mathrm{R}_{1}$ mRNA, we hypothesized that Inc-HZO4 in the cytoplasm might function as a ceRNA for miR-hz04 and abolishes miR-hz04-inhibited $\mathrm{IP}_{3} \mathrm{R}_{1}$ expression level. Firstly, overexpression of Inc-HZO4 reduced, whereas knockdown of Inc-HZO4 increased, the expression level of miR-hz04 in Swan 71 and HTR-8/SVneo cells (Fig. 4A, B; S4A), supporting that IncHZO4 negatively regulated miR-hzO4 level in human trophoblast cells. Lnc-HZO4 overexpression upregulated the $m R N A$ and protein levels of $\mathrm{IP}_{3} \mathrm{R}_{1}$, an effect which could be diminished by overexpressing miR-hz04 in either Swan 71 or HTR-8/SVneo cells (Fig. 4C-F; S4B). In contrast, knockdown of miR-hz04 abolished the reduction in the mRNA and protein levels of $\mathrm{IP}_{3} \mathrm{R}_{1}$ caused by knockdown of Inc-HZO4 (Fig. 4C-F; S4B). All these results supported that Inc-HZO4 functioned as a ceRNA for miR-hzO4 and diminished the inhibition effects of miR-hz04 on $\mathrm{IP}_{3} \mathrm{R}_{1}$ expression level.

To further explore how Inc-HZO4 and miR-hz04 regulated $I P_{3} R_{1}$ mRNA level, the mRNA stability of $I P_{3} R_{1}$ was determined after blockage of mRNA transcription by adding actinomycin D. Overexpression of IncHZO4 enhanced $I P_{3} R_{1}$ mRNA stability in Swan 71 and HTR-8/SVneo cells; and overexpression of miRhzO4 diminished this enhancement effect (Fig. 4G, H). Knockdown of Inc-HZO4 reduced $\mathrm{IP}_{3} \mathrm{R}_{1} \mathrm{mRNA}$ stability, which could be abolished by silencing miR-hz04 in both cells (Fig. 4J, K). As control, the stability of GAPDH mRNA was not changed after alteration of Inc-HZO4 and/or miR-hz04 (Fig. S4C-F). For cell phenotype, the ability of Inc-HZO4 to increase cell apoptosis was abolished by overexpressing miR-hz04 (Fig. 4l; S4G). Knockdown of Inc-HZO4 reduced cell apoptosis, which was diminished by silencing miRhz04 (Fig. 4L; S4H). Taken together, Inc-HZO4 acted as a ceRNA for miR-hz04 and diminished the inhibitory effects of miR-hzO4 on $\mathrm{IP}_{3} \mathrm{R}_{1}$ expression level and mRNA stability, and finally induced trophoblast cell apoptosis.

Lnc-HZO4 up-regulated $\mathrm{IP}_{3} \mathrm{R}_{1}$ level by direct and specific binding of miR-hzO4 on its binding site on Inc$\mathrm{HZO4}$ 
The potential interactions of miR-hz04 with Inc-HZO4 or $\mathrm{IP}_{3} \mathrm{R}_{1}$ mRNA were directly determined using Inc$\mathrm{HZO4}$ or $\mathrm{IP}_{3} \mathrm{R}_{1}$ mRNA containing wild-type (wt) or mutant (mut) target site for miR-hz04 (Fig. 5A). Dual luciferase assays showed that miR-hzO4 could directly interact with its target site on Inc-HZO4 or $I_{3} R_{1}$ mRNA, but not with its mutant (Fig. 5B, C), confirming that miR-hzO4 could interact with Inc-HZO4 or $I_{3} R_{1}$ mRNA by direct complementary binding onto its target site.

Next, Ago2 RIP assays showed that both Inc-HZO4 and $\mathrm{IP}_{3} \mathrm{R}_{1}$ mRNA could bind with Ago2 protein but not with IgG control (Fig. S5A, B), showing that both RNAs could interact with miRNA. MS2-RIP assays further confirmed that the endogenous miR-hzO4 was enriched by Inc-HZO4 or $\mathrm{IP}_{3} \mathrm{R}_{1}$ mRNA containing wt target site for miR-hz04 but not by its mutant or the empty vector (Fig. 5D-F). MiR-502-3p [52], which lacks the sequence that might be complementary with Inc-HZO4 or $\mathrm{IP}_{3} \mathrm{R}_{1} \mathrm{mRNA}$, could not be pull down by either wt or mut Inc-HZO4 or $\mathrm{IP}_{3} \mathrm{R}_{1}$ mRNA. Subsequently, RNA pull-down experiments provided more solid evidence. MiR-hzO4 could be pull down by biotin-labelled wt Inc-HZO4 or $\mathrm{IP}_{3} \mathrm{R}_{1} \mathrm{mRNA}$, but not by their mutant or the bead with empty vector (Fig. 5G-I). MiR-502-3p as negative control could not be pull down by wt or mut Inc-HZO4 or $\mathrm{IP}_{3} \mathrm{R}_{1}$ mRNA. Taken together, these results confirmed that miR-hz04 could directly interact with Inc-HZO4 or $\mathrm{IP}_{3} \mathrm{R}_{1}$ mRNA by directly binding onto its target site.

Furthermore, the competitive binding of miR-hzO4 with Inc-HZO4 or $\mathrm{IP}_{3} \mathrm{R}_{1} \mathrm{mRNA}$ was determined. Ago2 RIP assays showed that overexpression of Inc-HZO4 increased its enrichment by Ago2 protein but decreased the enrichment of $\mathrm{IP}_{3} \mathrm{R}_{1}$ mRNA (Fig. 5J). In contrast, knockdown of Inc-HZO4 reduced its enrichment by $A g o 2$ but increased the enrichment of $\mathrm{IP}_{3} \mathrm{R}_{1}$ mRNA (Fig. 5K). Similarly, overexpression of $I P_{3} R_{1}$ decreased, where knockdown of $I P_{3} R_{1}$ increased, the enrichment of Inc-HZO4 by Ago2 protein (Fig. $5 \mathrm{~L}, \mathrm{M})$. Moreover, RNA pull-down assays further showed that miR-hz04, which was enriched by wt Inc$\mathrm{HZO4}$ but not by its mutant, was reduced after overexpression of $I \mathrm{P}_{3} \mathrm{R}_{1} \mathrm{mRNA}$ and increased after knockdown of $I P_{3} R_{1}$ mRNA (Fig. $5 N$, 0). Similarly, miR-hz04, enriched by wt $I P_{3} R_{1} m R N A$, was reduced after overexpression of Inc-HZO4 and increased after knockdown of Inc-HZO4 (Fig. 5P, Q). Taken together, all these results supported that Inc-HZO4 and $\mathrm{IP}_{3} \mathrm{R}_{1}$ mRNA competitively bound with miR-hzO4 by direct binding miR-hzO4 on its target site.

Finally, the effects of miR-hzO4 binding site at Inc-HZO4 on the mRNA and protein levels of $\mathrm{IP}_{3} \mathrm{R}_{1}$ were further explored. Overexpression of wt Inc-HZO4, but not its mutant or empty vector, could up-regulate the mRNA and protein levels of $\mathrm{IP}_{3} \mathrm{R}_{1}$ in both Swan 71 and HTR-8/SVneo cells (Fig. 5R-T). Moreover, cotransfection of mutant Inc-HZO4 and miR-hzO4 abolished the promotion effects contributed by wt Inc$\mathrm{HZO4}$ and showed only the inhibitory effects of miR-hzO4 on the expression levels of $\mathrm{IP}_{3} \mathrm{R}_{1}$ (Fig. 5R-T). Taken together, these results showed that this miR-hz04 target site at Inc-HZO4 played crucial roles in the regulation of $\mathrm{IP}_{3} \mathrm{R}_{1}$ expression level in human trophoblast cells.

\section{MiR-hz04 down-regulated the level of Inc-HZ04 in human trophoblast cells}


Unexpectedly, we also found that miR-hz04 could regulate Inc-HZO4 level. Lnc-HZO4 was markedly downregulated in miR-hz04-overexpressed Swan 71 cells and up-regulated in miR-hz04-silenced cells (Fig. S5C, D). To further explore this inhibitory effects, the RNA stability of Inc-HZO4 was determined after blockage of RNA transcription. Overexpression of miR-hz04 reduced Inc-HZ04 RNA stability (Fig. S5E); whereas knockdown of miR-hz04 enhanced its stability (Fig. S5F). As control, GAPDH mRNA stability was not changed by miR-hz04 (Fig. S5G, H). Taken together, the results demonstrated that miR-hz04 downregulated Inc-HZO4 level by reducing its RNA stability.

In tissues, Inc-HZO4 was negatively and linearly correlated with miR-hz04 in the RM tissues, similar to that found in the untreated or BPDE-treated trophoblast cells (Fig. S5I). However, the level of Inc-HZO4 was relatively constant and independent of miR-hzO4 level in the HC tissues. The locations of data points in both groups were obviously separated, manifesting that these non-coding RNAs were differently regulated in both groups and they could be considered as miscarriage biomarkers. Taken together, the RM tissues and trophoblast cells may share the similar regulation mechanism in which Inc-HZO4 acted as a ceRNA for miR-hz04 and diminished the miR-hz04-inhibited $\mathrm{IP}_{3} \mathrm{R}_{1} / \mathrm{p}$-CaMKII/SGCB pathway.

\section{Down-regulated miR-hz04 activated murine $\mathrm{IP}_{3} \mathrm{R}_{1} /$ Camk2g/Sgcb pathway in pregnant mice with BaP- induced miscarriage}

Environmental $\mathrm{BaP}$ exposure might be one of the causes for the unexplained miscarriage. Then, a mouse model was made in which pregnant mice were treated with $0,0.05$, or $0.2 \mathrm{mg} / \mathrm{kg} \mathrm{BaP}$ to induce miscarriage [41] [42]. BaP could be metabolized to ultimately carcinogenic BPDE in mice. The uteri were collected from every mouse in each group. The obvious embryo resorption [43] was observed in the BaPtreated mice (Fig. 6A) and the embryo resorption rates were increased in the BaP-treated mice group (Fig. $6 B$ ), supporting that exposure of BaP to pregnant mice resulted in miscarriage [53] [54]. $\mathrm{P}_{3} \mathrm{R}_{1}, \mathrm{CaMKII}$, and SGCB are conserved in human, rhesus, elephants, dogs, and mice (Fig. S6A-C, Table S4), showing that this apoptosis pathway is evolutionarily conserved among these species. However, Inc-HZO4 sequence is conserved in human and rhesus, but not in mice (Fig. S6D), indicating its specific regulation roles in human. The levels of miR-hz04 were reduced (Fig. 6C), whereas those of murine $\mathbb{I P}_{3} R_{1}$, Camk2g, and Sgcb were all increased (Fig. 6D-G), in the BaP-treated mice group. After normalization of their relative levels, $I P_{3} R_{1}$, Camk2g, p-Camk2g, and Sgcb were all negatively and linearly correlated with miRhz04 in the placenta tissues in the BaP-treated mice (Fig. 6H, l; S6E-I). The locations of data points in both groups were obviously separated, showing that this pathway was differentially regulated in both groups and these molecules could be considered as miscarriage biomarkers. All these correlations in the BaP-treated mice were similar to those found in human trophoblast cells and the human RM tissues, indicating that the three cases may share the similar pathway and regulation mechanism: the downregulated miR-hz04 activated $\mathrm{IP}_{3} \mathrm{R}_{1} / \mathrm{p}$-CaMKII/SGCB pathway and increased trophoblast cell apoptosis, finally induced miscarriage after BPDE/BaP exposure.

\section{Discussion}


It has been reported that some IncRNAs or miRNAs could regulate the occurrence of miscarriage, such as IncRNA MEG8 [27] , HOTAIR [26], Inc-SLC4A1-1 [29], miR-98 [31]. However, all these non-coding RNAs were identified from the tissues of RM patients who have already miscarried. The dysfunctions of BPDEexposed human trophoblast cells and the occurrence of unexplained miscarriage have never been correlated and their underlying mechanisms have never been explored. In this study, we identified a novel up-regulated Inc-HZO4 and a novel down-regulated miR-hzO4 in both the BPDE-exposed trophoblast cells and the RM tissues, providing new explanation for the unexplained miscarriage: environmental BaP could induce miscarriage by increasing trophoblast cell apoptosis by up-regulating $\mathbb{I P}_{3} \mathrm{R}_{1} / \mathrm{p}$-CaMKII/SGCB pathway mediated by a novel Inc-HZO4 and a novel miR-hzO4.

The detailed regulation mechanisms of Inc-HZO4 and miR-hzO4 were proposed (Fig. 6J). MiR-hzO4 directly binds to its target site at $I P_{3} R_{1}$ mRNA and promotes $I_{3} R_{1}$ mRNA degradation. Lnc-HZO4 acts as a ceRNA for miR-hz04, directly and competitively binds with miR-hz04, and diminishes the miR-hz04inhibited $I P_{3} R_{1} R N A$ stability and expression level, thus up-regulating $\mathrm{Ca}^{2+}$-mediated $I \mathrm{P}_{3} \mathrm{R}_{1} / \mathrm{p}$ CaMKII/SGCB apoptosis pathway, which promotes trophoblast cell apoptosis. In normal trophoblast cells, Inc-HZO4 is down-regulated and miR-hz04 is up-regulated, which inactivates $\mathrm{IP}_{3} \mathrm{R}_{1} / \mathrm{p}$-CaMKII/SGCB pathway and inhibits trophoblast cell apoptosis, giving normal pregnancy. If trophoblast cells were exposed to BPDE or in the RM villous tissues, Inc-HZO4 is up-regulated and miR-hzO4 is down-regulated, and thus $I P_{3} R_{1} / p$-CaMKII/SGCB pathway is activated to result in trophoblast apoptosis and then induce miscarriage. In pregnant mice with BaP-induced miscarriage, the changes in murine miR-hzO4 and $I_{3} R_{1} / p$-CaMKII/SGCB are consistent with those found in the BPDE-treated trophoblast cells and the RM tissues, suggesting that environmental $\mathrm{BaP}$ could induce miscarriage by up-regulating the $\mathrm{Ca}^{2+}{ }^{2}$-mediated $\mathrm{IP}_{3} \mathrm{R}_{1} / \mathrm{p}$-CaMKII/SGCB apoptosis pathway. In human system, an extra Inc-HZO4 is involved in the epigenetic regulation of this pathway, showing more complicated regulation network in human system than that in mice.

It has been demonstrated that IncRNAs generally act as ceRNAs to rescue the miRNAs-inhibited target mRNA levels and up-regulate the mRNA-related cellular functions $[55,56]$. For example, by acting as an endogenous "sponge", IncRNA-HULC down-regulates miR-hz0472 to reduce the translational repression of its target gene PRKACB, which induces phosphorylation of CREB and modulates self-regulation in hepatocellular cancer [57]. Additionally, IncRNA-ATB up-regulates ZEB1 and ZEB2 by competitively binding to the miR-200 family and then induces EMT and invasion in hepatocellular carcinoma $[14,58]$. On the contrary, miRNAs can also regulate the expression levels of IncRNAs [59]. MiR-150 negatively modulates the expression of IncRNA-MIAT to suppress the proliferation, migration, and tube formation of human microvascular endothelial cells [60]. In this work, we revealed that Inc-HZO4 functions as a ceRNA for miR-hz04, directly interacts with miR-hz04, and further reduces miR-hz04 level. At the same time, miRhzO4 also down-regulates Inc-HZO4 level by promoting Inc-HZO4 degradation. Finally, Inc-HZO4 diminishes the miR-hz04-inhibited the mRNA expression level of $\mathrm{IP}_{3} \mathrm{R}_{1}$ and promotes trophoblast cell apoptosis. 
$\mathrm{IP}_{3} / \mathrm{Ca}^{2+} / \mathrm{CaMK}$ signaling pathway has been reported to modulate cell proliferation of cholangiocytes [61]. $\mathrm{Ca}^{2+} / \mathrm{CaMK}$ signaling cascade could modulate the expression and exon selection of $\mathrm{IP}_{3} \mathrm{R}_{1}$ and contributes the migration and synaptic refinement in granule cells from rat cerebellar cortex [62]. The downstream CaMKII and SGC were also reported to inhibit cell cycle progression in the prefrontal cortex of mice [63] and to participate in spinal reflex potentiation in anesthetized rats [64]. In this work, we revealed that the up-regulated $\mathrm{IP}_{3} \mathrm{R}_{1}$ could activate cellular $\mathrm{Ca}^{2+}$-mediated CaMKII/SGCB pathway to induce trophoblast apoptosis in the BPDE-treated trophoblast cells and in human RM villous tissues. The biomolecules in this pathway, as well as the intracellular free $\mathrm{Ca}^{2+}$ ion, might serve as miscarriage biomarkers.

It should be stressed that it is the trophoblast cell apoptosis but not BPDE that directly induces miscarriage. Once the $\mathrm{IP}_{3} \mathrm{R}_{1} / \mathrm{p}$-CaMKII/SGCB apoptosis pathway is activated, the upstream BPDE would become less important for the downstream miscarriage. More broadly, not only BaP or BPDE, but also other factors or pathways, such as cadmium [65] or hexavalent chromium $\left(\mathrm{Cr}^{\mathrm{Vl}}\right)$ [66], could also induce human trophoblast apoptosis, and possibly induce miscarriage. Therefore, BPDE is only one of the upstream environmental factors that could induce trophoblast cell apoptosis, and it is the trophoblast cell apoptosis that directly induces miscarriage.

\section{Conclusions}

In this work, we have identified novel Inc-HZO4 which acts as a ceRNA for novel miR-hzO and promotes trophoblast cell apoptosis by up-regulating $\mathrm{Ca}^{2+}$-mediated $\mathrm{IP}_{3} \mathrm{R}_{1} / \mathrm{p}$-CaMKII/SGCB signaling pathway, finally resulting in miscarriage. This pathway serves as a bridge to connect the BPDE-induced trophoblast cell apoptosis and the occurrence of miscarriage, providing novel scientific and clinical understanding in the occurrence of miscarriage.

\section{Declarations}

\section{Acknowledgements}

We also acknowledge the facility supports by Central Laboratory of West China College of Public Health at Sichuan University.

\section{Authors' contributions}

W.H., M.D., and H.Z. designed the study. W.H. and M.D. performed most of the experiments. W.H., M.D., and H.Z. wrote the draft manuscript. C.M. and T.L. were responsible for animal experiments. T.Q. and Z.X. contributed to the tissue preparation. J.X., W.C. and P.T. conducted the remaining experiments.

\section{Funding}


The authors acknowledge financial support from the Natural Science Foundation of China (NSFC No. 82073589), China Key Research and Development Program (2017YFC1002002), and the Fundamental Research Funds for the Central Universities.

\section{Availability of data and materials}

All data and materials are included in the manuscript, Figures, and the supplementary materials.

\section{Ethical Approval and Consent to participate}

The research protocols about villous tissue assays were approved by the Medical Ethics Committee of the West China Fourth Hospital, Sichuan University. Written informed consents were obtained from all the participants. The research protocols about mice assays were approved by the Medical Ethics Committee of the West China Fourth Hospital, Sichuan University.

\section{Consent for publication}

Not Applicable.

\section{Competing interests}

The authors declare that they have no competing interests.

\section{Author details}

${ }^{1}$ Key Laboratory of Environment and Female Reproductive Health, West China School of Public Health \& West China Fourth Hospital, Sichuan University, Chengdu 610041, China.

${ }^{2}$ Department of Toxicology, School of Public Health, Fujian Medical University, Fuzhou 350122, China.

\#These authors contributed equally to this work

*Corresponding author. E-mail: huidong.zhang@scu.edu.cn

\section{References}

1. Lee B, Shim G. Dietary exposure estimation of benzo[a]pyrene and cancer risk assessment. Journal of toxicology and environmental health Part A. 2007;70:1391-4; doi: 10.1080/15287390701434182.

2. Practice Committee of the American Society for Reproductive M. Evaluation and treatment of recurrent pregnancy loss: a committee opinion. Fertility and sterility. 2012;98 5:1103-11; doi: 10.1016/j.fertnstert.2012.06.048. http://www.ncbi.nlm.nih.gov/pubmed/22835448.

3. Rai R, Regan L. Recurrent miscarriage. Lancet. 2006;368 9535:601-11; doi: 10.1016/S01406736(06)69204-0. http://www.ncbi.nlm.nih.gov/pubmed/16905025. 
4. Lamont K, Scott NW, Jones GT, Bhattacharya S. Risk of recurrent stillbirth: systematic review and meta-analysis. Bmj. 2015;350:h3080; doi: 10.1136/bmj.h3080.

http://www.ncbi.nlm.nih.gov/pubmed/26109551.

5. Garrido-Gimenez C, Alijotas-Reig J. Recurrent miscarriage: causes, evaluation and management. Postgraduate medical journal. 2015;91 1073:151-62; doi: 10.1136/postgradmedj-2014-132672. http://www.ncbi.nlm.nih.gov/pubmed/25681385.

6. Rull K, Nagirnaja L, Laan M. Genetics of recurrent miscarriage: challenges, current knowledge, future directions. Frontiers in genetics. 2012;3:34; doi: 10.3389/fgene.2012.00034.

http://www.ncbi.nlm.nih.gov/pubmed/22457663.

7. Green RS, Malig B, Windham GC, Fenster L, Ostro B, Swan S. Residential exposure to traffic and spontaneous abortion. Environmental health perspectives. 2009;117 12:1939-44; doi:

10.1289/ehp.0900943. http://www.ncbi.nlm.nih.gov/pubmed/20049215.

8. Zhang BY, Wei YS, Niu JM, Li Y, Miao ZL, Wang ZN. Risk factors for unexplained recurrent spontaneous abortion in a population from southern China. International journal of gynaecology and obstetrics: the official organ of the International Federation of Gynaecology and Obstetrics. 2010;108 2:135-8; doi: 10.1016/j.ijgo.2009.09.019. http://www.ncbi.nlm.nih.gov/pubmed/19897189.

9. Rajab K, Mohammad A, Mustafa F. Incidence of spontaneous abortion in Bahrain before and after the Gulf War of 1991. International journal of gynaecology and obstetrics: the official organ of the International Federation of Gynaecology and Obstetrics. 2000;68 2:139-44; doi: 10.1016/s00207292(99)00195-2.

10. Neal M, Zhu J, Holloway A, Foster W. Follicle growth is inhibited by benzo-[a]-pyrene, at concentrations representative of human exposure, in an isolated rat follicle culture assay. Human reproduction (Oxford, England). 2007;22 4:961-7; doi: 10.1093/humrep/del487.

11. Ptashekas J, Ciuniene E, Barkiene M, Zurlyte I, Jonauskas G, Sliachtic N, et al. Environmental and health monitoring in Lithuanian cities: exposure to heavy metals and benz(a)pyrene in Vilnius and Siauliai residents. Journal of environmental pathology, toxicology and oncology : official organ of the International Society for Environmental Toxicology and Cancer. 1996;15:135-41.

12. Guo L, Jiang X, Tian H, Yao S, Li B, Zhang R, et al. Detection of BPDE-DNA adducts in human umbilical cord blood by LC-MS/MS analysis. Journal of food and drug analysis. 2019;27 2:518-25; doi: 10.1016/j.jfda.2019.03.001.

13. Wu J, Hou H, Ritz B, Chen Y. Exposure to polycyclic aromatic hydrocarbons and missed abortion in early pregnancy in a Chinese population. The Science of the total environment. 2010;408 11:2312-8; doi: 10.1016/j.scitotenv.2010.02.028.

14. Yuan JH, Yang F, Wang F, Ma JZ, Guo YJ, Tao QF, et al. A long noncoding RNA activated by TGF-beta promotes the invasion-metastasis cascade in hepatocellular carcinoma. Cancer cell. 2014;25 5:66681; doi: 10.1016/j.ccr.2014.03.010. http://www.ncbi.nlm.nih.gov/pubmed/24768205.

15. Archibong AE, Inyang F, Ramesh A, Greenwood M, Nayyar T, Kopsombut $P$, et al. Alteration of pregnancy related hormones and fetal survival in F-344 rats exposed by inhalation to 
benzo(a)pyrene. Reprod Toxicol. 2002;16 6:801-8; doi: Pii S0890-6238(02)00058-8 Doi 10.1016/S0890-6238(02)00058-8. <Go to ISI>://WOS:000179265300010.

16. Red-Horse K, Zhou Y, Genbacev O, Prakobphol A, Foulk R, McMaster M, et al. Trophoblast differentiation during embryo implantation and formation of the maternal-fetal interface. $\mathrm{J}$ Clin Invest. 2004;114 6:744-54; doi: 10.1172/Jci200422991. <Go to ISI>://WOS:000223868700002.

17. Liu HN, Tang XM, Wang XQ, Gao J, Li N, Wang YY, et al. MiR-93 Inhibits Trophoblast Cell Proliferation and Promotes Cell Apoptosis by Targeting BCL2L2 in Recurrent Spontaneous Abortion. Reprod Sci. 2020;27 1:152-62; doi: 10.1007/s43032-019-00003-w. <Go to ISI>://WOS:000525433300016.

18. Sun $Q$, Zhang $X$. Research on apoptotic signaling pathways of recurrent spontaneous abortion caused by dysfunction of trophoblast infiltration. European review for medical and pharmacological sciences. 2017;21:12-9.

19. Zhang Y, Zhou J, Li MQ, Xu J, Zhang JP, Jin LP. MicroRNA-184 promotes apoptosis of trophoblast cells via targeting WIG1 and induces early spontaneous abortion. Cell death \& disease. 2019;10 3:223; doi: 10.1038/s41419-019-1443-2. http://www.ncbi.nlm.nih.gov/pubmed/30833572.

20. Wang WP, Wang R, Zhang Q, Mor G, Zhang HD. Benzo(a)pyren-7,8-dihydrodio1-9,10-epoxide induces human trophoblast Swan 71 cell dysfunctions due to cell apoptosis through disorder of mitochondrial fission/fusion. Environmental Pollution. 2018;233:820-32; doi:

10.1016/j.envpol.2017.11.022. <Go to ISI ://WOS:000424177000087.

21. La Rovere RM, Roest G, Bultynck G, Parys JB. Intracellular $\mathrm{Ca}(2+)$ signaling and $\mathrm{Ca}(2+)$ microdomains in the control of cell survival, apoptosis and autophagy. Cell calcium. 2016;60 2:74-87; doi: 10.1016/j.ceca.2016.04.005. http://www.ncbi.nlm.nih.gov/pubmed/27157108.

22. Anderson KJ, Cormier RT, Scott PM. Role of ion channels in gastrointestinal cancer. World J Gastroentero. 2019;25 38:5732-72; doi: 10.3748/wjg.v25.i38.5732. <Go to |S|>://WOS:000489947600001.

23. Premkumar KV, Chaube SK. RyR channel-mediated increase of cytosolic free calcium level signals cyclin B1 degradation during abortive spontaneous egg activation in rat. In vitro cellular \& developmental biology Animal. 2014;50 7:640-7; doi: 10.1007/s11626-014-9749-y. http://www.ncbi.nlm.nih.gov/pubmed/24696373.

24. Xu D, Peng Y. Apolipoprotein E 4 triggers multiple pathway-mediated Ca2+ overload, causes CaMK II phosphorylation abnormity and aggravates oxidative stress caused cerebral cortical neuron damage. European review for medical and pharmacological sciences. 2017;21 24:5717-28; doi: 10.26355/eurrev_201712_14018. http://www.ncbi.nlm.nih.gov/pubmed/29272008.

25. Hu Y, Liu P, Kang L, Li J, Li R, Liu T. Mechanism of Marsdenia tenacissima extract promoting apoptosis of lung cancer by regulating $\mathrm{Ca}(2+) / \mathrm{CaM} / \mathrm{CaMK}$ signaling. Journal of ethnopharmacology. 2020;251:112535; doi: 10.1016/j.jep.2019.112535. http://www.ncbi.nlm.nih.gov/pubmed/31926315.

26. Zhang Y, Jin F, Li XC, Shen FJ, Ma XL, Wu F, et al. The YY1-HOTAIR-MMP2 Signaling Axis Controls Trophoblast Invasion at the Maternal-Fetal Interface. Molecular Therapy. 2017;25 10:2394-403; doi: 
10.1016/j.ymthe.2017.06.028. <Go to ISI>://WOS:000412968200021.

27. Sheng F, Sun N, Ji Y, Ma Y, Ding H, Zhang Q, et al. Aberrant expression of imprinted IncRNA MEG8 causes trophoblast dysfunction and abortion. Journal of cellular biochemistry. 2019;120 10:1737890; doi: 10.1002/jcb.29002. http://www.ncbi.nlm.nih.gov/pubmed/31265183.

28. Liu LP, Gong YB. LncRNA-TCL6 promotes early abortion and inhibits placenta implantation via the EGFR pathway. European review for medical and pharmacological sciences. 2018;22 21:7105-12; doi: 10.26355/eurrev_201811_16242. http://www.ncbi.nlm.nih.gov/pubmed/30468451.

29. Huang Z, Du G, Huang X, Han L, Han X, Xu B, et al. The enhancer RNA Inc-SLC4A1-1 epigenetically regulates unexplained recurrent pregnancy loss (URPL) by activating CXCL8 and NF-kB pathway. EBioMedicine. 2018;38:162-70; doi: 10.1016/j.ebiom.2018.11.015. http://www.ncbi.nlm.nih.gov/pubmed/30448228.

30. Zheng Q, Zhang D, Yang YU, Cui X, Sun J, Liang C, et al. MicroRNA-200c impairs uterine receptivity formation by targeting FUT4 and alpha1,3-fucosylation. Cell death and differentiation. 2017;24 12:2161-72; doi: 10.1038/cdd.2017.136. http://www.ncbi.nlm.nih.gov/pubmed/28914881.

31. Zhu Q, Dong Y, Zhang L, Ma X, Xia H. miR-98 is involved in missed abortion by targeting GDF6 and FAPP2. Reproduction (Cambridge, England). 2020;159 5:525-37; doi: 10.1530/rep-19-0282.

32. Nik-Zainal S, Kucab JE, Morganella S, Glodzik D, Alexandrov LB, Arlt VM, et al. The genome as a record of environmental exposure. Mutagenesis. 2015;30 6:763-70; doi: 10.1093/mutage/gev073. $<$ Go to ISI>://WOS:000368265500006.

33. Hainaut P, Pfeifer GP. Patterns of p53 G -> T transversions in lung cancers reflect the primary mutagenic signature of DNA-damage by tobacco smoke. Carcinogenesis. 2001;22 3:367-74; doi: 10.1093/carcin/22.3.367. <Go to ISI>://WOS:000167447000001.

34. Slack FJ, Chinnaiyan AM. The Role of Non-coding RNAs in Oncology. Cell. 2019;179 5:1033-55; doi: 10.1016/j.cell.2019.10.017. <Go to ISI>://WOS:000496914200005.

35. Tay Y, Rinn J, Pandolfi PP. The multilayered complexity of ceRNA crosstalk and competition. Nature. 2014;505 7483:344-52; doi: 10.1038/nature12986. http://www.ncbi.nlm.nih.gov/pubmed/24429633.

36. Straszewski-Chavez S, Abrahams V, Alvero A, Aldo P, Ma Y, Guller S, et al. The isolation and characterization of a novel telomerase immortalized first trimester trophoblast cell line, Swan 71. Placenta. 2009;30 11:939-48; doi: 10.1016/j.placenta.2009.08.007.

37. Tian F, He X, Wang J, Li X, Ma X, Wu F, et al. Elevated Tristetraprolin Impairs Trophoblast Invasion in Women with Recurrent Miscarriage by Destabilization of HOTAIR. Molecular therapy Nucleic acids. 2018;12:600-9; doi: 10.1016/j.omtn.2018.07.001.

38. Fazio S, Berti G, Russo F, Evangelista M, D'Aurizio R, Mercatanti A, et al. The miR-28-5p Targetome Discovery Identified SREBF2 as One of the Mediators of the miR-28-5p Tumor Suppressor Activity in Prostate Cancer Cells. Cells. 2020;9 2; doi: 10.3390/cells9020354.

39. Antigny F, Konig S, Bernheim L, Frieden M. Inositol 1,4,5 trisphosphate receptor 1 is a key player of human myoblast differentiation. Cell calcium. 2014;56 6:513-21; doi: 10.1016/j.ceca.2014.10.014. 
40. Nacson J, Di Marcantonio D, Wang Y, Bernhardy A, Clausen E, Hua X, et al. BRCA1 Mutational Complementation Induces Synthetic Viability. Molecular cell. 2020;78 5:951-9.e6; doi: 10.1016/j.molcel.2020.04.006.

41. Li X, Shen C, Liu X, He J, Ding Y, Gao R, et al. Exposure to benzo[a]pyrene impairs decidualization and decidual angiogenesis in mice during early pregnancy. Environmental pollution (Barking, Essex : 1987). 2017;222:523-31; doi: 10.1016/j.envpol.2016.11.029.

42. Zhao Y, Chen X, Liu X, Ding Y, Gao R, Qiu Y, et al. Exposure of mice to benzo(a)pyrene impairs endometrial receptivity and reduces the number of implantation sites during early pregnancy. Food and chemical toxicology : an international journal published for the British Industrial Biological Research Association. 2014;69:244-51; doi: 10.1016/j.fct.2014.04.021.

43. Zenclussen A, Joachim R, Hagen E, Peiser C, Klapp B, Arck P. Heme oxygenase is downregulated in stress-triggered and interleukin-12-mediated murine abortion. Scandinavian journal of immunology. 2002;55 6:560-9; doi: 10.1046/j.1365-3083.2002.01091.x.

44. Wang R, Wang WP, Ao L, Wang Z, Hao XL, Zhang HD. Benzo[a]pyrene-7,8-diol-9,10-epoxide suppresses the migration and invasion of human extravillous trophoblast HTR-8/SVneo cells by down-regulating MMP2 through inhibition of FAK/SRC/PI3K/AKT pathway. Toxicology. 2017;386:7283; doi: 10.1016/j.tox.2017.05.008. <Go to ISI>://WOS:000408298700008.

45. Wang L, Park HJ, Dasari S, Wang S, Kocher JP, Li W. CPAT: Coding-Potential Assessment Tool using an alignment-free logistic regression model. Nucleic acids research. 2013;41 6:e74; doi:

10.1093/nar/gkt006. http://www.ncbi.nlm.nih.gov/pubmed/23335781.

46. Marchler-Bauer A, Bryant SH. CD-Search: protein domain annotations on the fly. Nucleic acids research. 2004;32 Web Server issue:W327-31; doi: 10.1093/nar/gkh454.

http://www.ncbi.nlm.nih.gov/pubmed/15215404.

47. Finn RD, Coggill P, Eberhardt RY, Eddy SR, Mistry J, Mitchell AL, et al. The Pfam protein families database: towards a more sustainable future. Nucleic acids research. 2016;44 D1:D279-85; doi: 10.1093/nar/gkv1344. http://www.ncbi.nlm.nih.gov/pubmed/26673716.

48. Hudecova S, Markova J, Simko V, Csaderova L, Stracina T, Sirova M, et al. Sulforaphane-induced apoptosis involves the type 1 IP3 receptor. Oncotarget. 2016;7 38:61403-18; doi: 10.18632/oncotarget.8968. http://www.ncbi.nlm.nih.gov/pubmed/27528021.

49. Shimobayashi E, Kapfhammer JP. Calcium Signaling, PKC Gamma, IP3R1 and CAR8 Link Spinocerebellar Ataxias and Purkinje Cell Dendritic Development. Current neuropharmacology. 2018;16 2:151-9; doi: 10.2174/1570159X15666170529104000. http://www.ncbi.nlm.nih.gov/pubmed/28554312.

50. Gawronski AR, Uhl M, Zhang Y, Lin YY, Niknafs YS, Ramnarine VR, et al. MechRNA: prediction of IncRNA mechanisms from RNA-RNA and RNA-protein interactions. Bioinformatics. 2018;34 18:310110; doi: 10.1093/bioinformatics/bty208. http://www.ncbi.nlm.nih.gov/pubmed/29617966.

51. Royce-Tolland ME, Andersen AA, Koyfman HR, Talbot DJ, Wutz A, Tonks ID, et al. The A-repeat links ASF/SF2-dependent Xist RNA processing with random choice during $X$ inactivation. Nature structural 
\& molecular biology. 2010;17 8:948-54; doi: 10.1038/nsmb.1877.

http://www.ncbi.nlm.nih.gov/pubmed/20657585.

52. Hu YP, Jin YP, Wu XS, Yang Y, Li YS, Li HF, et al. LncRNA-HGBC stabilized by HuR promotes gallbladder cancer progression by regulating miR-502-3p/SET/AKT axis. Molecular cancer. 2019;18 1:167; doi: 10.1186/s12943-019-1097-9. http://www.ncbi.nlm.nih.gov/pubmed/31752906.

53. Zhang M, Miao Y, Chen Q, Cai M, Dong W, Dai X, et al. BaP exposure causes oocyte meiotic arrest and fertilization failure to weaken female fertility. FASEB journal : official publication of the Federation of American Societies for Experimental Biology. 2018;32 1:342-52; doi: 10.1096/fj.201700514R.

54. Yi T, Liu M, Li X, Liu X, Ding Y, He J, et al. Benzo(a)pyrene inhibits endometrial cell apoptosis in early pregnant mice via the WNT5A pathway. Journal of cellular physiology. 2019;234 7:11119-29; doi: 10.1002/jcp.27762.

55. Cesana M, Cacchiarelli D, Legnini I, Santini T, Sthandier O, Chinappi M, et al. A long noncoding RNA controls muscle differentiation by functioning as a competing endogenous RNA. Cell. 2011;147 2:358-69; doi: 10.1016/j.cell.2011.09.028. http://www.ncbi.nlm.nih.gov/pubmed/22000014.

56. Salmena L, Poliseno L, Tay Y, Kats L, Pandolfi PP. A ceRNA hypothesis: the Rosetta Stone of a hidden RNA language? Cell. 2011;146 3:353-8; doi: 10.1016/j.cell.2011.07.014. http://www.ncbi.nlm.nih.gov/pubmed/21802130.

57. Wang JY, Liu XF, Wu HC, Ni PH, Gu ZD, Qiao YX, et al. CREB up-regulates long non-coding RNA, HULC expression through interaction with microRNA-372 in liver cancer. Nucleic acids research. 2010;38 16:5366-83; doi: 10.1093/nar/gkq285. <Go to ISI>://WOS:000281720500016.

58. Wu XS, Wang F, Li HF, Hu YP, Jiang L, Zhang F, et al. LncRNA-PAGBC acts as a microRNA sponge and promotes gallbladder tumorigenesis. EMBO reports. 2017;18 10:1837-53; doi:

10.15252/embr.201744147. http://www.ncbi.nlm.nih.gov/pubmed/28887321.

59. Huang Y. The novel regulatory role of IncRNA-miRNA-mRNA axis in cardiovascular diseases. Journal of cellular and molecular medicine. 2018;22 12:5768-75; doi: 10.1111/jcmm.13866. http://www.ncbi.nlm.nih.gov/pubmed/30188595.

60. Yan BA, Yao J, Liu JY, Li XM, Wang XQ, Li YJ, et al. IncRNA-MIAT Regulates Microvascular Dysfunction by Functioning as a Competing Endogenous RNA. Circ Res. 2015;116 7:1143-+; doi: 10.1161/Circresaha.116.305510. <Go to ISI ://WOS:000351834500015.

61. Marzioni M, Alpini G, Saccomanno S, De Minicis S, Glaser S, Francis H, et al. Endogenous opioids modulate the growth of the biliary tree in the course of cholestasis. Gastroenterology. 2006;130 6:1831-47; doi: 10.1053/j.gastro.2006.02.021. <Go to ISI>://WOS:000237686700032.

62. Choi JY, Beaman-Hall CM, Vallano ML. Granule neurons in cerebellum express distinct splice variants of the inositol trisphosphate receptor that are modulated by calcium. Am J Physiol-Cell Ph. 2004;287 4:C971-C80; doi: 10.1152/ajpcell.00571.2003. <Go to ISI>://WOS:000223762000017.

63. Pesarico AP, Stangherlin EC, Rosa SG, Mantovani AC, Zeni G, Nogueira CW. Contribution of NMDA, GABA(A) and GABA(B) receptors and L-arginine-NO-cGMP, MEK1/2 and CaMK-Il pathways in the 
antidepressant-like effect of 7-fluoro-1,3-diphenylisoquinoline-1-amine in mice. Eur J Pharmacol. 2016;782:6-13; doi: 10.1016/j.ejphar.2016.04.046. <Go to ISI>://WOS:000375545700002.

64. Chen GD, Peng ML, Wang PY, Lee SD, Chang HM, Pan SF, et al. Calcium/calmodulin-dependent kinase II mediates NO-elicited PKG activation to participate in spinal reflex potentiation in anesthetized rats. Am J Physiol-Reg I. 2008;294 2:R487-R93; doi: 10.1152/ajpregu.00600.2007. <Go to ISI>://WOS:000252772800025.

65. Zhu HL, Xu XF, Shi XT, Feng YJ, Xiong YW, Nan Y, et al. Activation of autophagy inhibits cadmiumtriggered apoptosis in human placental trophoblasts and mouse placenta. Environ Pollut. 2019;254; doi: Artn 112991 Unsp 11299110.1016/J.Envpol.2019.112991. <Go to ISI>://WOS:000488887500042.

66. Banu SK, Stanley JA, Sivakumar KK, Arosh JA, Taylor RJ, Burghardt RC. Chromium VI - Induced developmental toxicity of placenta is mediated through spatiotemporal dysregulation of cell survival and apoptotic proteins. Reprod Toxicol. 2017;68:171-90; doi: 10.1016/j.reprotox.2016.07.006. <Go to |S|>://WOS:000398652000014.

\section{Figures}


Fig.1
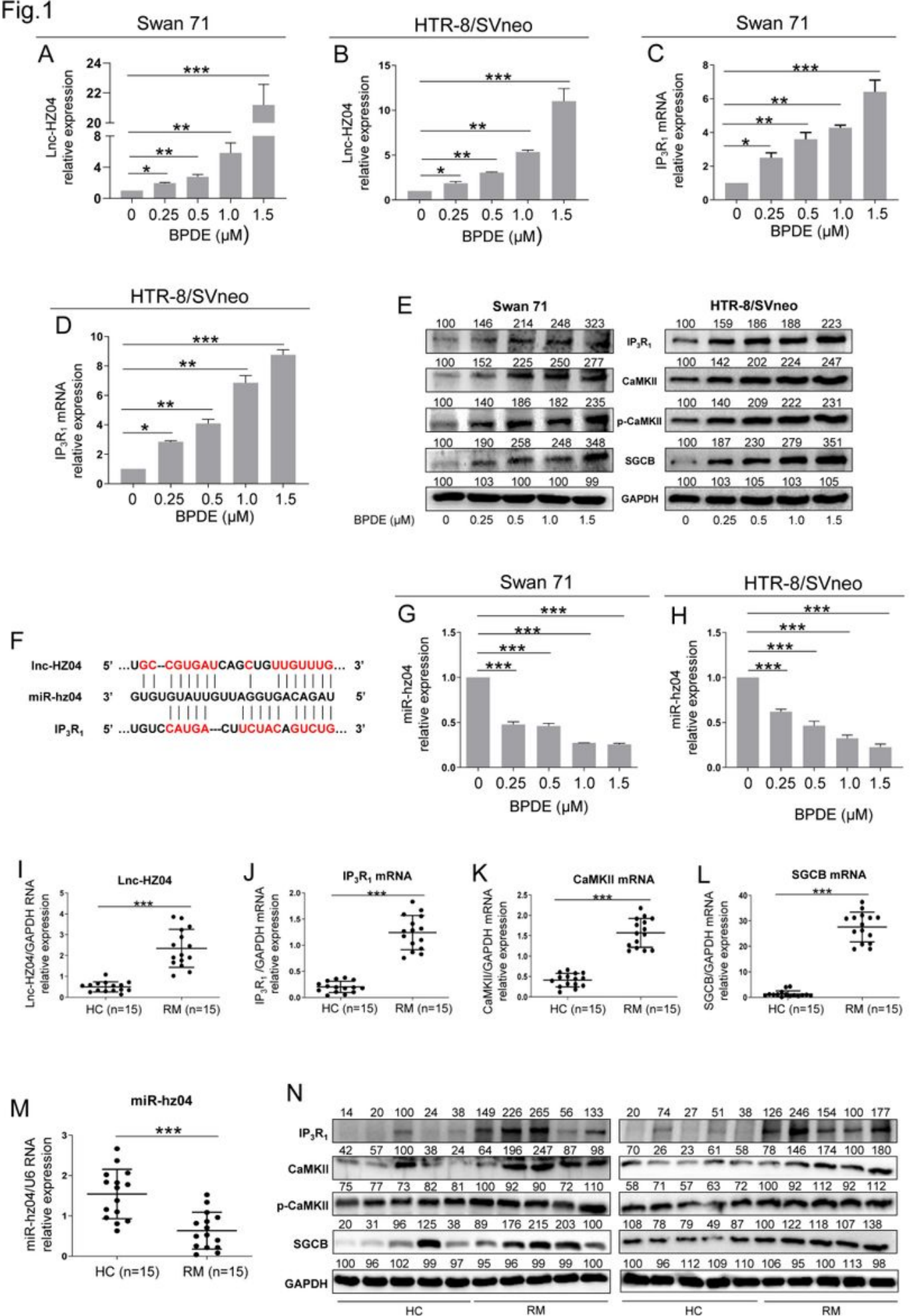

\section{Figure 1}

Lnc-HZ04 and IP3R1/p-CaMKII/SGCB pathway were up-regulated and miR-hz04 was down-regulated in both the BPDE-exposed human trophoblast cells and the human RM tissues (A and B) RT-qPCR analysis of the level of Inc-HZO4 in the BPDE-treated Swan 71 (A) or HTR-8/SVneo (B) cells. (C and D) RT-qPCR analysis of the mRNA level of IP3R1 in the BPDE-treated Swan 71 (C) or HTR-8/SVneo (D) cells. (E) Western blot analysis of the protein levels of IP3R1, CaMKII, p-CaMKII, and SGCB in the BPDE-treated 
Swan 71 or HTR-8/SVneo cells, with GAPDH as internal standard. The relative intensity of each band was quantified. (F) The complementary sequences of miR-hz04 and its binding site on Inc-HZ04 and IP3R1 mRNA. ( $G$ and H) RT-qPCR analysis of the level of miR-hz04 in the BPDE-treated Swan 71 (G) or HTR8/SVneo (H) cells. (I-M) RT-qPCR analysis of the RNA levels of Inc-HZ04 (I), IP3R1 (J), CaMKII (K), SGCB $(\mathrm{L})$, and miR-hz04 $(\mathrm{M})$ in the $\mathrm{HC}$ and RM tissues (each $\mathrm{n}=15)$. $(\mathrm{N})$ Western blot analysis of the protein levels of IP3R1, CaMKII, p-CaMKII, and SGCB in the HC and RM tissues (each $n=10$ ). The relative intensity of each band was quantified. Representative data in $(E, I-N)$ represent three independent experiments. Data in (A-D, G-H) show mean \pm SD of three independent experiments. Two-tailed Student's t-test for (I-M); one-way ANOVA analysis for (A-D, G-H); *p $<0.05$, ** $p<0.01$, and ${ }^{* \star *} p<0.001$. RM, recurrent miscarriage group; $\mathrm{HC}$, healthy control group; $\mathrm{n}$, the number of biologically independent samples. 
Fig.1
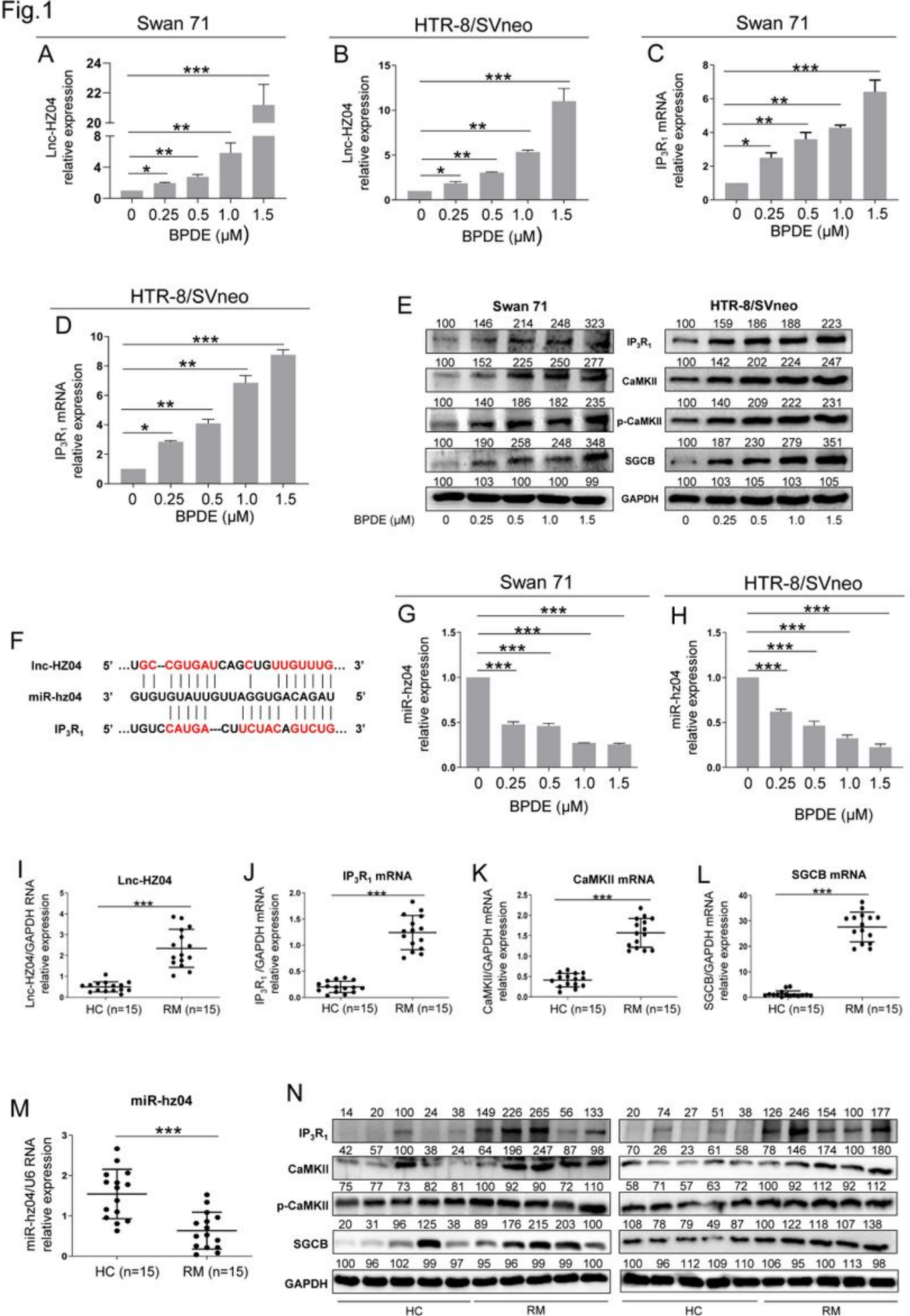

\section{Figure 1}

Lnc-HZ04 and IP3R1/p-CaMKII/SGCB pathway were up-regulated and miR-hz04 was down-regulated in both the BPDE-exposed human trophoblast cells and the human RM tissues (A and B) RT-qPCR analysis of the level of Inc-HZO4 in the BPDE-treated Swan 71 (A) or HTR-8/SVneo (B) cells. (C and D) RT-qPCR analysis of the mRNA level of IP3R1 in the BPDE-treated Swan 71 (C) or HTR-8/SVneo (D) cells. (E) Western blot analysis of the protein levels of IP3R1, CaMKII, p-CaMKII, and SGCB in the BPDE-treated 
Swan 71 or HTR-8/SVneo cells, with GAPDH as internal standard. The relative intensity of each band was quantified. (F) The complementary sequences of miR-hz04 and its binding site on Inc-HZ04 and IP3R1 mRNA. ( $G$ and H) RT-qPCR analysis of the level of miR-hz04 in the BPDE-treated Swan 71 (G) or HTR8/SVneo (H) cells. (I-M) RT-qPCR analysis of the RNA levels of Inc-HZ04 (I), IP3R1 (J), CaMKII (K), SGCB $(\mathrm{L})$, and miR-hz04 $(\mathrm{M})$ in the $\mathrm{HC}$ and RM tissues (each $\mathrm{n}=15)$. $(\mathrm{N})$ Western blot analysis of the protein levels of IP3R1, CaMKII, p-CaMKII, and SGCB in the HC and RM tissues (each $n=10$ ). The relative intensity of each band was quantified. Representative data in $(E, I-N)$ represent three independent experiments. Data in (A-D, G-H) show mean \pm SD of three independent experiments. Two-tailed Student's t-test for (I-M); one-way ANOVA analysis for (A-D, G-H); *p $<0.05$, ** $p<0.01$, and ${ }^{* \star *} p<0.001$. RM, recurrent miscarriage group; $\mathrm{HC}$, healthy control group; $\mathrm{n}$, the number of biologically independent samples. 
Fig.1
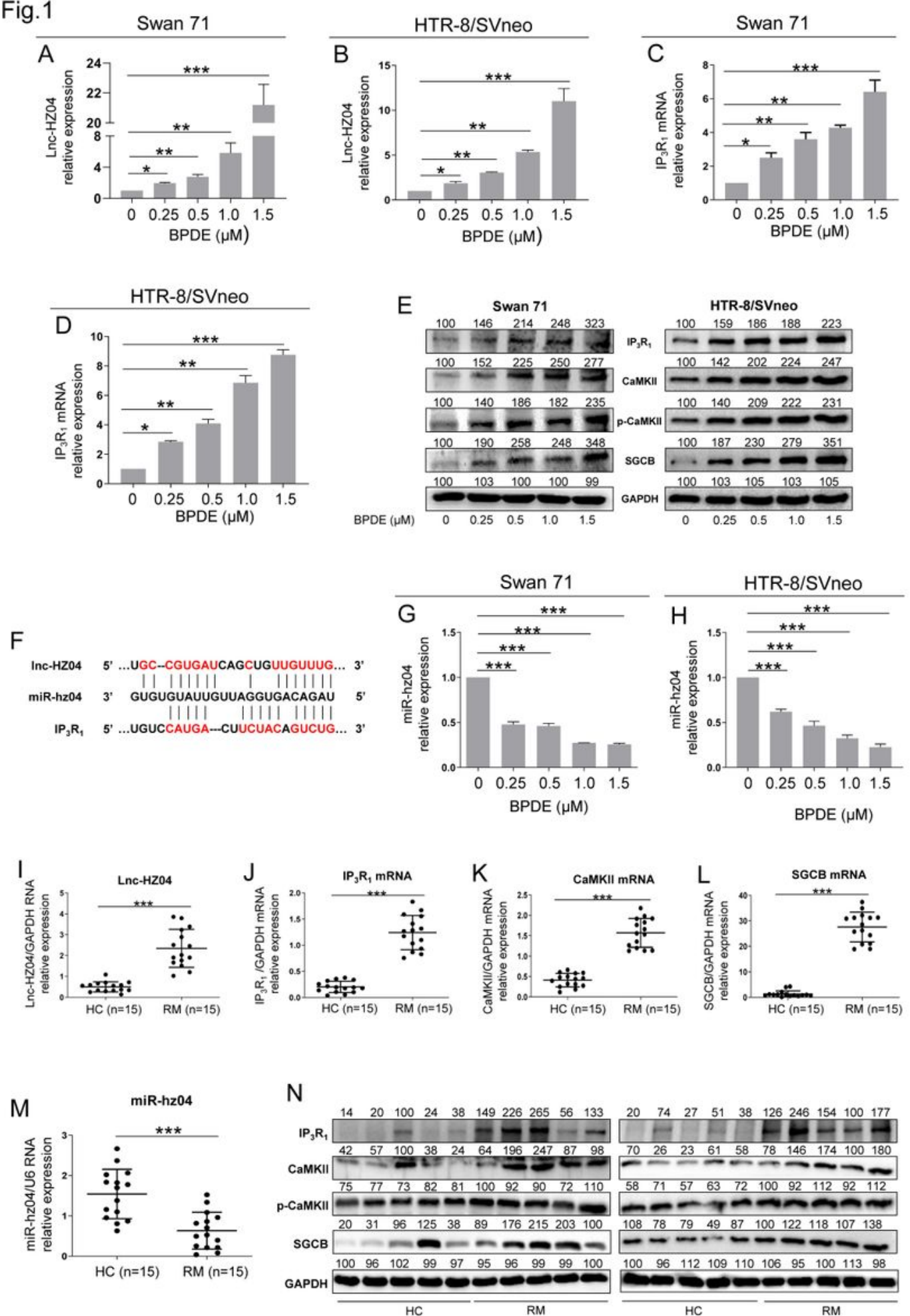

\section{Figure 1}

Lnc-HZ04 and IP3R1/p-CaMKII/SGCB pathway were up-regulated and miR-hz04 was down-regulated in both the BPDE-exposed human trophoblast cells and the human RM tissues (A and B) RT-qPCR analysis of the level of Inc-HZO4 in the BPDE-treated Swan 71 (A) or HTR-8/SVneo (B) cells. (C and D) RT-qPCR analysis of the mRNA level of IP3R1 in the BPDE-treated Swan 71 (C) or HTR-8/SVneo (D) cells. (E) Western blot analysis of the protein levels of IP3R1, CaMKII, p-CaMKII, and SGCB in the BPDE-treated 
Swan 71 or HTR-8/SVneo cells, with GAPDH as internal standard. The relative intensity of each band was quantified. (F) The complementary sequences of miR-hz04 and its binding site on Inc-HZ04 and IP3R1 mRNA. ( $G$ and H) RT-qPCR analysis of the level of miR-hz04 in the BPDE-treated Swan 71 (G) or HTR8/SVneo (H) cells. (I-M) RT-qPCR analysis of the RNA levels of Inc-HZ04 (I), IP3R1 (J), CaMKII (K), SGCB $(\mathrm{L})$, and miR-hz04 $(\mathrm{M})$ in the $\mathrm{HC}$ and RM tissues (each $\mathrm{n}=15)$. $(\mathrm{N})$ Western blot analysis of the protein levels of IP3R1, CaMKII, p-CaMKII, and SGCB in the HC and RM tissues (each $n=10$ ). The relative intensity of each band was quantified. Representative data in $(E, I-N)$ represent three independent experiments. Data in (A-D, G-H) show mean \pm SD of three independent experiments. Two-tailed Student's t-test for (I-M); one-way ANOVA analysis for (A-D, G-H); *p $<0.05$, ** $p<0.01$, and ${ }^{* \star *} p<0.001$. RM, recurrent miscarriage group; $\mathrm{HC}$, healthy control group; $\mathrm{n}$, the number of biologically independent samples. 
Fig.2
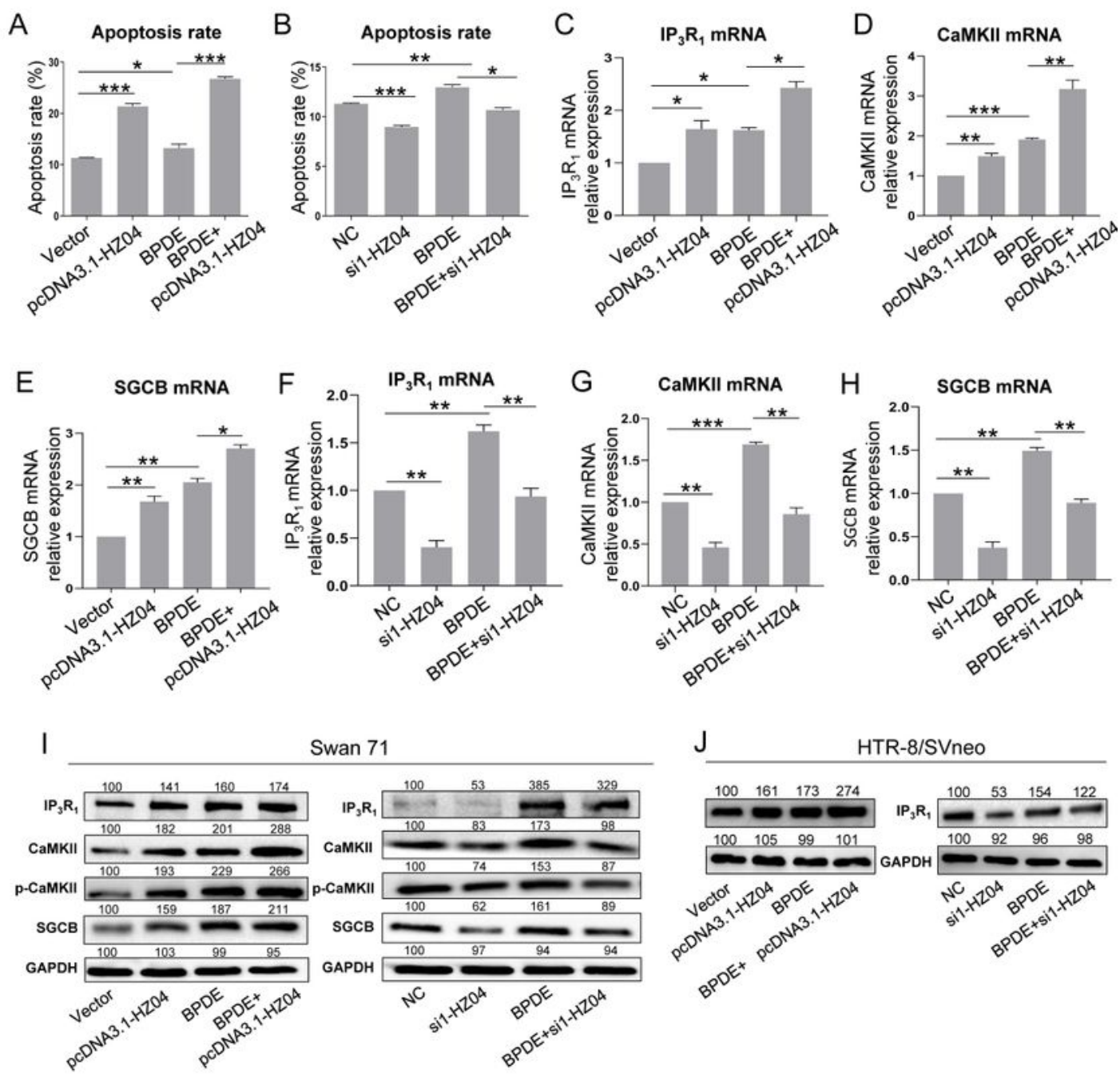

J HTR-8/SVneo
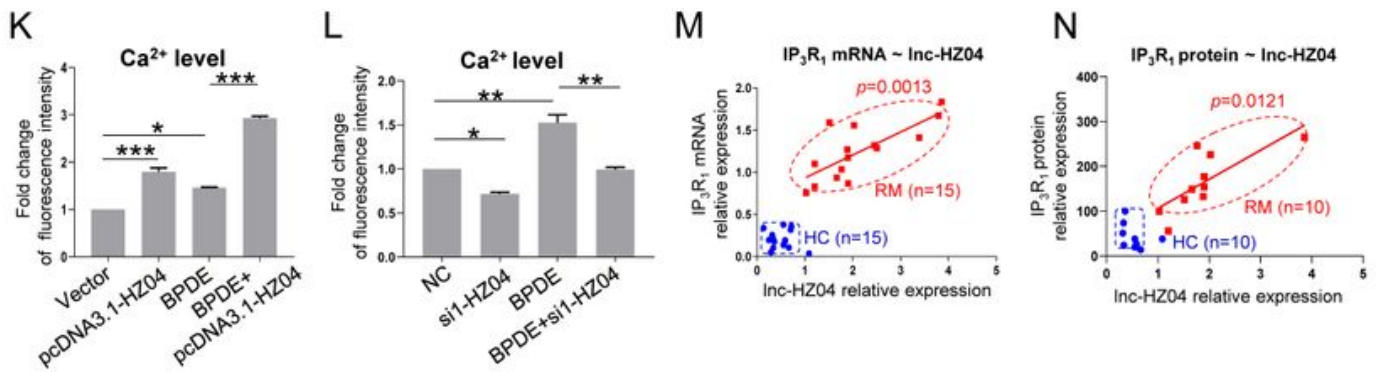

\section{Figure 2}

Up-regulated Inc-HZO4 activated Ca2+-mediated IP3R1/p-CaMKII/SGCB pathway and induced cell apoptosis in the BPDE-exposed trophoblast cells and the human RM tissues. (A and B) Flow cytometry analysis of the apoptosis rate of the untreated or $0.5 \mu \mathrm{M}$ BPDE-treated Swan 71 cells with overexpression (A) or knockdown (B) of Inc-HZ04. (C-H) RT-qPCR analysis of the mRNA levels of IP3R1 (C, F), CaMKII (D, $\mathrm{G})$, and SGCB $(\mathrm{E}, \mathrm{H})$ in the untreated or $0.5 \mu \mathrm{M}$ BPDE-treated Swan 71 cells with overexpression (C-E) or 
knockdown ( $\mathrm{F}-\mathrm{H})$ of Inc-HZ04. (I and J) Western blot analysis of the protein levels of IP3R1, CaMKII, pCaMKII, and SGCB in the untreated or $0.5 \mu \mathrm{M}$ BPDE-treated Swan 71 (I) or HTR-8/SVneo (J) cells with overexpression or knockdown of Inc-HZO4. (K and L) The intracellular $\mathrm{Ca} 2+$ level in the untreated or 0.5 $\mu M$ BPDE-treated Swan 71 cells with overexpression (K) or knockdown ( $L$ ) of Inc-HZ04. (M and N) The correlation between the mRNA (M, each $n=15)$ or protein $(N$, each $n=10)$ levels of IP3R1 and the levels of Inc-HZO4 in the HC (blue) and RM (red) groups. Representative data in (I-J, M-N) represent three independent experiments. Data in $(A-H, K-L)$ show mean $\pm S D$ of three independent experiments. One-way ANOVA analysis for (A-H, K-L); pearson analysis for (M-N); ${ }^{*} p<0.05$, ${ }^{\star \star} \mathrm{p}<0.01$, and ${ }^{* \star \star} \mathrm{p}<0.001$. RM, recurrent miscarriage group; $\mathrm{HC}$, healthy control group; NC, negative control of siRNA; Vector, empty vector of pcDNA3.1; pcDNA3.1-HZO4, overexpression of Inc-HZO4; si-HZO4, knockdown of Inc-HZO4; n, the number of biologically independent samples. 
Fig.2
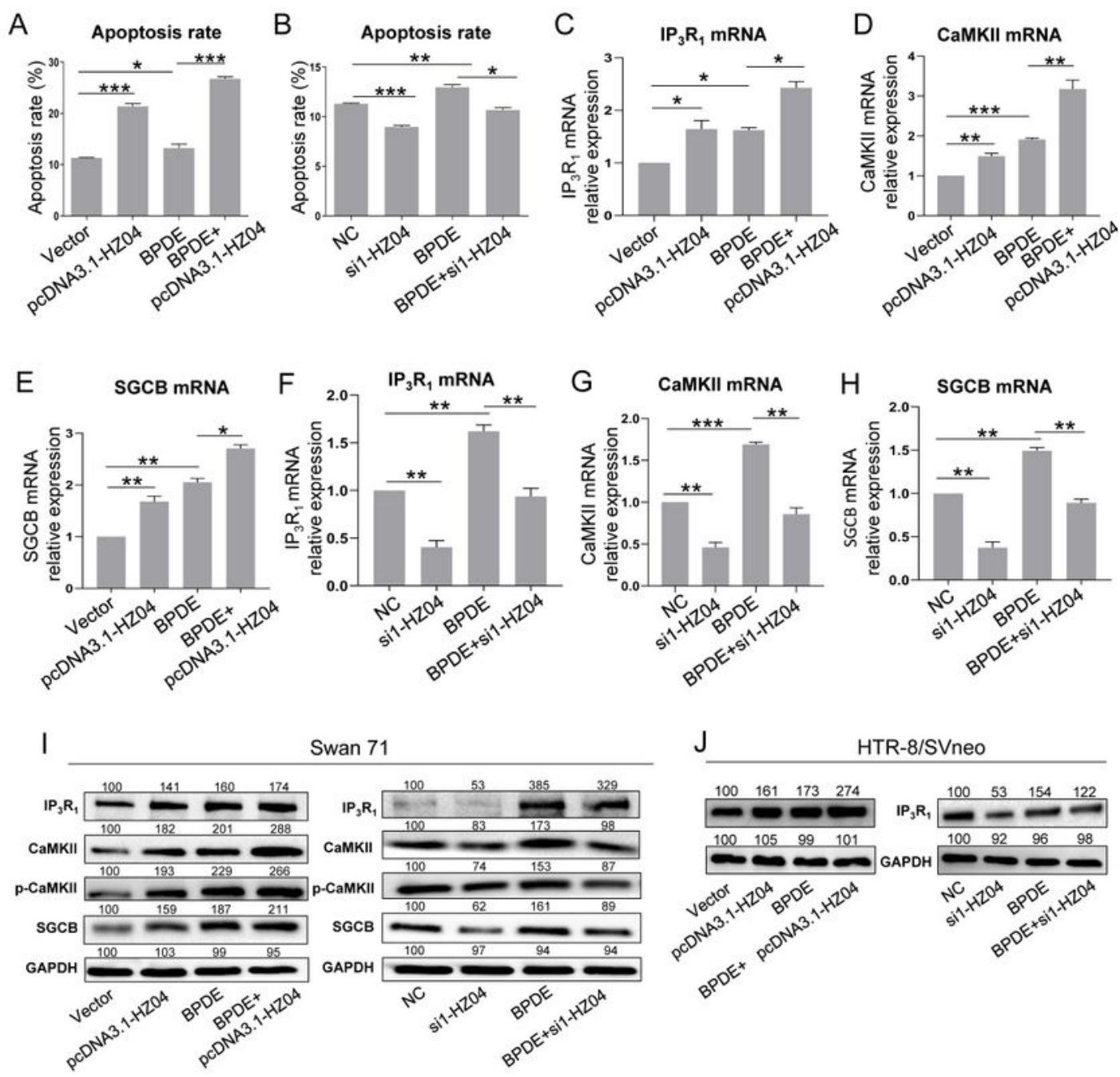

J HTR-8/SVneo
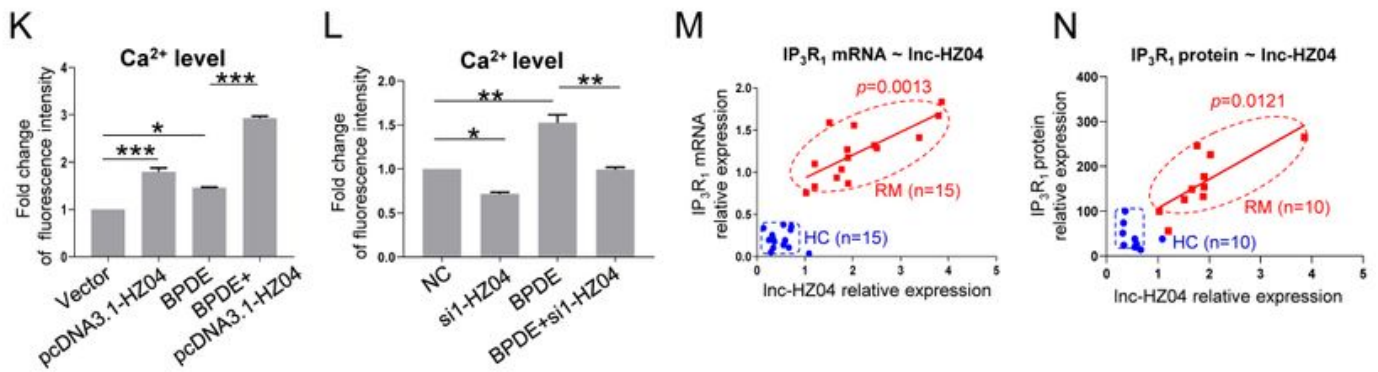

\section{Figure 2}

Up-regulated Inc-HZO4 activated Ca2+-mediated IP3R1/p-CaMKII/SGCB pathway and induced cell apoptosis in the BPDE-exposed trophoblast cells and the human RM tissues. (A and B) Flow cytometry analysis of the apoptosis rate of the untreated or $0.5 \mu \mathrm{M}$ BPDE-treated Swan 71 cells with overexpression (A) or knockdown (B) of Inc-HZ04. (C-H) RT-qPCR analysis of the mRNA levels of IP3R1 (C, F), CaMKII (D, $\mathrm{G})$, and SGCB $(\mathrm{E}, \mathrm{H})$ in the untreated or $0.5 \mu \mathrm{M}$ BPDE-treated Swan 71 cells with overexpression (C-E) or 
knockdown ( $\mathrm{F}-\mathrm{H})$ of Inc-HZ04. (I and J) Western blot analysis of the protein levels of IP3R1, CaMKII, pCaMKII, and SGCB in the untreated or $0.5 \mu \mathrm{M}$ BPDE-treated Swan 71 (I) or HTR-8/SVneo (J) cells with overexpression or knockdown of Inc-HZO4. (K and L) The intracellular $\mathrm{Ca} 2+$ level in the untreated or 0.5 $\mu M$ BPDE-treated Swan 71 cells with overexpression (K) or knockdown ( $L$ ) of Inc-HZ04. (M and N) The correlation between the mRNA (M, each $n=15)$ or protein $(N$, each $n=10)$ levels of IP3R1 and the levels of Inc-HZO4 in the HC (blue) and RM (red) groups. Representative data in (I-J, M-N) represent three independent experiments. Data in $(A-H, K-L)$ show mean $\pm S D$ of three independent experiments. One-way ANOVA analysis for (A-H, K-L); pearson analysis for (M-N); ${ }^{*} p<0.05$, ${ }^{\star \star} \mathrm{p}<0.01$, and ${ }^{* \star \star} \mathrm{p}<0.001$. RM, recurrent miscarriage group; $\mathrm{HC}$, healthy control group; NC, negative control of siRNA; Vector, empty vector of pcDNA3.1; pcDNA3.1-HZO4, overexpression of Inc-HZO4; si-HZO4, knockdown of Inc-HZO4; n, the number of biologically independent samples. 
Fig. 2
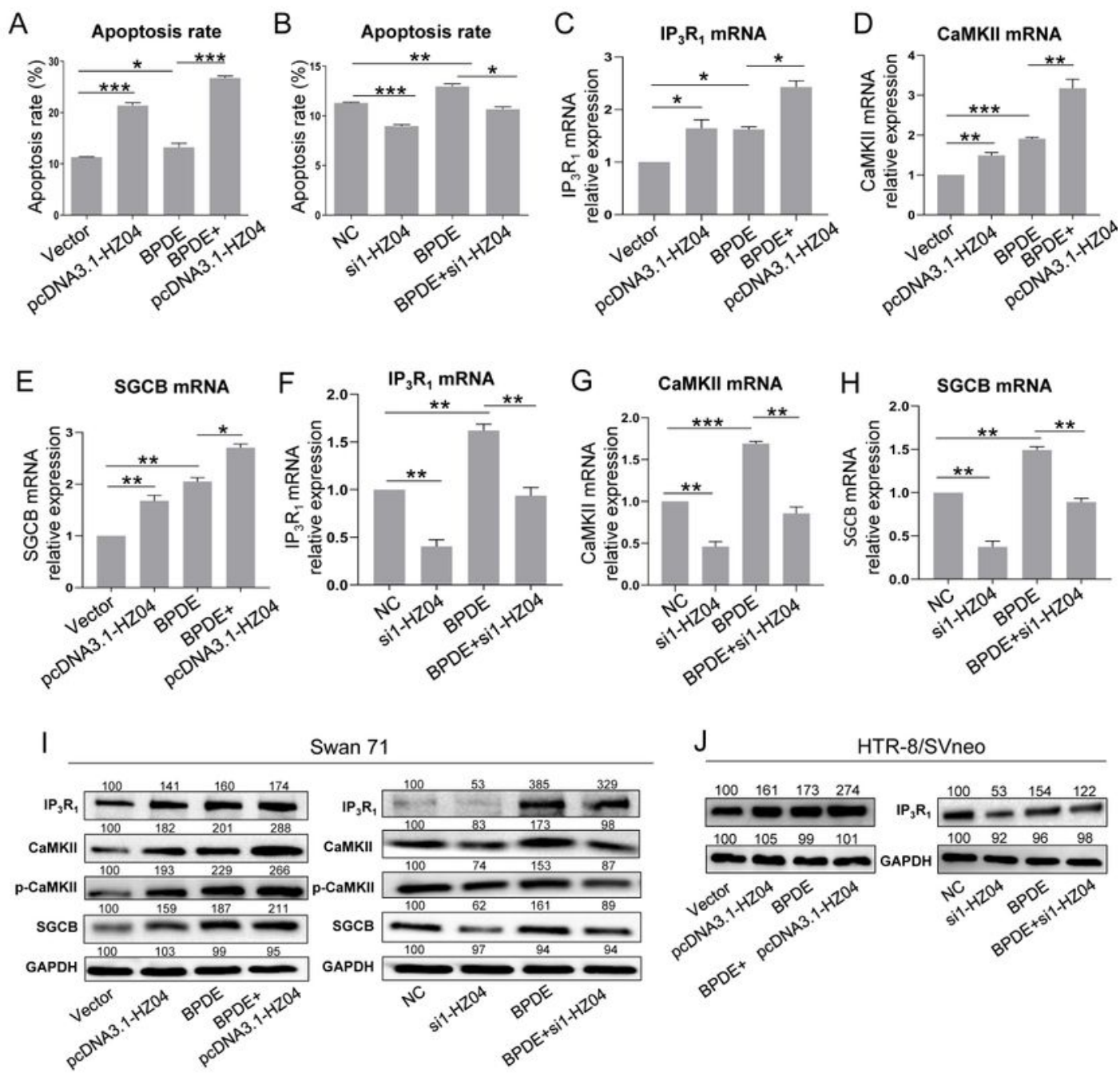

J HTR-8/SVneo
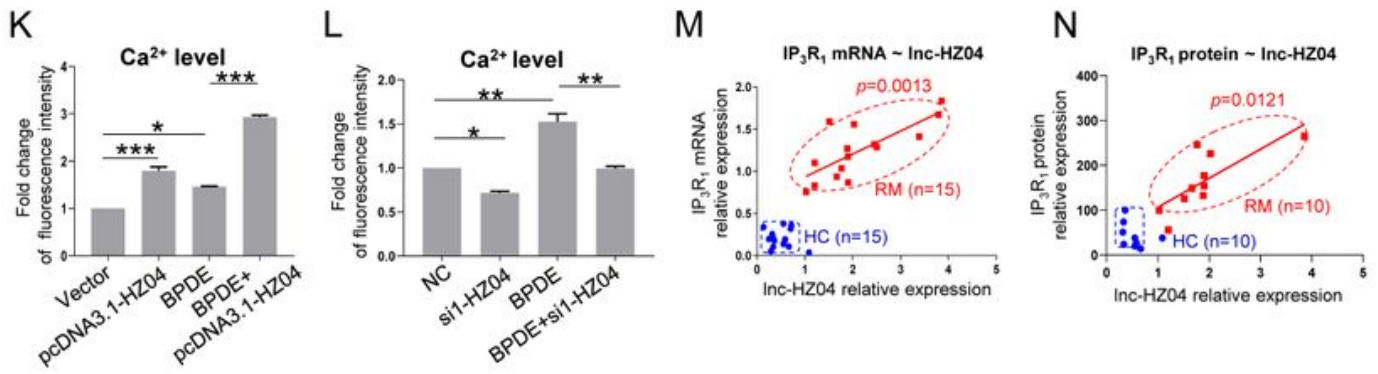

\section{Figure 2}

Up-regulated Inc-HZO4 activated Ca2+-mediated IP3R1/p-CaMKII/SGCB pathway and induced cell apoptosis in the BPDE-exposed trophoblast cells and the human RM tissues. (A and B) Flow cytometry analysis of the apoptosis rate of the untreated or $0.5 \mu \mathrm{M}$ BPDE-treated Swan 71 cells with overexpression (A) or knockdown (B) of Inc-HZ04. (C-H) RT-qPCR analysis of the mRNA levels of IP3R1 (C, F), CaMKII (D, $\mathrm{G})$, and SGCB $(\mathrm{E}, \mathrm{H})$ in the untreated or $0.5 \mu \mathrm{M}$ BPDE-treated Swan 71 cells with overexpression (C-E) or 
knockdown ( $\mathrm{F}-\mathrm{H})$ of Inc-HZ04. (I and J) Western blot analysis of the protein levels of IP3R1, CaMKII, pCaMKII, and SGCB in the untreated or $0.5 \mu \mathrm{M}$ BPDE-treated Swan 71 (I) or HTR-8/SVneo (J) cells with overexpression or knockdown of Inc-HZO4. (K and L) The intracellular $\mathrm{Ca} 2+$ level in the untreated or 0.5 $\mu M$ BPDE-treated Swan 71 cells with overexpression (K) or knockdown ( $L$ ) of Inc-HZ04. (M and N) The correlation between the mRNA (M, each $n=15)$ or protein $(N$, each $n=10)$ levels of IP3R1 and the levels of Inc-HZO4 in the HC (blue) and RM (red) groups. Representative data in (I-J, M-N) represent three independent experiments. Data in $(A-H, K-L)$ show mean $\pm S D$ of three independent experiments. One-way ANOVA analysis for (A-H, K-L); pearson analysis for (M-N); ${ }^{*} p<0.05$, ${ }^{\star \star} \mathrm{p}<0.01$, and ${ }^{* \star \star} \mathrm{p}<0.001$. RM, recurrent miscarriage group; $\mathrm{HC}$, healthy control group; NC, negative control of siRNA; Vector, empty vector of pcDNA3.1; pcDNA3.1-HZO4, overexpression of Inc-HZO4; si-HZO4, knockdown of Inc-HZO4; n, the number of biologically independent samples. 
Fig.3
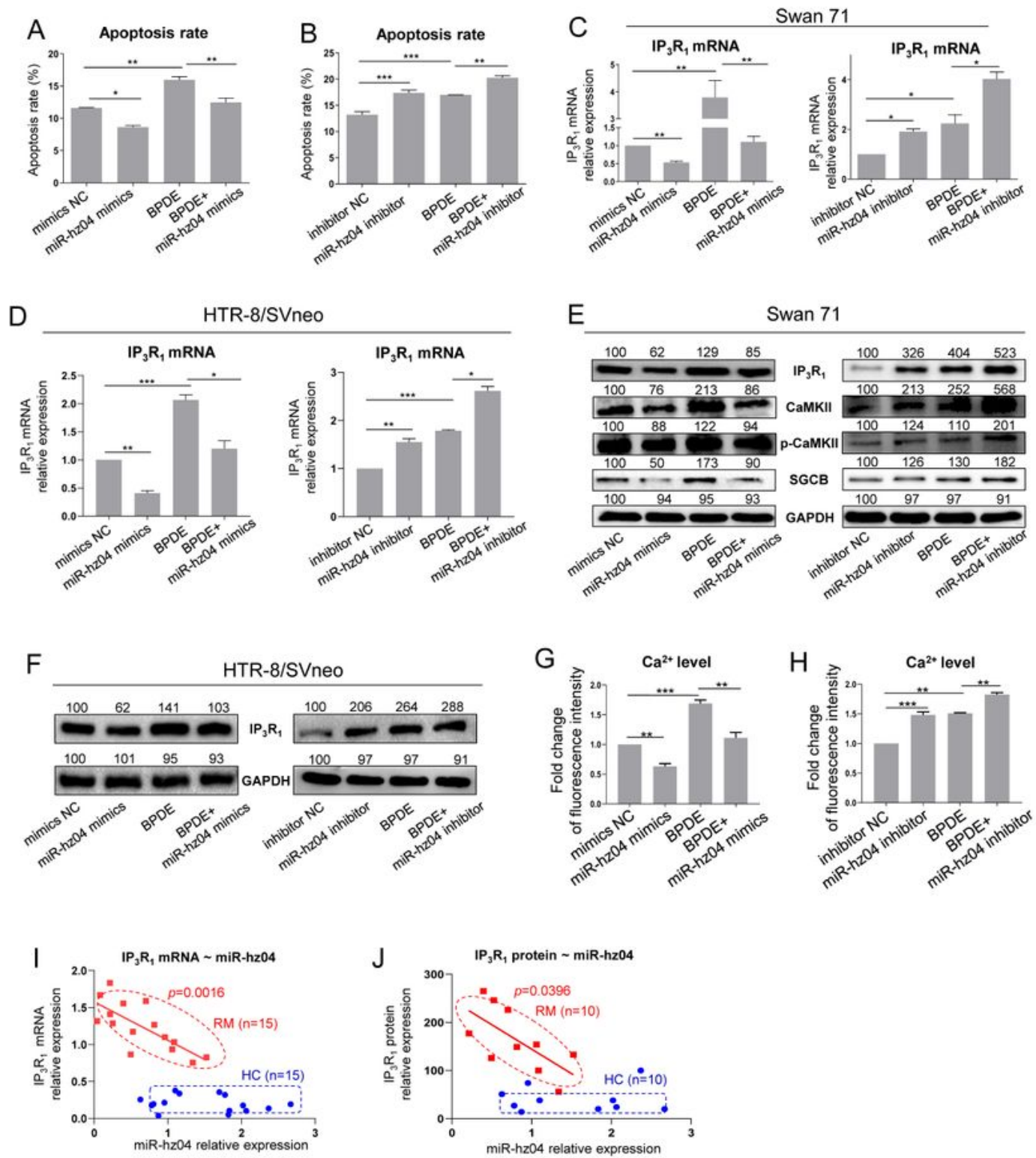

\section{Figure 3}

Down-regulated miR-hz04 activated Ca2+-mediated IP3R1/p-CaMKII/SGCB pathway and induced cell apoptosis in the BPDE-treated trophoblast cells and the human RM tissues. (A and B) Flow cytometry analysis of the apoptosis of the untreated or $0.5 \mu \mathrm{M}$ BPDE-treated Swan 71 cells transfected with miRhz04 mimics (A) or miR-hz04 inhibitor (B). (C and D) RT-qPCR analysis of the mRNA level of IP3R1 in the untreated or $0.5 \mu \mathrm{M}$ BPDE-treated Swan 71 (C) or HTR-8/SVneo (D) cells transfected with miR-hz04 
mimics or inhibitor. (E and F) Western blot analysis of the protein levels of IP3R1, CaMKII, p-CaMKII, and SGCB in the untreated or $0.5 \mu \mathrm{M}$ BPDE-treated Swan 71 (E) or HTR-8/SVneo (F) cells transfected with miR-hz04 mimics or inhibitor. ( $G$ and $H$ ) The intracellular Ca2+ level in the untreated or $0.5 \mu \mathrm{M} \mathrm{BPDE-}$ treated Swan 71 cells with overexpression $(\mathrm{G})$ or knockdown $(\mathrm{H})$ of miR-hz04. (I and $\mathrm{J}$ ) The correlation between the mRNA (I, each $n=15)$ or protein $(J$, each $n=10)$ levels of IP3R1 and the levels of miR-hz04 in the $\mathrm{HC}$ (blue) and RM (red) tissues. Representative data in (E-F, I-J) represent three independent experiments. Data in (A-D, G-H) show mean $\pm S D$ of three independent experiments. One-way ANOVA analysis for $(A-D, G-H)$; pearson analysis for $(I-J) ;{ }^{*} p<0.05$, ${ }^{\star \star} p<0.01$, and ${ }^{\star \star \star} p<0.001$. RM, recurrent miscarriage group; $\mathrm{HC}$, healthy control group; mimics NC, negative control of mimics; inhibitor NC, negative control of inhibitor; miR-hz04 mimics, overexpression of miR-hz04; miR-hz04 inhibitor, knockdown of miR-hz04; $\mathrm{n}$, the number of biologically independent samples. 
Fig.3
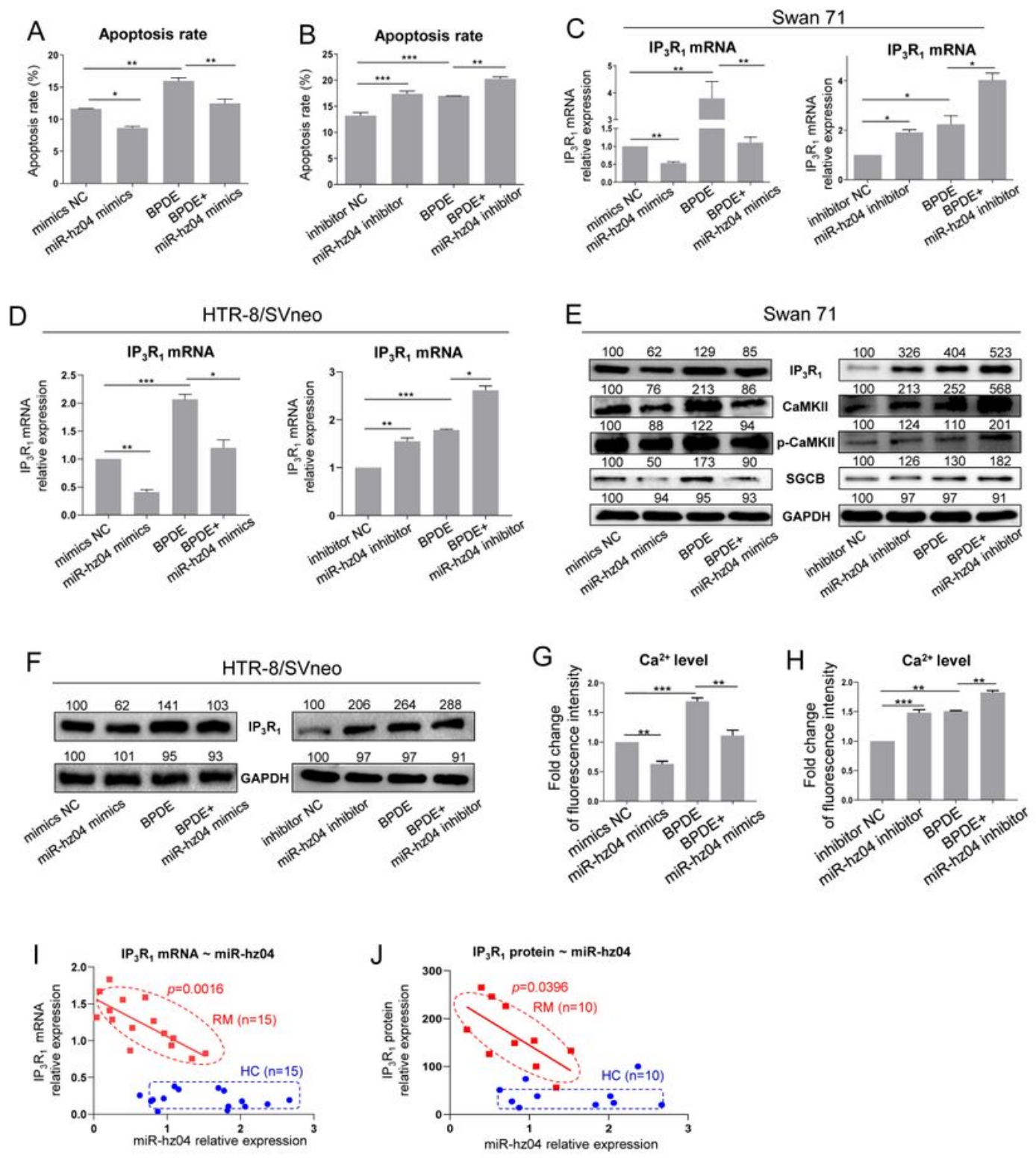

\section{Figure 3}

Down-regulated miR-hz04 activated Ca2+-mediated IP3R1/p-CaMKII/SGCB pathway and induced cell apoptosis in the BPDE-treated trophoblast cells and the human RM tissues. (A and B) Flow cytometry analysis of the apoptosis of the untreated or $0.5 \mu \mathrm{M}$ BPDE-treated Swan 71 cells transfected with miRhz04 mimics (A) or miR-hz04 inhibitor (B). (C and D) RT-qPCR analysis of the mRNA level of IP3R1 in the untreated or $0.5 \mu \mathrm{M}$ BPDE-treated Swan 71 (C) or HTR-8/SVneo (D) cells transfected with miR-hz04 
mimics or inhibitor. (E and F) Western blot analysis of the protein levels of IP3R1, CaMKII, p-CaMKII, and SGCB in the untreated or $0.5 \mu \mathrm{M}$ BPDE-treated Swan 71 (E) or HTR-8/SVneo (F) cells transfected with miR-hz04 mimics or inhibitor. ( $G$ and $H$ ) The intracellular Ca2+ level in the untreated or $0.5 \mu \mathrm{M} \mathrm{BPDE-}$ treated Swan 71 cells with overexpression $(\mathrm{G})$ or knockdown $(\mathrm{H})$ of miR-hz04. (I and $\mathrm{J}$ ) The correlation between the mRNA (I, each $n=15)$ or protein $(J$, each $n=10)$ levels of IP3R1 and the levels of miR-hz04 in the $\mathrm{HC}$ (blue) and RM (red) tissues. Representative data in (E-F, I-J) represent three independent experiments. Data in (A-D, G-H) show mean $\pm S D$ of three independent experiments. One-way ANOVA analysis for $(A-D, G-H)$; pearson analysis for $(I-J) ;{ }^{*} p<0.05$, ${ }^{\star \star} p<0.01$, and ${ }^{\star \star \star} p<0.001$. RM, recurrent miscarriage group; $\mathrm{HC}$, healthy control group; mimics NC, negative control of mimics; inhibitor NC, negative control of inhibitor; miR-hz04 mimics, overexpression of miR-hz04; miR-hz04 inhibitor, knockdown of miR-hz04; $\mathrm{n}$, the number of biologically independent samples. 
Fig.3
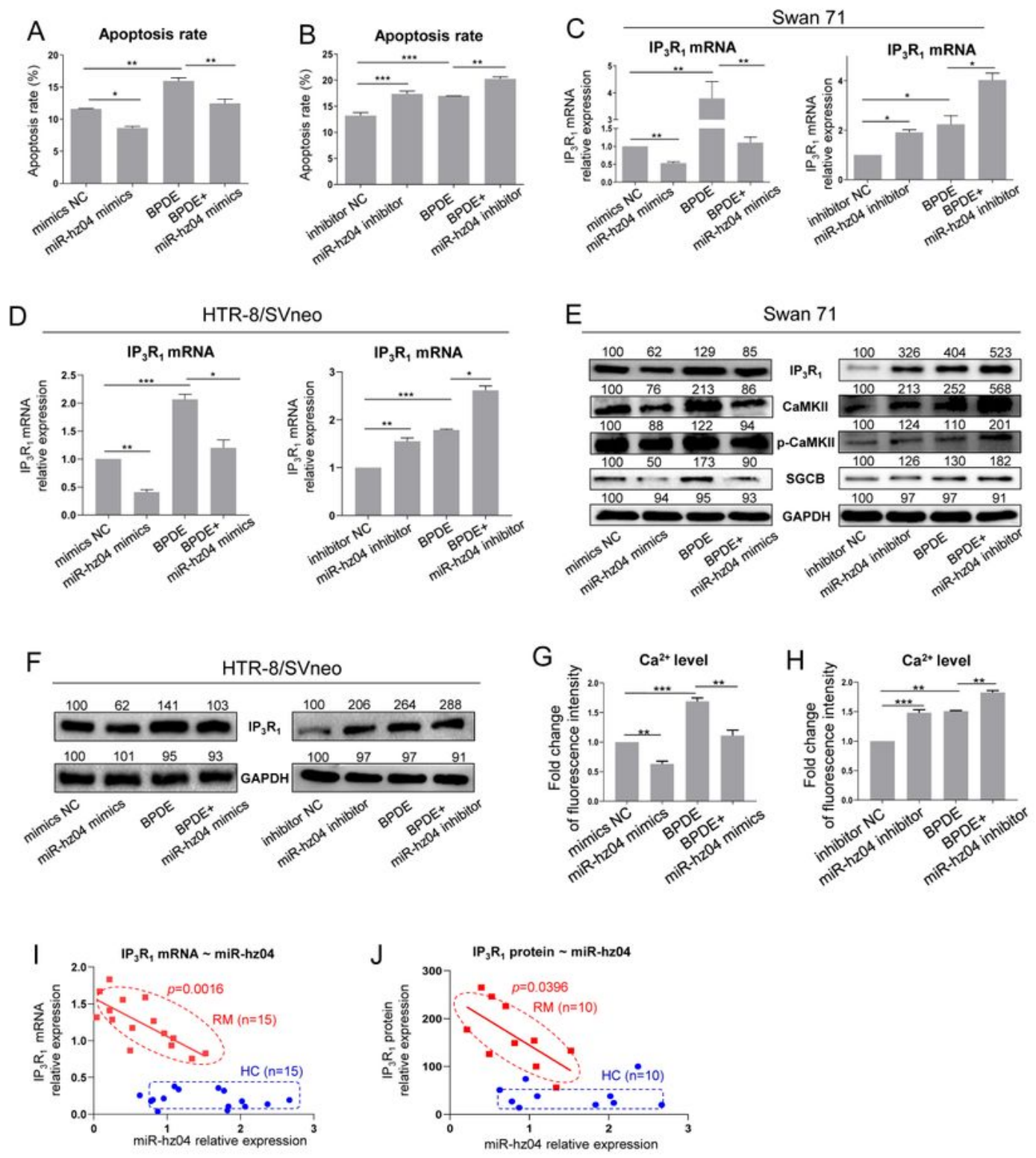

\section{Figure 3}

Down-regulated miR-hz04 activated Ca2+-mediated IP3R1/p-CaMKII/SGCB pathway and induced cell apoptosis in the BPDE-treated trophoblast cells and the human RM tissues. (A and B) Flow cytometry analysis of the apoptosis of the untreated or $0.5 \mu \mathrm{M}$ BPDE-treated Swan 71 cells transfected with miRhz04 mimics (A) or miR-hz04 inhibitor (B). (C and D) RT-qPCR analysis of the mRNA level of IP3R1 in the untreated or $0.5 \mu \mathrm{M}$ BPDE-treated Swan 71 (C) or HTR-8/SVneo (D) cells transfected with miR-hz04 
mimics or inhibitor. (E and F) Western blot analysis of the protein levels of IP3R1, CaMKII, p-CaMKII, and SGCB in the untreated or $0.5 \mu \mathrm{M}$ BPDE-treated Swan 71 (E) or HTR-8/SVneo (F) cells transfected with miR-hz04 mimics or inhibitor. ( $G$ and $H$ ) The intracellular Ca2+ level in the untreated or $0.5 \mu \mathrm{M} \mathrm{BPDE-}$ treated Swan 71 cells with overexpression $(\mathrm{G})$ or knockdown $(\mathrm{H})$ of miR-hz04. (I and $\mathrm{J}$ ) The correlation between the mRNA (I, each $n=15)$ or protein $(J$, each $n=10)$ levels of IP3R1 and the levels of miR-hz04 in the $\mathrm{HC}$ (blue) and RM (red) tissues. Representative data in (E-F, I-J) represent three independent experiments. Data in (A-D, G-H) show mean $\pm S D$ of three independent experiments. One-way ANOVA analysis for $(A-D, G-H)$; pearson analysis for $(I-J) ;{ }^{*} p<0.05$, ${ }^{\star \star} p<0.01$, and ${ }^{\star \star \star} p<0.001$. RM, recurrent miscarriage group; $\mathrm{HC}$, healthy control group; mimics NC, negative control of mimics; inhibitor NC, negative control of inhibitor; miR-hz04 mimics, overexpression of miR-hz04; miR-hz04 inhibitor, knockdown of miR-hz04; $\mathrm{n}$, the number of biologically independent samples. 
Fig.4
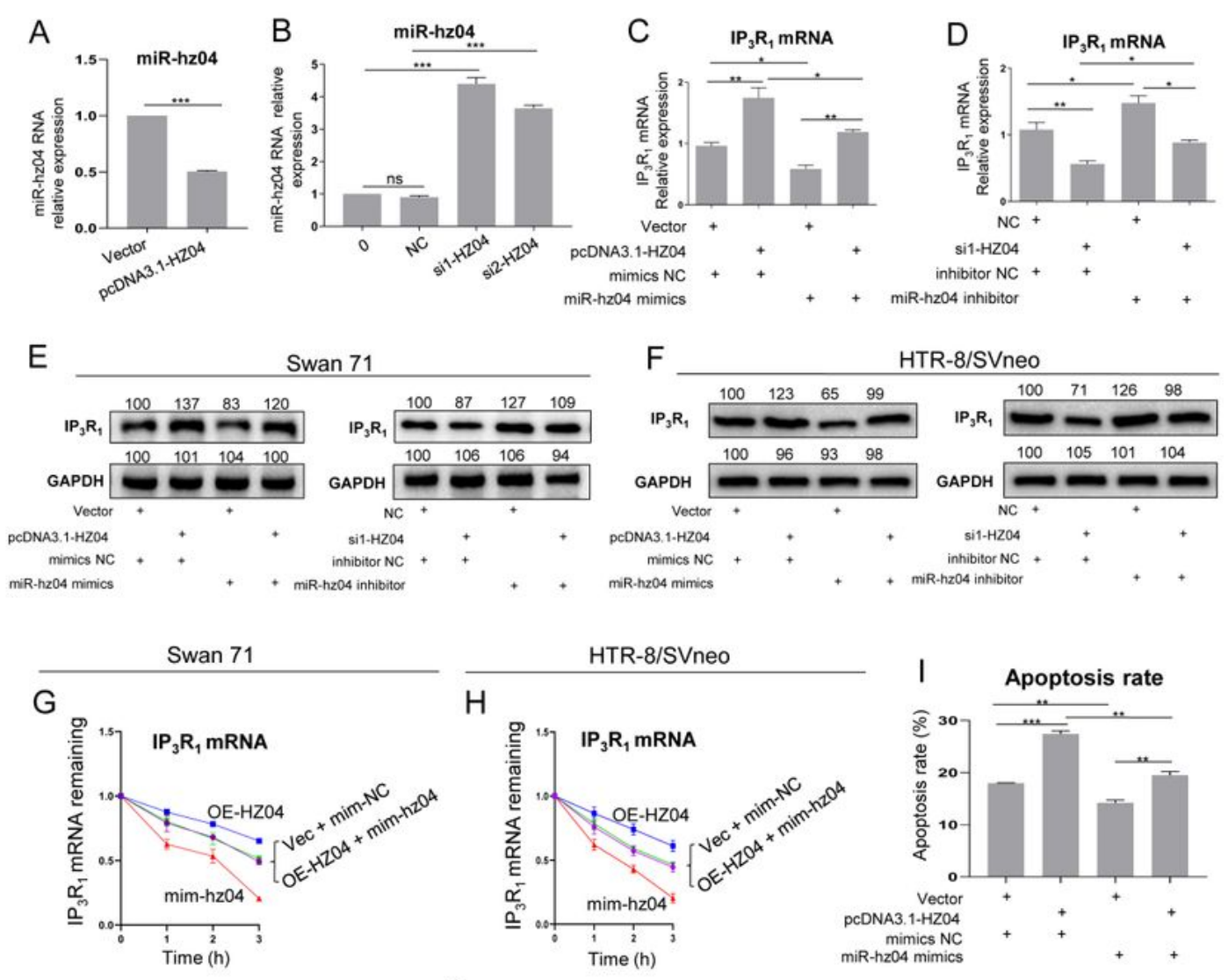

J

K
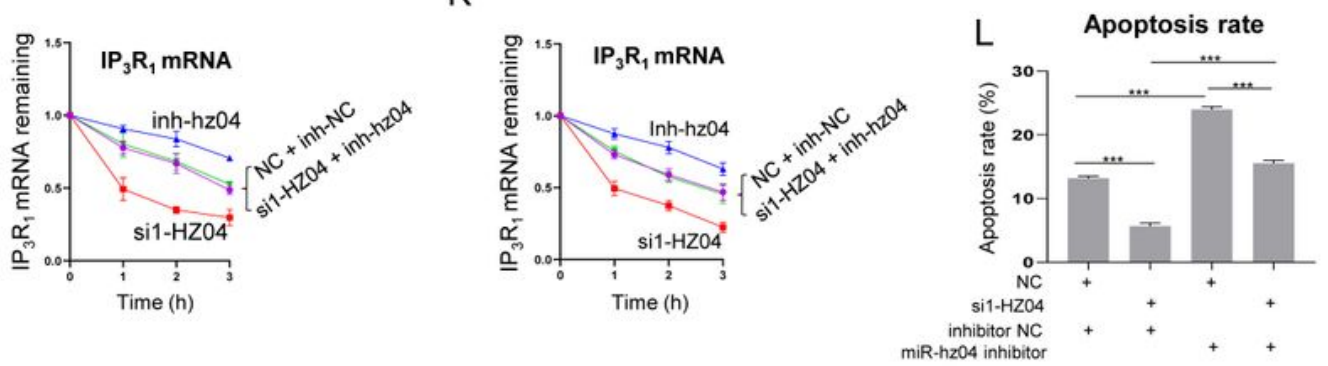

\section{Figure 4}

Lnc-HZ04 functioned as a ceRNA for miR-hz04, up-regulated IP3R1 expression level, and promoted trophoblast cell apoptosis (A and B) RT-qPCR analysis of miR-hz04 expression level in Swan 71 cells with overexpression (A) or knockdown (B) of Inc-HZ04. (C and D) The mRNA level of IP3R1 in Swan 71 cells with overexpression (C) or knockdown (D) of Inc-HZO4 and/or miR-hzO4. (E and F) The protein level of IP3R1 in Swan 71 (E) and HTR-8/SVneo (F) cells with overexpression or knockdown of Inc-HZ04 and/or 
miR-hz04. ( $\mathrm{G}$ and $\mathrm{H}, \mathrm{J}$ and $\mathrm{K}$ ) The stability of IP3R1 mRNA in Swan 71 ( $\mathrm{G}$ and $\mathrm{J}$ ) and HTR-8/SVneo (H and K) cells with overexpression or knockdown of Inc-HZ04 and/or miR-hz04. (I and L) Flow cytometry analysis of the apoptosis of Swan 71 cells with overexpression (I) or knockdown (L) of Inc-HZO4 and/or miR-hz04. Representative data in (E-F) represent three independent experiments. Data in (A-D, G-L) show mean $\pm S D$ of three independent experiments. One-way ANOVA analysis for $(A-D, I, L) ;{ }^{\star} p<0.05$, ** $<<$ 0.01 , and $* * * p<0.001$. NC, negative control of siRNA; Vector or Vec, empty vector of pcDNA3.1; mimics NC or mim-NC, negative control of mimics; inhibitor NC or inh-NC, negative control of inhibitor; pcDNA3.1$\mathrm{HZO4}$ or OE-HZ04, overexpression of Inc-HZ04; miR-hz04 mimics or mim-hz04, overexpression of miRhz04; si-HZ04, knockdown of Inc-HZ04; miR-hz04 inhibitor or inh-hz04, knockdown of miR-hz04. 
Fig.4
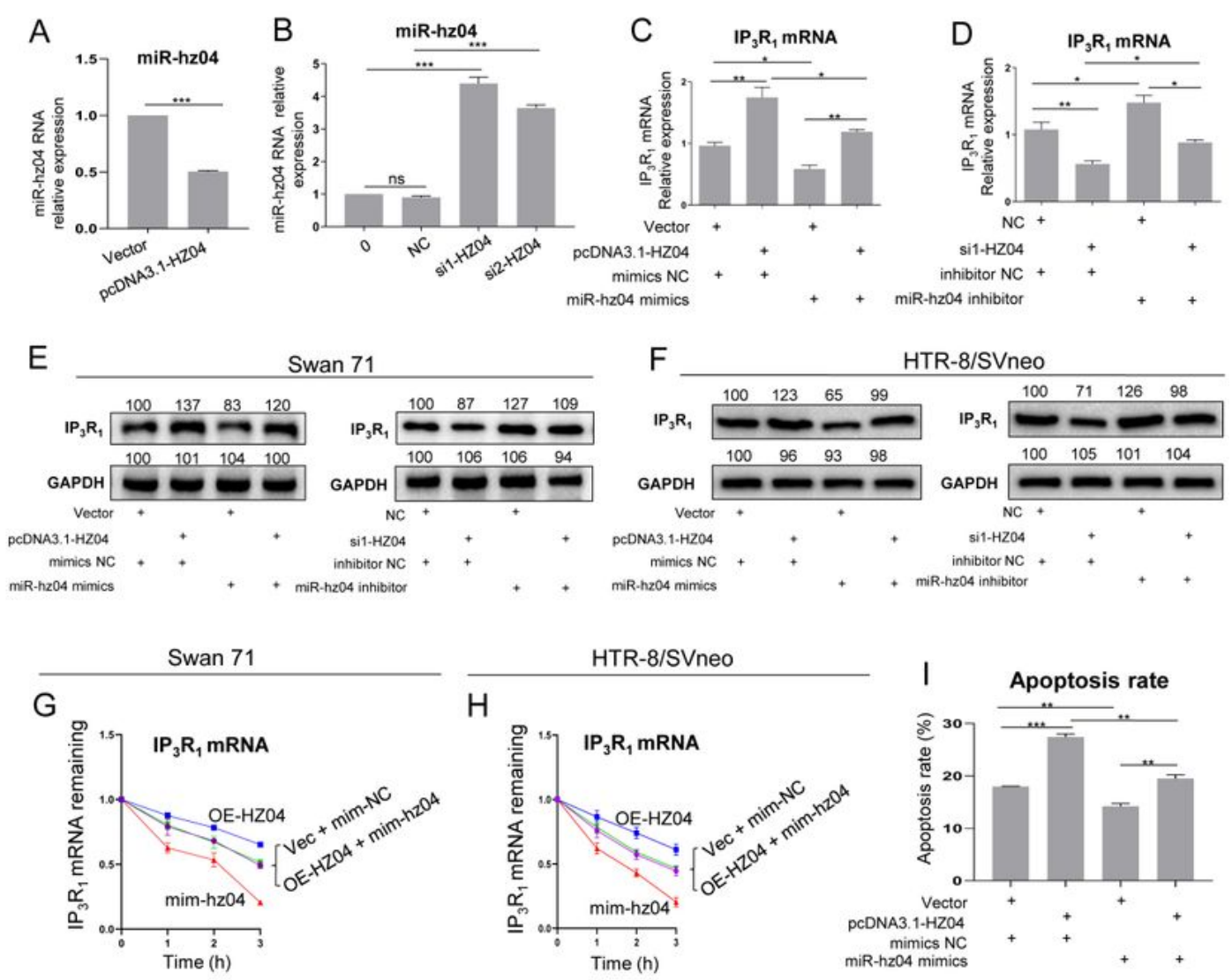

J

K
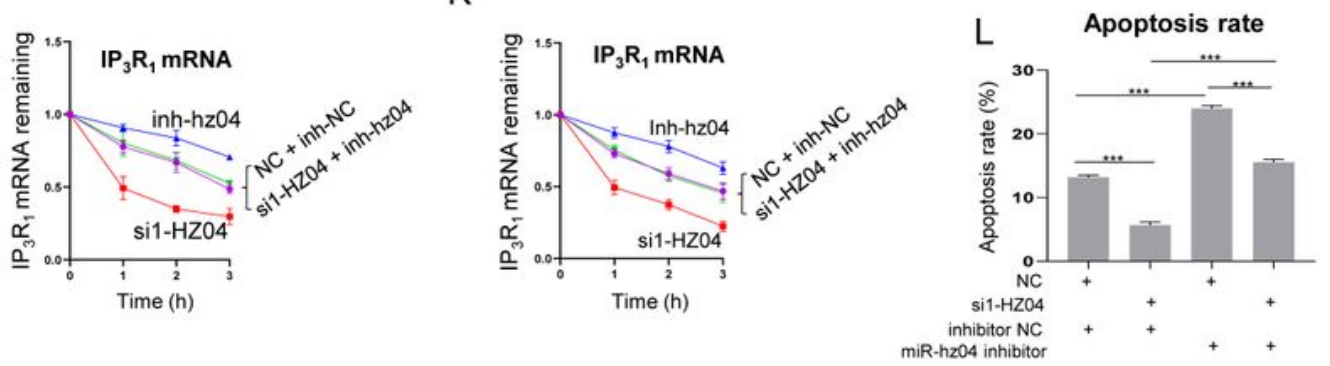

\section{Figure 4}

Lnc-HZ04 functioned as a ceRNA for miR-hz04, up-regulated IP3R1 expression level, and promoted trophoblast cell apoptosis (A and B) RT-qPCR analysis of miR-hz04 expression level in Swan 71 cells with overexpression (A) or knockdown (B) of Inc-HZ04. (C and D) The mRNA level of IP3R1 in Swan 71 cells with overexpression (C) or knockdown (D) of Inc-HZO4 and/or miR-hzO4. (E and F) The protein level of IP3R1 in Swan 71 (E) and HTR-8/SVneo (F) cells with overexpression or knockdown of Inc-HZO4 and/or 
miR-hz04. ( $\mathrm{G}$ and $\mathrm{H}, \mathrm{J}$ and $\mathrm{K}$ ) The stability of IP3R1 mRNA in Swan 71 ( $\mathrm{G}$ and $\mathrm{J}$ ) and HTR-8/SVneo (H and K) cells with overexpression or knockdown of Inc-HZ04 and/or miR-hz04. (I and L) Flow cytometry analysis of the apoptosis of Swan 71 cells with overexpression (I) or knockdown (L) of Inc-HZO4 and/or miR-hz04. Representative data in (E-F) represent three independent experiments. Data in (A-D, G-L) show mean $\pm S D$ of three independent experiments. One-way ANOVA analysis for $(A-D, I, L) ;{ }^{\star} p<0.05$, ** $<<$ 0.01 , and $* * * p<0.001$. NC, negative control of siRNA; Vector or Vec, empty vector of pcDNA3.1; mimics NC or mim-NC, negative control of mimics; inhibitor NC or inh-NC, negative control of inhibitor; pcDNA3.1$\mathrm{HZO4}$ or OE-HZ04, overexpression of Inc-HZ04; miR-hz04 mimics or mim-hz04, overexpression of miRhz04; si-HZ04, knockdown of Inc-HZ04; miR-hz04 inhibitor or inh-hz04, knockdown of miR-hz04. 
Fig.4
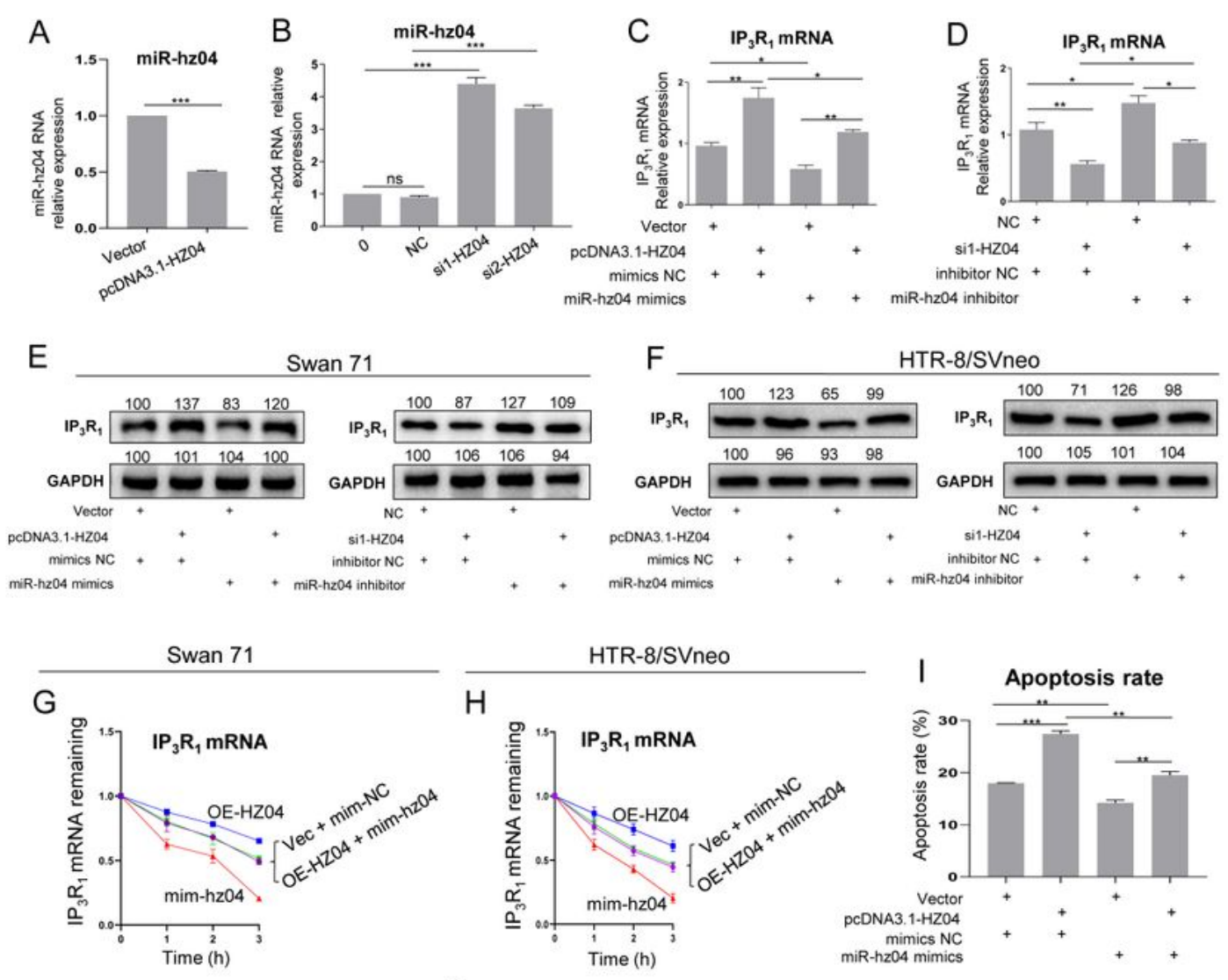

J

K
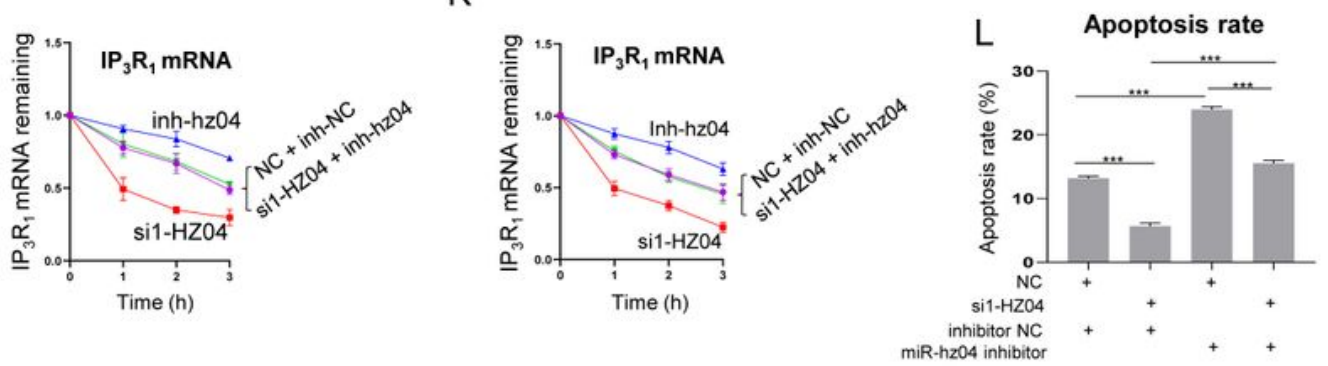

\section{Figure 4}

Lnc-HZ04 functioned as a ceRNA for miR-hz04, up-regulated IP3R1 expression level, and promoted trophoblast cell apoptosis (A and B) RT-qPCR analysis of miR-hz04 expression level in Swan 71 cells with overexpression (A) or knockdown (B) of Inc-HZ04. (C and D) The mRNA level of IP3R1 in Swan 71 cells with overexpression (C) or knockdown (D) of Inc-HZO4 and/or miR-hzO4. (E and F) The protein level of IP3R1 in Swan 71 (E) and HTR-8/SVneo (F) cells with overexpression or knockdown of Inc-HZ04 and/or 
miR-hz04. ( $\mathrm{G}$ and $\mathrm{H}, \mathrm{J}$ and $\mathrm{K}$ ) The stability of IP3R1 mRNA in Swan 71 ( $\mathrm{G}$ and $\mathrm{J}$ ) and HTR-8/SVneo (H and K) cells with overexpression or knockdown of Inc-HZ04 and/or miR-hz04. (I and L) Flow cytometry analysis of the apoptosis of Swan 71 cells with overexpression (I) or knockdown (L) of Inc-HZO4 and/or miR-hz04. Representative data in (E-F) represent three independent experiments. Data in (A-D, G-L) show mean $\pm S D$ of three independent experiments. One-way ANOVA analysis for $(A-D, I, L) ;{ }^{\star} p<0.05$, ** $<<$ 0.01 , and $* * * p<0.001$. NC, negative control of siRNA; Vector or Vec, empty vector of pcDNA3.1; mimics NC or mim-NC, negative control of mimics; inhibitor NC or inh-NC, negative control of inhibitor; pcDNA3.1$\mathrm{HZO4}$ or OE-HZ04, overexpression of Inc-HZ04; miR-hz04 mimics or mim-hz04, overexpression of miRhz04; si-HZ04, knockdown of Inc-HZ04; miR-hz04 inhibitor or inh-hz04, knockdown of miR-hz04. 
Fig.5
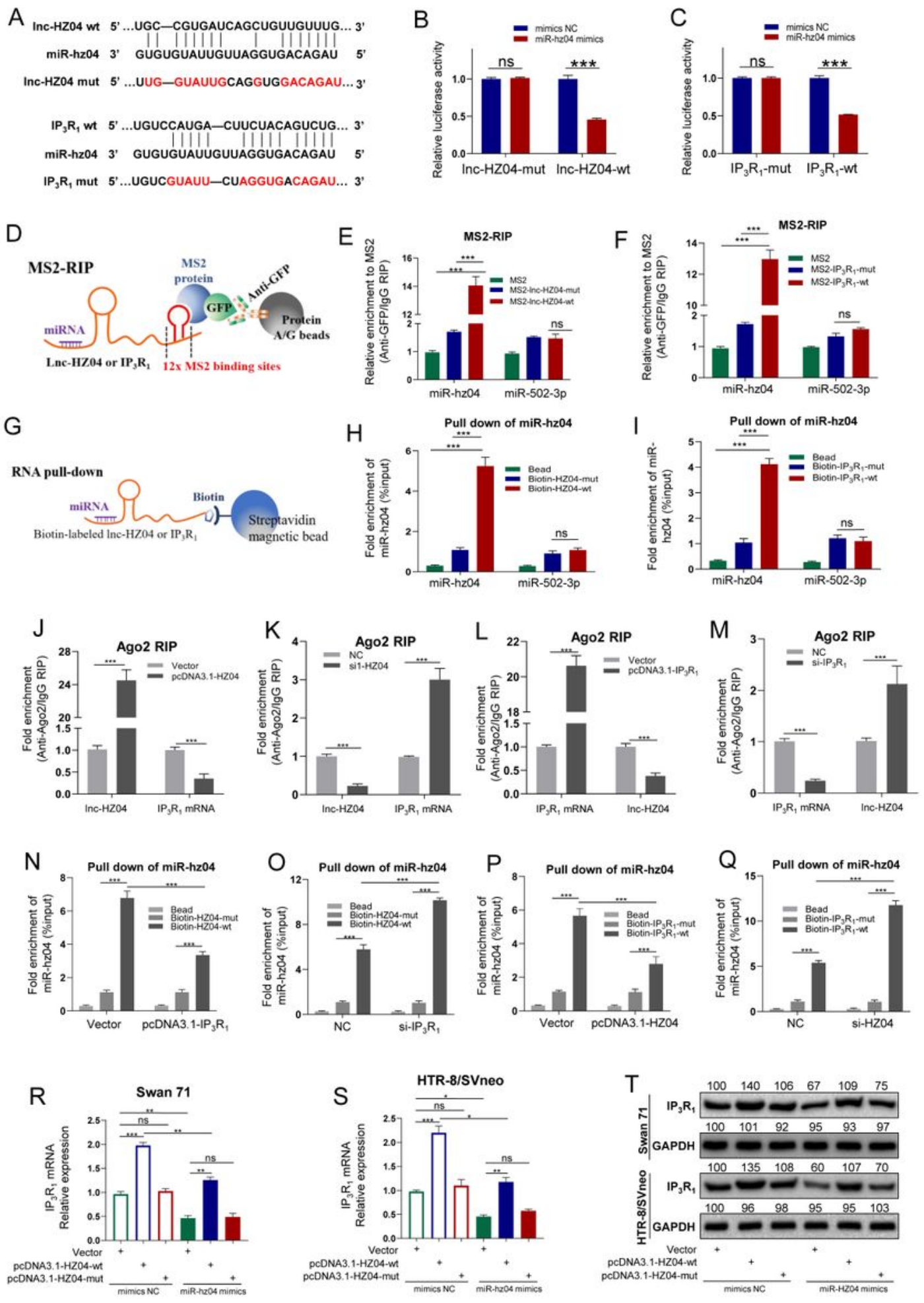

\section{Figure 5}

Lnc-HZ04 up-regulated IP3R1 level by direct and specific binding of miR-hz04 on its binding site on IncHZ04 (A-C) PmirGLO vector containing Inc-HZ04 (B) or IP3R1 mRNA (C) sequence with wild-type (wt) or mutant (mut) binding site for miR-hz04 together with miR-hz04 were co-transfected into Swan 71 cells for dual luciferase detection. (D-F) RT-qPCR analysis of the level of miR-hz04 that was associated with IncHZO4 or IP3R1 mRNA containing wt or mut miR-hz04 binding site in MS2-RIP assays using Swan 71 
cells, with miR-502-3p as negative control. (G-I) RT-qPCR analysis of the level of miR-hz04 pull down by biotinylated Inc-HZ04 and IP3R1 mRNA containing wt or mut miR-hz04 binding site in RNA pull-down assays using Swan 71 cells, with miR-502-3p as negative control. ( $\mathrm{J}$ to M) RT-qPCR analysis of the level of Inc-HZ04 or IP3R1 mRNA enriched by Ago2 protein using Swan 71 cells with overexpression or knockdown of Inc-HZ04 ( $\mathrm{J}$ and K) or IP3R1 mRNA ( $\mathrm{L}$ and M) in Ago2 RIP assays. (N-Q) RT-qPCR analysis of the level of miR-hz04 enriched by wt or mut Inc-HZ04 ( N and O) or IP3R1 mRNA (P and Q) in Swan 71 cells with overexpression or knockdown of IP3R1 mRNA ( $\mathrm{N}$ and $\mathrm{O}$ ) or Inc-HZ04 (P and Q), respectively. (RS) RT-qPCR analysis of IP3R1 mRNA level in Swan $71(\mathrm{R})$ or HTR-8/SVneo (H) cells with overexpression of wt or mut Inc-HZO4 and miR-hzO4 mimics or mimics NC. (T) Western blot analysis of the protein level of IP3R1 in Swan 71 or HTR-8/SVneo cells with overexpression of wt or mut Inc-HZO4 and miR-hz04 mimics or mimics NC. Representative data in $(\mathrm{T})$ represent three independent experiments. Data in (B-C, E$\mathrm{F}, \mathrm{H}-\mathrm{S}$ ) show mean $\pm \mathrm{SD}$ of three independent experiments. Two-tailed Student's t-test for (B-C, J-M); oneway ANOVA analysis for (E-F, H-I, N-S); ns, non-significance; ${ }^{\star} \mathrm{p}<0.05,{ }^{*} \mathrm{p}<0.01$, and ${ }^{\star \star \star *} \mathrm{p}<0.001$. NC, negative control of siRNA; Vector, empty vector of pcDNA3.1; mimics NC, negative control of mimics; inhibitor NC, negative control of inhibitor; pcDNA3.1-HZ04, overexpression of Inc-HZ04; pcDNA3.1-IP3R1, overexpression of IP3R1 mRNA; si-HZ04, knockdown of Inc-HZ04; si-IP3R1, knockdown of IP3R1 mRNA; miR-hz04 mimics, overexpression of miR-hz04; miR-hz04 inhibitor, knockdown of miR-hz04. 
Fig.5
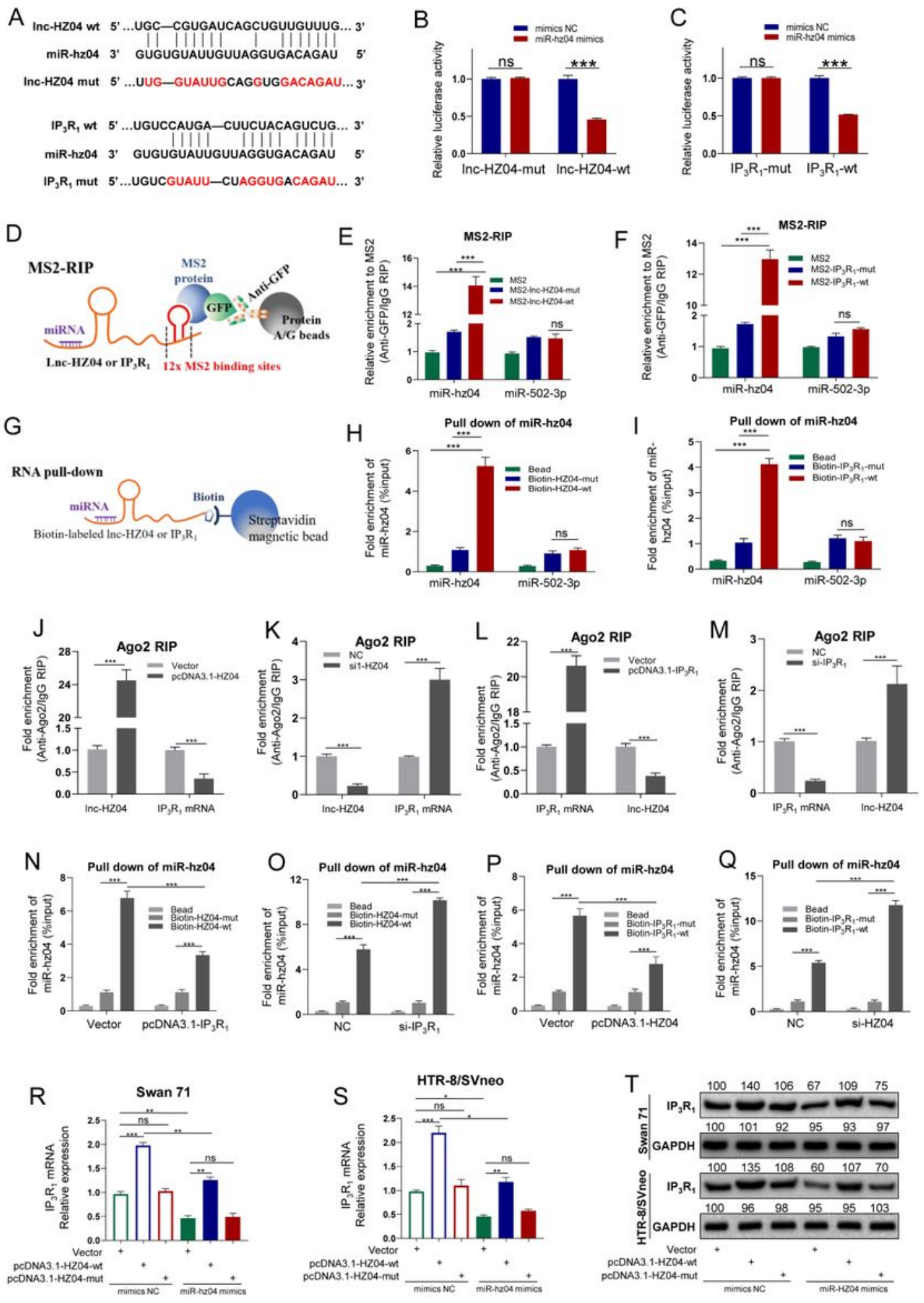

\section{Figure 5}

Lnc-HZ04 up-regulated IP3R1 level by direct and specific binding of miR-hz04 on its binding site on IncHZ04 (A-C) PmirGLO vector containing Inc-HZ04 (B) or IP3R1 mRNA (C) sequence with wild-type (wt) or mutant (mut) binding site for miR-hz04 together with miR-hz04 were co-transfected into Swan 71 cells for dual luciferase detection. (D-F) RT-qPCR analysis of the level of miR-hz04 that was associated with IncHZO4 or IP3R1 mRNA containing wt or mut miR-hz04 binding site in MS2-RIP assays using Swan 71 
cells, with miR-502-3p as negative control. (G-I) RT-qPCR analysis of the level of miR-hz04 pull down by biotinylated Inc-HZ04 and IP3R1 mRNA containing wt or mut miR-hz04 binding site in RNA pull-down assays using Swan 71 cells, with miR-502-3p as negative control. ( $\mathrm{J}$ to M) RT-qPCR analysis of the level of Inc-HZ04 or IP3R1 mRNA enriched by Ago2 protein using Swan 71 cells with overexpression or knockdown of Inc-HZ04 ( $\mathrm{J}$ and K) or IP3R1 mRNA ( $\mathrm{L}$ and M) in Ago2 RIP assays. (N-Q) RT-qPCR analysis of the level of miR-hz04 enriched by wt or mut Inc-HZ04 ( N and O) or IP3R1 mRNA (P and Q) in Swan 71 cells with overexpression or knockdown of IP3R1 mRNA ( $\mathrm{N}$ and $\mathrm{O}$ ) or Inc-HZ04 (P and Q), respectively. (RS) RT-qPCR analysis of IP3R1 mRNA level in Swan $71(\mathrm{R})$ or HTR-8/SVneo (H) cells with overexpression of wt or mut Inc-HZO4 and miR-hzO4 mimics or mimics NC. (T) Western blot analysis of the protein level of IP3R1 in Swan 71 or HTR-8/SVneo cells with overexpression of wt or mut Inc-HZO4 and miR-hz04 mimics or mimics NC. Representative data in $(\mathrm{T})$ represent three independent experiments. Data in (B-C, E$\mathrm{F}, \mathrm{H}-\mathrm{S}$ ) show mean $\pm \mathrm{SD}$ of three independent experiments. Two-tailed Student's t-test for (B-C, J-M); oneway ANOVA analysis for (E-F, H-I, N-S); ns, non-significance; ${ }^{\star} \mathrm{p}<0.05,{ }^{*} \mathrm{p}<0.01$, and ${ }^{\star \star \star *} \mathrm{p}<0.001$. NC, negative control of siRNA; Vector, empty vector of pcDNA3.1; mimics NC, negative control of mimics; inhibitor NC, negative control of inhibitor; pcDNA3.1-HZ04, overexpression of Inc-HZ04; pcDNA3.1-IP3R1, overexpression of IP3R1 mRNA; si-HZ04, knockdown of Inc-HZ04; si-IP3R1, knockdown of IP3R1 mRNA; miR-hz04 mimics, overexpression of miR-hz04; miR-hz04 inhibitor, knockdown of miR-hz04. 
Fig.5
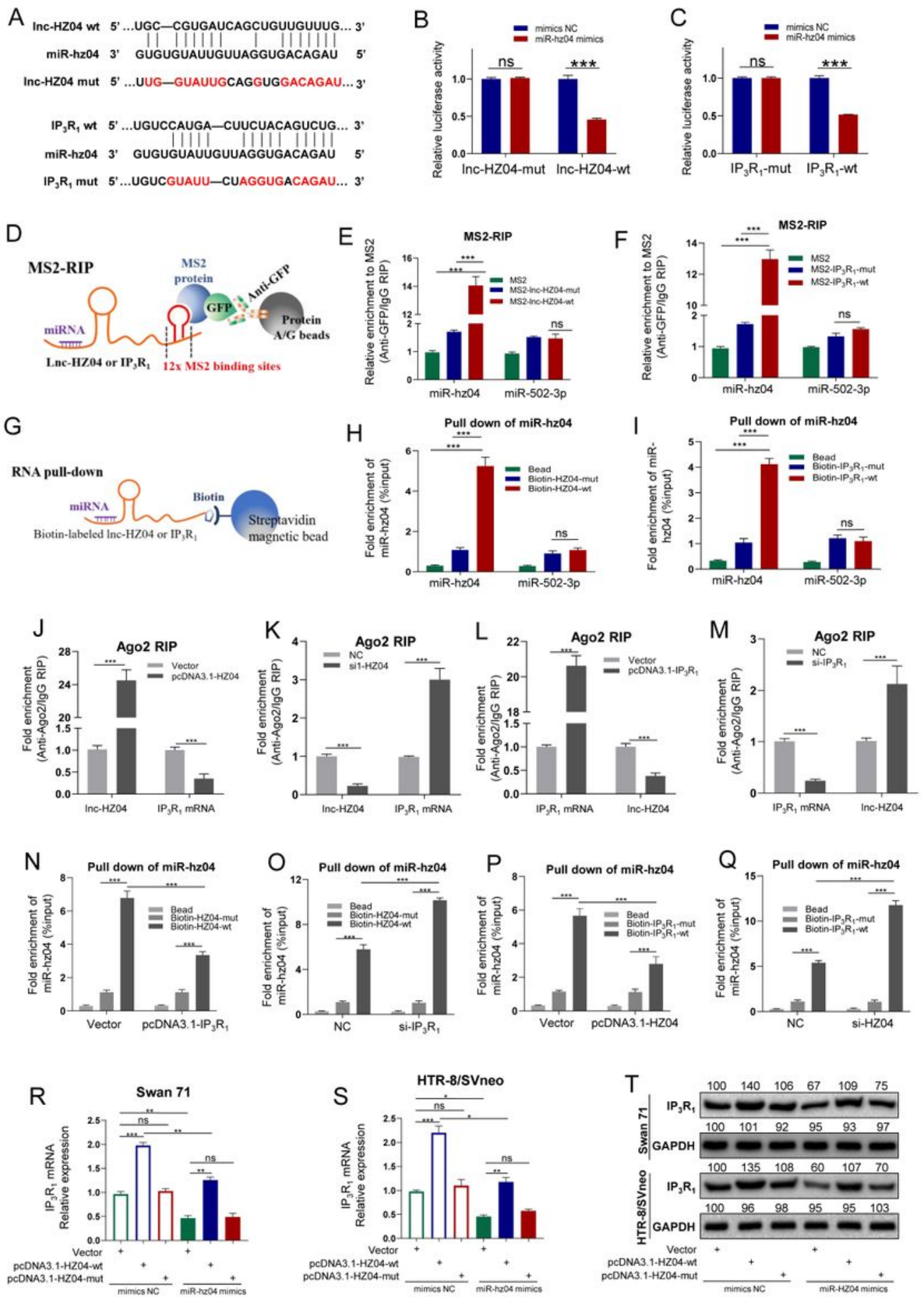

\section{Figure 5}

Lnc-HZ04 up-regulated IP3R1 level by direct and specific binding of miR-hz04 on its binding site on IncHZ04 (A-C) PmirGLO vector containing Inc-HZ04 (B) or IP3R1 mRNA (C) sequence with wild-type (wt) or mutant (mut) binding site for miR-hz04 together with miR-hz04 were co-transfected into Swan 71 cells for dual luciferase detection. (D-F) RT-qPCR analysis of the level of miR-hz04 that was associated with IncHZO4 or IP3R1 mRNA containing wt or mut miR-hz04 binding site in MS2-RIP assays using Swan 71 
cells, with miR-502-3p as negative control. (G-I) RT-qPCR analysis of the level of miR-hz04 pull down by biotinylated Inc-HZ04 and IP3R1 mRNA containing wt or mut miR-hz04 binding site in RNA pull-down assays using Swan 71 cells, with miR-502-3p as negative control. ( $\mathrm{J}$ to M) RT-qPCR analysis of the level of Inc-HZ04 or IP3R1 mRNA enriched by Ago2 protein using Swan 71 cells with overexpression or knockdown of Inc-HZ04 ( $\mathrm{J}$ and K) or IP3R1 mRNA ( $\mathrm{L}$ and M) in Ago2 RIP assays. (N-Q) RT-qPCR analysis of the level of miR-hz04 enriched by wt or mut Inc-HZ04 ( N and O) or IP3R1 mRNA (P and Q) in Swan 71 cells with overexpression or knockdown of IP3R1 mRNA ( $\mathrm{N}$ and $\mathrm{O}$ ) or Inc-HZ04 (P and Q), respectively. (RS) RT-qPCR analysis of IP3R1 mRNA level in Swan $71(\mathrm{R})$ or HTR-8/SVneo (H) cells with overexpression of wt or mut Inc-HZO4 and miR-hzO4 mimics or mimics NC. (T) Western blot analysis of the protein level of IP3R1 in Swan 71 or HTR-8/SVneo cells with overexpression of wt or mut Inc-HZO4 and miR-hz04 mimics or mimics NC. Representative data in $(\mathrm{T})$ represent three independent experiments. Data in (B-C, E$\mathrm{F}, \mathrm{H}-\mathrm{S}$ ) show mean $\pm \mathrm{SD}$ of three independent experiments. Two-tailed Student's t-test for (B-C, J-M); oneway ANOVA analysis for (E-F, H-I, N-S); ns, non-significance; ${ }^{\star} \mathrm{p}<0.05,{ }^{*} \mathrm{p}<0.01$, and ${ }^{\star \star \star *} \mathrm{p}<0.001$. NC, negative control of siRNA; Vector, empty vector of pcDNA3.1; mimics NC, negative control of mimics; inhibitor NC, negative control of inhibitor; pcDNA3.1-HZ04, overexpression of Inc-HZ04; pcDNA3.1-IP3R1, overexpression of IP3R1 mRNA; si-HZ04, knockdown of Inc-HZ04; si-IP3R1, knockdown of IP3R1 mRNA; miR-hz04 mimics, overexpression of miR-hz04; miR-hz04 inhibitor, knockdown of miR-hz04. 
Fig.6

A

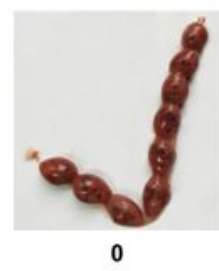

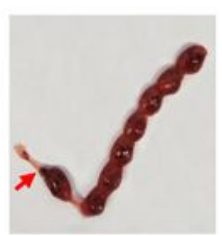

$0.05 \mathrm{mg} / \mathrm{kg}$

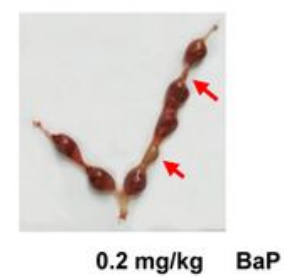

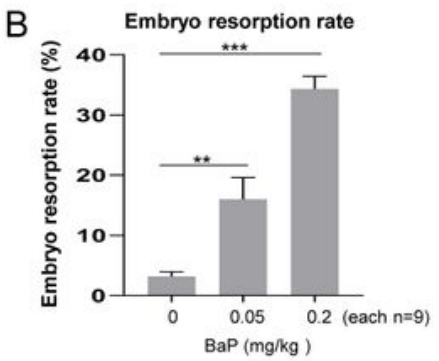
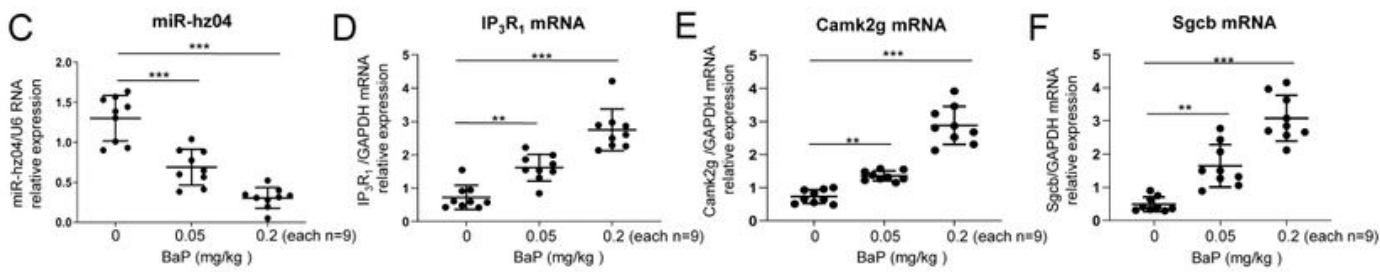

G
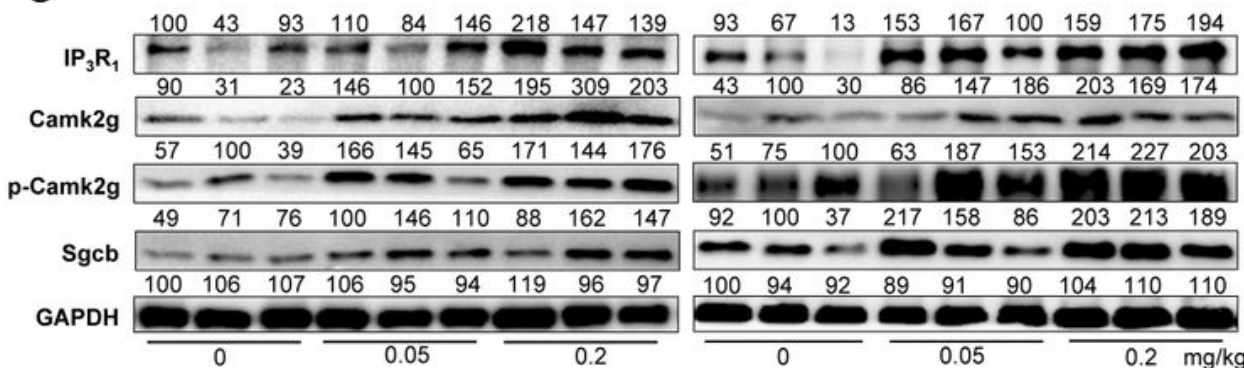

$\mathrm{H}$
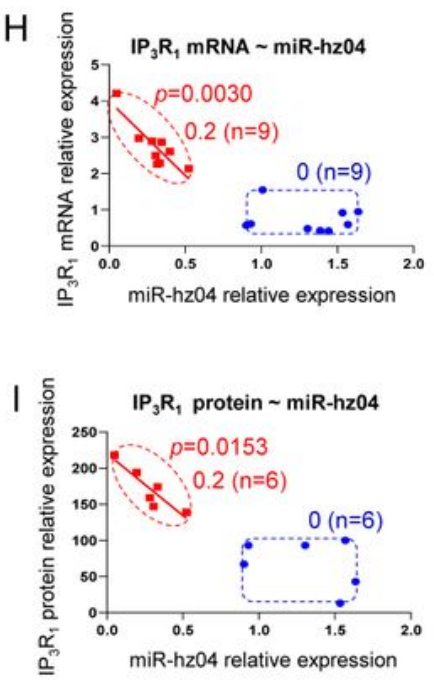

$J$

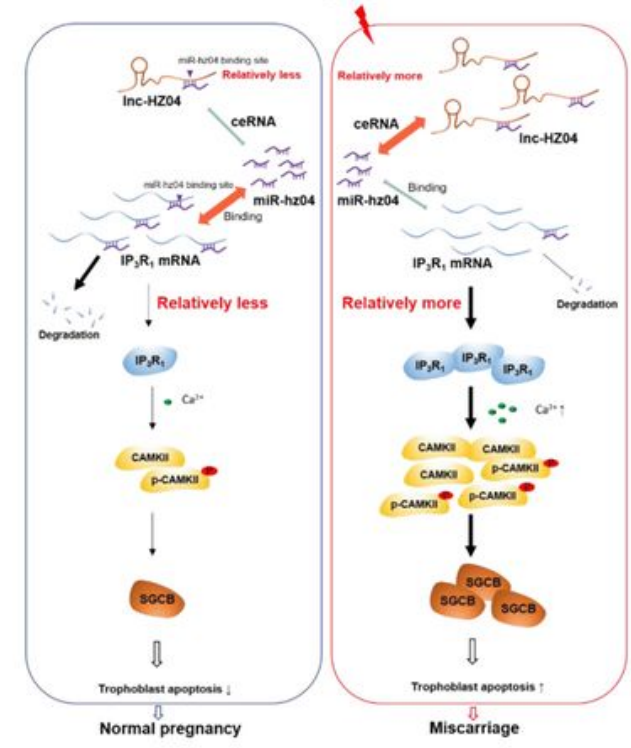

\section{Figure 6}

Murine miR-hz04 was down-regulated and IP3R1/p-Camk2g /Sgcb pathway was up-regulated in pregnant mice model with BaP-induced miscarriage (A) Embryo resorption (red arrows) in pregnant mice model with BaP-induced miscarriage. (B) The average rates of embryo resorption in each group of BaPtreated mice ( $n=9$ mice). (C to F) RT-qPCR analysis of the RNA levels of miR-hz04 (C), IP3R1 (D), Camk2g $(E)$, and Sgcb $(F)$ in each group (each $n=9$ mice). (G) Western blot analysis of the protein levels of IP3R1, 
Camk2g, p-Camk2g, and Sgcb in each group (each $n=6$ random mice) and their relative intensities were quantified. ( $\mathrm{H}$ and $\mathrm{I})$ The correlation between the mRNA $(\mathrm{H}$, each $\mathrm{n}=9$ mice) and protein (l, each $\mathrm{n}=6$ random mice) levels of IP3R1 and the levels of miR-hz04 in the control mice group (0, blue) and 0.2 $\mathrm{mg} / \mathrm{kg}$ BaP-treated mice group (0.2, red). (J) The regulation mechanism of Inc-HZO4/miR-hz04. Lnc-HZ04 acts as a ceRNA for miR-hz04 and diminishes the inhibition effects of miR-hz04 on IP3R1 mRNA expression, thus activates Ca2+-mediated IP3R1/p-CaMKII/SGCB pathway to promote trophoblast cell apoptosis. In normal trophoblast cells, relatively less Inc-HZO4 and more miR-hzO4 inhibit this apoptosis pathway and lead to normal pregnancy. After exposure to BPDE, relatively more Inc-HZO4 and less miRhz04 activate this apoptosis pathway and induce miscarriage. Representative data in (A and C-I) represent three independent experiments. Data in (B) show mean \pm SD of nine mice in each group. Oneway ANOVA analysis for (B-F); pearson analysis for $(\mathrm{H}-\mathrm{I})$; ${ }^{*} \mathrm{p}<0.05$, ${ }^{*} \mathrm{p}<0.01$, and ${ }^{* \star *} \mathrm{p}<0.001$. The number $n$, the number of biologically independent mice. 
Fig.6

A

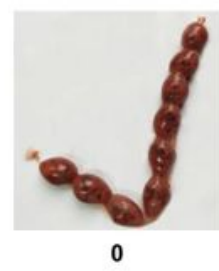

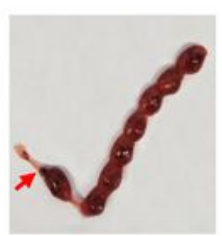

$0.05 \mathrm{mg} / \mathrm{kg}$

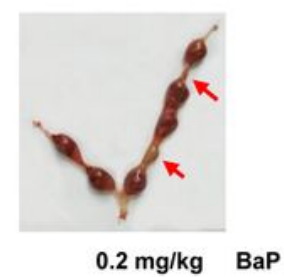

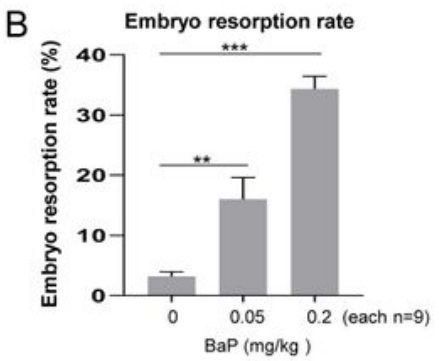
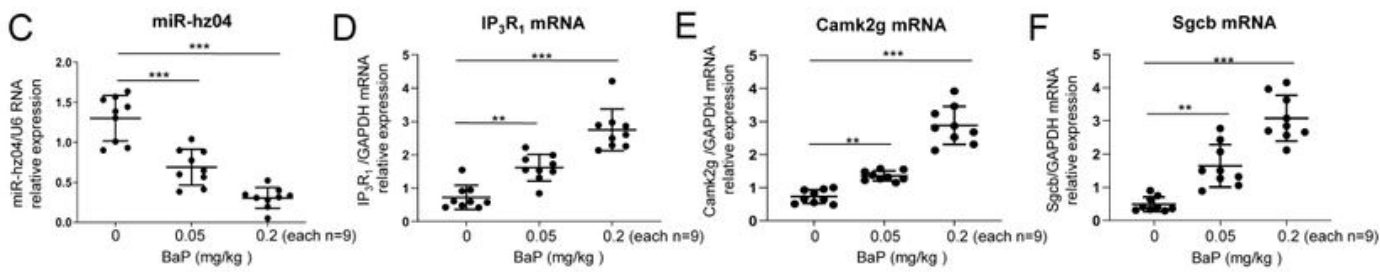

G
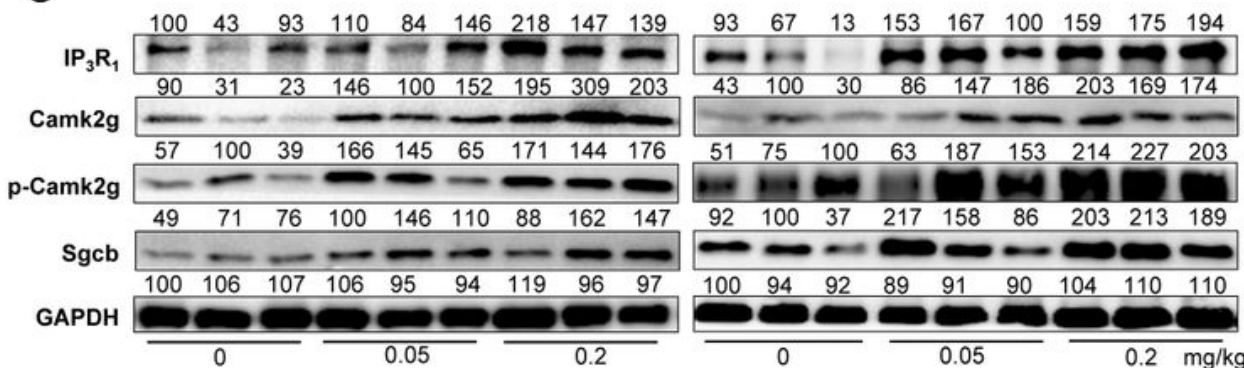

$\mathrm{H}$
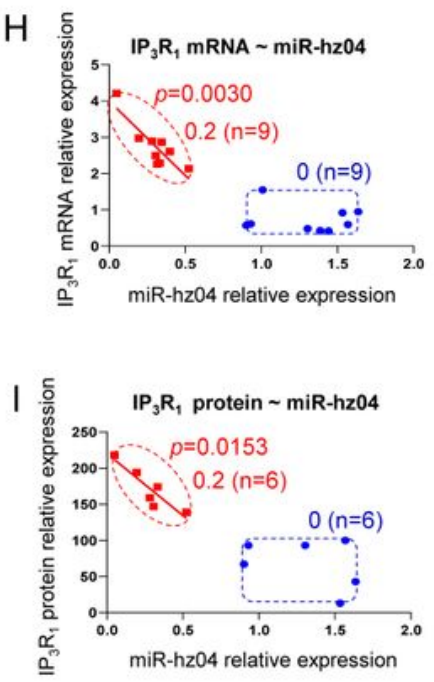

$J$

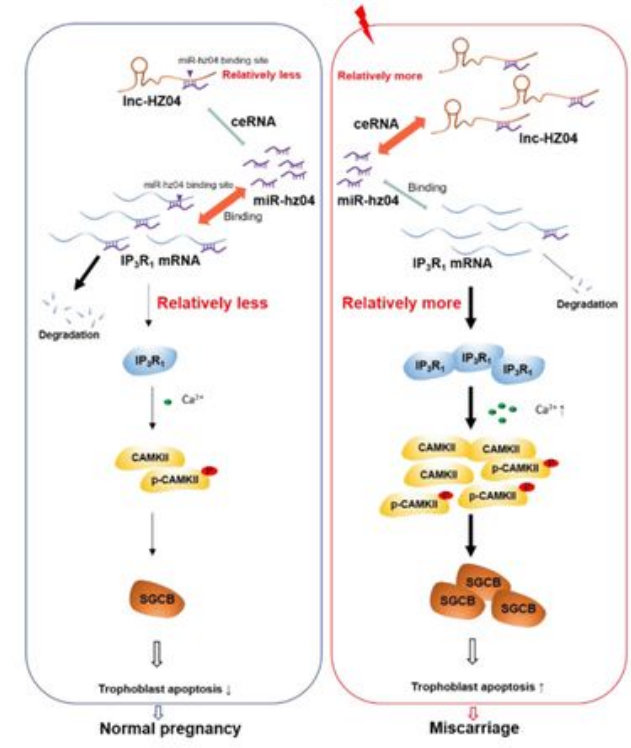

\section{Figure 6}

Murine miR-hz04 was down-regulated and IP3R1/p-Camk2g /Sgcb pathway was up-regulated in pregnant mice model with BaP-induced miscarriage (A) Embryo resorption (red arrows) in pregnant mice model with BaP-induced miscarriage. (B) The average rates of embryo resorption in each group of BaPtreated mice ( $n=9$ mice). (C to F) RT-qPCR analysis of the RNA levels of miR-hz04 (C), IP3R1 (D), Camk2g $(E)$, and Sgcb $(F)$ in each group (each $n=9$ mice). (G) Western blot analysis of the protein levels of IP3R1, 
Camk2g, p-Camk2g, and Sgcb in each group (each $n=6$ random mice) and their relative intensities were quantified. ( $\mathrm{H}$ and $\mathrm{I})$ The correlation between the mRNA $(\mathrm{H}$, each $\mathrm{n}=9$ mice) and protein (l, each $\mathrm{n}=6$ random mice) levels of IP3R1 and the levels of miR-hz04 in the control mice group (0, blue) and 0.2 $\mathrm{mg} / \mathrm{kg} \mathrm{BaP-treated} \mathrm{mice} \mathrm{group} \mathrm{(0.2,} \mathrm{red).} \mathrm{(J)} \mathrm{The} \mathrm{regulation} \mathrm{mechanism} \mathrm{of} \mathrm{Inc-HZO4/miR-hz04.} \mathrm{Lnc-HZO4}$ acts as a ceRNA for miR-hz04 and diminishes the inhibition effects of miR-hz04 on IP3R1 mRNA expression, thus activates Ca2+-mediated IP3R1/p-CaMKII/SGCB pathway to promote trophoblast cell apoptosis. In normal trophoblast cells, relatively less Inc-HZO4 and more miR-hzO4 inhibit this apoptosis pathway and lead to normal pregnancy. After exposure to BPDE, relatively more Inc-HZO4 and less miRhz04 activate this apoptosis pathway and induce miscarriage. Representative data in (A and C-I) represent three independent experiments. Data in (B) show mean \pm SD of nine mice in each group. Oneway ANOVA analysis for (B-F); pearson analysis for $(\mathrm{H}-\mathrm{I})$; ${ }^{*} \mathrm{p}<0.05$, ${ }^{*} \mathrm{p}<0.01$, and ${ }^{* \star *} \mathrm{p}<0.001$. The number $n$, the number of biologically independent mice. 
Fig.6

A

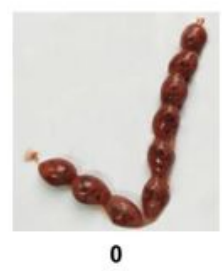

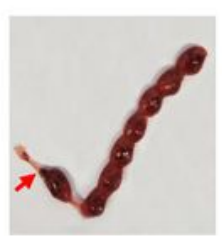

$0.05 \mathrm{mg} / \mathrm{kg}$

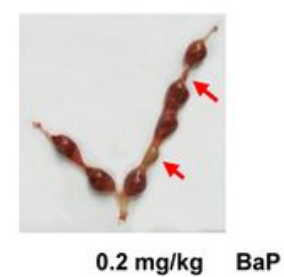

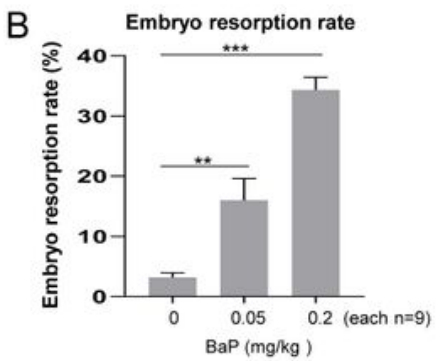
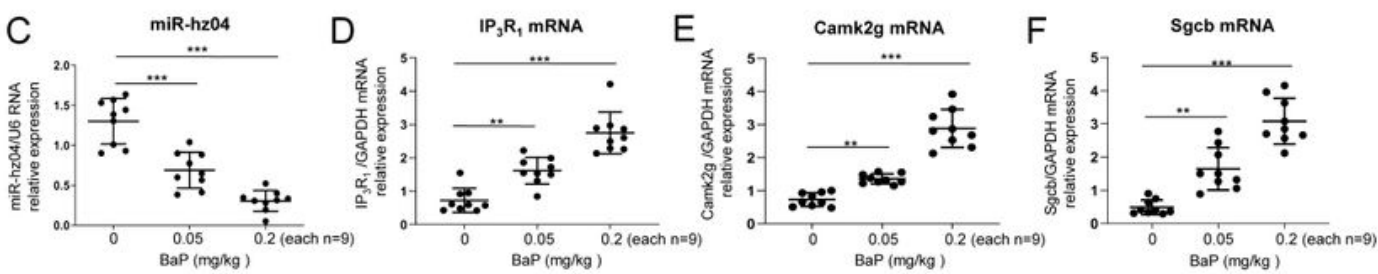

G
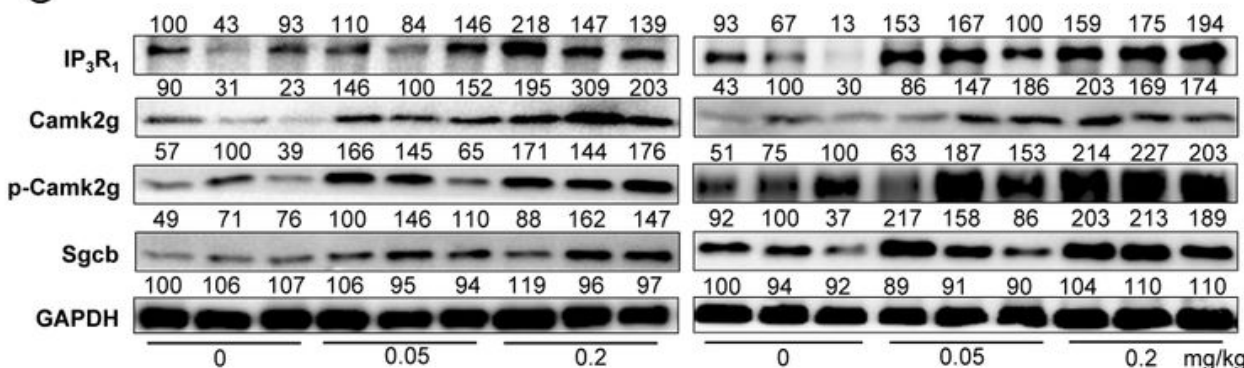

$\mathrm{H}$
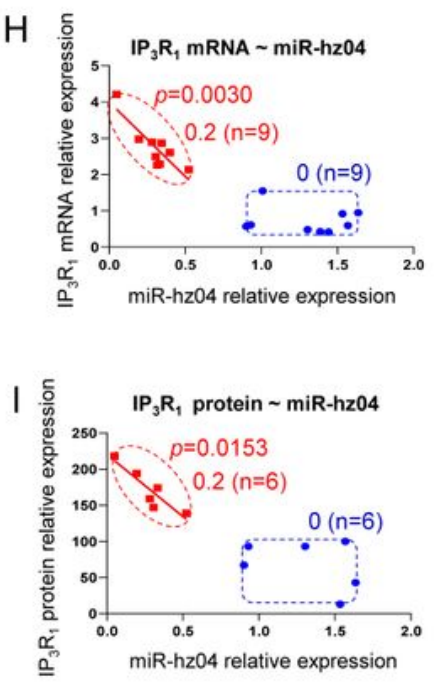

$J$

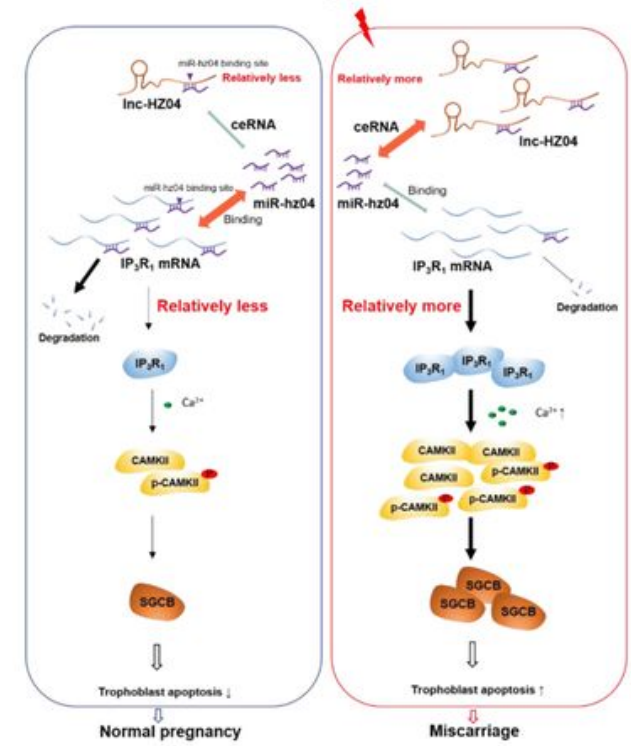

\section{Figure 6}

Murine miR-hz04 was down-regulated and IP3R1/p-Camk2g /Sgcb pathway was up-regulated in pregnant mice model with BaP-induced miscarriage (A) Embryo resorption (red arrows) in pregnant mice model with BaP-induced miscarriage. (B) The average rates of embryo resorption in each group of BaPtreated mice ( $\mathrm{n}=9$ mice). (C to F) RT-qPCR analysis of the RNA levels of miR-hz04 (C), IP3R1 (D), Camk2g $(E)$, and Sgcb (F) in each group (each $n=9$ mice). (G) Western blot analysis of the protein levels of IP3R1, 
Camk2g, p-Camk2g, and Sgcb in each group (each $n=6$ random mice) and their relative intensities were quantified. ( $\mathrm{H}$ and $\mathrm{I})$ The correlation between the mRNA $(\mathrm{H}$, each $\mathrm{n}=9$ mice) and protein (l, each $\mathrm{n}=6$ random mice) levels of IP3R1 and the levels of miR-hz04 in the control mice group (0, blue) and 0.2 $\mathrm{mg} / \mathrm{kg}$ BaP-treated mice group (0.2, red). (J) The regulation mechanism of Inc-HZO4/miR-hz04. Lnc-HZ04 acts as a ceRNA for miR-hz04 and diminishes the inhibition effects of miR-hz04 on IP3R1 mRNA expression, thus activates Ca2+-mediated IP3R1/p-CaMKII/SGCB pathway to promote trophoblast cell apoptosis. In normal trophoblast cells, relatively less Inc-HZO4 and more miR-hzO4 inhibit this apoptosis pathway and lead to normal pregnancy. After exposure to BPDE, relatively more Inc-HZO4 and less miRhz04 activate this apoptosis pathway and induce miscarriage. Representative data in (A and C-I) represent three independent experiments. Data in (B) show mean \pm SD of nine mice in each group. Oneway ANOVA analysis for (B-F); pearson analysis for $(\mathrm{H}-\mathrm{I})$; ${ }^{*} \mathrm{p}<0.05$, ${ }^{*} \mathrm{p}<0.01$, and ${ }^{* \star *} \mathrm{p}<0.001$. The number $n$, the number of biologically independent mice.

\section{Supplementary Files}

This is a list of supplementary files associated with this preprint. Click to download.

- Supplementarytable1to6.docx

- Supplementarytable1 to6.docx

- Supplementarytable1to6.docx

- Supplementaryfigure1.jpg

- Supplementaryfigure1.jpg

- Supplementaryfigure1.jpg

- Supplementaryfigure2.jpg

- Supplementaryfigure2.jpg

- Supplementaryfigure2.jpg

- Supplementaryfigure3.jpg

- Supplementaryfigure3.jpg

- Supplementaryfigure3.jpg

- Supplementaryfigure4.jpg

- Supplementaryfigure4.jpg

- Supplementaryfigure4.jpg

- Supplementaryfigure5.jpg

- Supplementaryfigure5.jpg

- Supplementaryfigure5.jpg

- Supplementaryfigure6.jpg

- Supplementaryfigure6.jpg 
- Supplementaryfigure6.jpg 